UNIVERSIDADE DE SÃO PAULO

FACULDADE DE ZOOTECNIA E ENGENHARIA DE ALIMENTOS

JESSICA ANGELA BET

Indutores de maturação e a qualidade tecnológica da cana-deaçúcar

Versão Corrigida

Pirassununga 


\title{
Indutores de maturação e a qualidade tecnológica da cana-de- açúcar
}

\author{
Versão Corrigida
}

Dissertação apresentada à Faculdade de Zootecnia e Engenharia de Alimentos da Universidade de São Paulo, como parte dos requisitos para a obtenção do Título de Mestre em Ciências do programa de pós-graduação em Zootecnia.

Área de Concentração: Qualidade e Produtividade Animal

Orientador: Prof. Dr. Pedro Henrique de Cerqueira Luz 
Dados Internacionais de Catalogação na Publicação

Serviço de Biblioteca e Informação da Faculdade de Zootecnia e Engenharia de Alimentos da Universidade de São Paulo

Bet, Jessica Angela

Indutores de maturação e a qualidade tecnológica da cana-de-açúcar / Jessica Angela Bet. -- Pirassununga, 2015 .

$112 \mathrm{f}$.

Dissertação (Mestrado) -- Faculdade de Zootecnia e Engenharia de Alimentos - Universidade de São Paulo. Departamento de Zootecnia.

Área de Concentração: Qualidade e Produtividade Animal.

Orientador: Prof. Dr. Pedro Henrique de Cerqueira Luz .

1. Produção de açúcar 2. Reguladores vegetais

3. Saccharum sp. I. Título. 


\title{
DEDICATÓRIA
}

\author{
Aos meus pais
}

Por toda dedicação, amor, estímulo nesses anos de estudo e por tudo o que eles representam

À minha família e amigos

Pelo incentivo, apoio e carinho

Aos meus professores

Pelos valiosos ensinamentos e experiências compartilhadas

Aos trabalhadores

Que retiram da cana o pão de cada dia 


\section{AGRADECIMENTOS}

À Deus pela oportunidade de crescimento e privilégio de conviver com tantas pessoas especiais:

\section{Prof $^{\circ}$ Dr. Pedro Henrique de Cerqueira Luz}

Meu exemplo e inspiração profissional

Pela oportunidade de cursar o mestrado sob sua orientação, por sua valiosa amizade, apoio durante as atividades e por compartilhar tamanha experiência e conhecimento. Cada momento vivido ao seu lado foi um grande aprendizado

\section{Prof $^{\circ}$ Dr. Valdo Rodrigues Herling}

Por todos seus ensinamentos, atenção, amizade, incentivo, oportunidade de acompanhar as atividades e aprender com o GEFEP

\section{Prof ${ }^{\circ}$ Dr. Felipe Barros Macedo}

Por todo seu apoio desde o planejamento do experimento, amizade, experiências e conhecimentos transmitidos

\section{Gabriela Strozzi}

Por sua grande amizade, por estar sempre ao meu lado nas dificuldades que encontrei pelo caminho e alegria. Não existem palavras para descrever você e a Isabella

\section{Vanessa Piotto}

Por sua amizade, apoio e enorme companheirismo no dia a dia e durante as disciplinas da pós-graduação

César Oliveira Rocha, Liliane Romualdo, Fernanda de Fátima da Silva, Thiago Pereira Motta, Syeda Husseim, Damião Nguluve, Jessica Coldebello, João Sanchez, Mariana Campana, Celso Bonafé, Hugo Telles e Fábio Cortes

Por me ajudarem a seguir com alegria, pelo apoio, convivência e momentos felizes compartilhados nas Agrárias e nos experimentos. Vocês são demais!

\section{Paulo Tonetti e Leonardo Lunardi}

Por toda ajuda e apoio prestados do planejamento ao término dos experimentos, $e$, principalmente, durante os imprevistos

\section{Marcos Ferraz}

Por sua confiança, amizade, ensinamentos transmitidos e auxílio

Estagiários do Laboratório de Solos e Agrárias: Alessandra Rodrigues, Suele Pereira, Renata Ferigato, Letícia Sheffer, Layane Santos, Rafael Lunardi, Natália, Andreliza, Diego e David Pela dedicação de cada um, troca de experiências e oportunidades em que trabalhamos $e$ aprendemos juntos 


\section{Prof Dr. Julio Balieiro}

Por sua atenção, ensinamentos, disponibilidade em ajudar, suporte na realização das análises estatísticas e oportunidade de conhecer a FZEA através de sua disciplina da pósgraduação

\section{Prof. Dr. Fabricio Rossi, Prof. Dra. Lilian Elgalise e Prof ${ }^{\circ}$ Dr. Junior César}

Pela colaboração, convívio e amizade durante este período

Juliana Fanhani e Jonas Fanhani

Por me apresentarem a FZEA. Ju sua amizade e apoio foram essenciais, sem você eu não estaria aqui

Professores da Universidade Camilo Castelo Branco: Fábio Mazzonetto, Vera Monelli e Alexandre Dalri

Por tudo o que fizeram por mim durante a graduação, pelos conhecimentos transmitidos $e$ pelo incentivo para a realização do mestrado

Prof. Dr. Márcio Roberto Soares

Por sua atenção, contribuições e disponibilidade em participar da banca.

Dra. Raffaella Rossetto

Por sua atenção.

Faculdade de Zootecnia e Engenharia de Alimentos

Pela oportunidade de realização do mestrado e todo suporte disponibilizado durante as disciplinas e experimentos realizados

Professores da FZEA

Pela oportunidade de convivência e de aprendizagem nas disciplinas ministradas

Funcionários da FZEA

Por toda ajuda prestada

Prof $^{\circ}$ Dr. Saulo e Serviço de Pós-Graduação

Pelo atendimento e auxílio

Stoller

Pelo apoio no experimento

Usina Abengoa São Luis

Pela disponibilização das equipes de campo e laboratório, além das estruturas para a realização do experimento. Vocês foram fundamentais!

\section{Capes}

Pela concessão da bolsa de estudos

A todos que participaram direta e indiretamente nas atividades realizadas: Muito obrigada!

O conhecimento absorvido pelo convívio com vocês é maior do que qualquer título! 
EPÍGRAFE

Fascam tudo com amos

1 Goríntios 16:14 


\section{RESUMO}

\section{BET, J.A. Indutores de maturação e a qualidade tecnológica da cana-de-açúcar 2015.} 112f. Dissertação (Mestrado) - Faculdade de Zootecnia e Engenharia de Alimentos, Universidade de São Paulo, Pirassununga, 2015.

Tecnologias que permitam explorar o potencial genético das variedades de cana-deaçúcar nos diversos ambientes de produção e possibilitem o planejamento da colheita são fundamentais para aumentar a rentabilidade do setor sucroenergético. Dentre estas tecnologias, o emprego de indutores de maturação destaca-se por possibilitar o manejo da cultura em seu sistema de produção e proporcionar melhorias na qualidade da matéria-prima. A utilização conjunta de maturadores e nutrientes em pré-colheita pode fornecer a indústria matéria prima de melhor qualidade tecnológica. Entretanto, questões relacionadas a épocas de utilização e a associação de maturadores com nutrientes não estão totalmente esclarecidas. Neste sentido, o propósito deste trabalho foi avaliar o efeito da aplicação de maturadores e nutrientes, em diferentes épocas de manejo, sobre parâmetros tecnológicos da cana-de-açúcar em início de safra. Foram conduzidos, em cana planta variedade RB 85 5453, dois experimentos compostos por 14 tratamentos: Controle, Orthosulfamuron, Etil-Trinexapac, Sulfometuron metil, Sulfometuron metil/ Boro $150 \mathrm{~g} / \mathrm{ha}$, Nitrato de Potássio, Boro $50 \mathrm{~g} / \mathrm{ha}$, Boro $150 \mathrm{~g} / \mathrm{ha}$, Boro $250 \mathrm{~g} / \mathrm{ha}$, Nitrato de Potássio + Boro $50 \mathrm{~g} / \mathrm{ha}$, Complexo de micronutrientes, Complexo de Micronutrientes + Biorregulador, Sulfometuron metil + Complexo de Micronutrientes, Sulfometuron metil + Complexo de Micronutrientes + Biorregulador; em delineamento de blocos casualizados, com 4 repetições. Foram realizadas 2 aplicações com intervalo de 33 dias entre aplicação. Os parâmetros Brix\%, Fibra, Pol do caldo, Pol da cana), Pureza, Açúcares Redutores do Caldo, Açúcares Redutores da Cana e Açúcar Total Recuperável foram avaliados em intervalos quinzenais, aos 0, 15, 30, 45 e 60 dias após a aplicação dos produtos. Verificou-se que a utilização dos maturadores promoveu melhorias na qualidade da cana-de-açúcar e que a associação de nutrientes ao maturador não potencializou a ação dos maturadores. Diferentes épocas de aplicação dos produtos em précolheita resultaram em diferentes respostas da cana-de-açúcar.

Palavras-chave: Produção de sacarose, reguladores vegetais; Saccharum sp, 


\begin{abstract}
BET, J.A. Ripeners and the technological quality of sugarcane 2015. 112f. M.Sc. Dissertation - Faculty of Animal Science and Food Engineering, University of São Paulo, Pirassununga, 2015.

Technologies to exploit the genetic potential of the varieties of sugarcane in different production environments and enable the planning of crop are essential to increase the profitability of the sugarcane industry. Among these technologies, the use of ripeners stands out by enabling the management of culture in its production system and provide improvements in the quality of the raw material. The joint use of ripeners and nutrients before the harvest can supply the raw material of better quality technology industry, however, issues related to the use of times and the ripeners of association with nutrients are not fully clarified. In this sense, the purpose of this study was to evaluate the effect of applying ripeners and nutrients at different times of management on technological parameters of sugarcane in early harvest. Were conducted, in sugarcane plant, variety RB 85 5453, two experiments consist of 14 treatments: Control, Orthosulfamuron, Ethyl-trinexapac, Sulfomethuron methyl, Sulfomethuron methyl + Boron $150 \mathrm{~g} / \mathrm{ha}$, Potassium Nitrate, Boron $50 \mathrm{~g} / \mathrm{ha}$, Boron $150 \mathrm{~g} / \mathrm{Ha}$, Boron $250 \mathrm{~g} / \mathrm{ha}$, Potassium Nitrate + Boro $50 \mathrm{~g} / \mathrm{ha}$, Complex micronutrients, Complex micronutrients + plant growth regulator, Sulfomethuron methyl + Complex micronutrients, Sulfomethuron methyl + Complex Micronutrients + Plant growth regulator; in a randomized block design with four replications. The applications were made on 28 March and 30 April. The parameters Brix\%, fiber, Pol broth, Pol cane, Purity, reducing sugars, and recoverable total sugar were assessed at fortnightly intervals at $0,15,30,45$ and 60 days after application of the products. The use of ripeners promoted improvements in the quality of sugarcane and that the combination of nutrients to the ripeners didn't potentiate the action of ripeners. Different times of application of the products before the harvest resulted in different responses of sugarcane
\end{abstract}

Key words: Plant growth regulator, sucrose yield, Saccharum spp., 


\section{LISTA DE ILUSTRAÇÕES}

Figura 1. Composição química da cana-de-açúcar. 39

Figura 2. Localização da área experimental (talhão 33).

Figura 3. Precipitação $\left(\mathrm{mm} \mathrm{mês}^{-1}\right)$ e temperaturas $\left({ }^{\circ} \mathrm{C}\right)$ máxima, mínima e média registradas durante o período experimental na estação meteorológica localizada na Universidade de São Paulo (Pirassununga-SP).

Figura 4. Umidade do solo (Centibar) e temperaturas $\left({ }^{\circ} \mathrm{C}\right)$ média, máxima e mínima registradas durante o período experimental na estação meteorológica localizada na Universidade de São Paulo (Pirassununga-SP). 46

Figura 5. Extrato do balanço hídrico ao longo do ano de 2013. Calculado com base nos dados da estação meteorológica localizada na Universidade de São Paulo (Pirassununga-SP).

Figura 6. Deficiência, excedente, retirada e reposição hídrica ao longo do ano de 2013. Calculados com base nos dados da estação meteorológica localizada na Universidade de São Paulo (Pirassununga-SP).

Figura 7. Disposição dos tratamentos no campo

Figura 8. (A) Aplicação dos tratamentos; (B) Detalhe da barra aplicadora; (C) Solução preparada para aplicação na parcela correspondente.

Figura 9. Amostragens periódicas realizadas: (A) Corte e despalha; (B) Preparo dos feixes; (C) Identificação; (D) Feixes na parcela correspondente.

Figura 10. Padrões de variação do teor de Brix\% em função do tempo após a aplicação dos tratamentos. (A) Controle, (B) Orthosulfamuron, (C) Etil-trinexapac, (D) Sulfometuron metil, (E) Sulfometuron metil + Boro $150 \mathrm{~g} / \mathrm{ha}$ e (F) Nitrato de Potássio. $(\mathrm{p}<0,01)$. Tempo (dias) para o tratamento atingir Brix $=18 \%$

Figura 11. Padrões de variação do teor de Brix\% em função do tempo após a aplicação dos tratamentos. (A) Boro 50g/ha, (B) Boro $150 \mathrm{~g} / \mathrm{ha}$, (C) Boro $250 \mathrm{~g} / \mathrm{ha}$, (D) Nitrato de Potássio + Boro $150 \mathrm{~g} / \mathrm{ha}$, (E) Complexo de micronutrientes, (F) Complexo de micronutrientes + Biorregulador. $(\mathrm{p}<0,01)$. Tempo (dias) para o tratamento atingir Brix $=18 \%$

Figura 12. Padrões de variação do teor de Brix\% em função do tempo após a aplicação dos tratamentos. (A) Sulfometuron metil + Complexo de micronutrientes, (B) Sulfometuron metil + Complexo de micronutrientes + Biorregulador $(\mathrm{p}<0,01) . \ldots$ Tempo (dias) para o tratamento atingir $\mathrm{Brix}=18 \%$.

Figura 13. Padrão de variação da porcentagem de fibra em função do tempo após a aplicação dos tratamentos e equação. 
Figura 14. Padrões de variação de Pol do Caldo em função do tempo após a aplicação dos tratamentos. (A) Controle, (B) Orthosulfamuron, (C) Etil-trinexapac, (D) Sulfometuron metil. $(\mathrm{p}<0,01) . \ldots$ Tempo (dias) para o tratamento atingir Pol do caldo $=15,3 \%$. 66

Figura 15. Padrões de variação de Pol do caldo em função do tempo após a aplicação dos tratamentos. (A) Sulfometuron metil + Boro $150 \mathrm{~g} / \mathrm{ha}$, (B) Nitrato de Potássio; (C) Boro 50g/ha, (D) Boro 150 g/ha, (E) Boro 250 g/ha, (F) Nitrato de Potássio + Boro 150 g/ha. $(\mathrm{p}<0,01)$._._. Tempo (dias) para o tratamento atingir Pol do caldo $=15,3 \%$.

Figura 16 Padrões de variação de Pol do caldo em função do tempo após a aplicação dos tratamentos. (A) Complexo de micronutrientes, (B) Complexo de micronutrientes + biorregulador (C) Sulfometuron metil + Complexo de micronutrientes, (D) Sulfometuron metil + Complexo de micronutrientes + Biorregulador. $(\mathrm{p}<0,01)$. _...Tempo (dias) para o tratamento atingir Pol do caldo $=15,3 \%$

Figura 17. Padrões de variação de Pol da Cana em função do tempo após a aplicação dos tratamentos. (A) Controle, (B) Orthosulfamuron, (C) Etil-trinexapac, (D) Sulfometuron metil, (E) Sulfometuron metil + Boro 150g/ha e (F) Nitrato de Potássio. $(\mathrm{p}<0,01)$. _._. Tempo (dias) para o tratamento atingir Pol da Cana $=13,0 \%$.

Figura 18. Padrões de variação de Pol da cana em função do tempo após a aplicação dos tratamentos. (A) Boro 50g/ha, (B) Boro $150 \mathrm{~g} / \mathrm{ha}$, (C) Boro $250 \mathrm{~g} / \mathrm{ha}$, (D) Nitrato de Potássio+ Boro $150 \mathrm{~g} / \mathrm{ha}$, (E) Complexo de micronutrientes, (F) Complexo de micronutrientes + Biorregulador $(\mathrm{p}<0,01) \ldots$ Tempo (dias) para o tratamento atingir Pol da Cana $=13,0 \% \ldots . .72$ Figura 19. Padrões de variação de Pol da cana em função do tempo após a aplicação dos tratamentos. (A) Sulfometuron metil + Complexo de micronutrientes, (B) Sulfometuron metil + Complexo de micronutrientes + Biorregulador. $(\mathrm{p}<0,01)$. Tempo (dias) para o tratamento atingir Pol da Cana $=13,0 \%$

Figura 20. Padrão de variação de pureza em função do tempo após a aplicação dos tratamentos e equação. ..... Tempo (dias) para atingir pureza $=85 \%$. .75

Figura 21. Padrão de variação de açúcares redutores do caldo em função do tempo após a aplicação dos tratamentos e equação. .77

Figura 22. Padrões de variação de açúcares redutores da cana em função do tempo após a aplicação dos tratamentos e equação.

Figura 23 Padrões de variação de ATR da cana em função do tempo após a aplicação dos tratamentos. (A) Controle, (B) Orthosulfamuron, (C) Etil-trinexapac, (D) Sulfometuron metil, (E) Sulfometuron metil + Boro 150 g/ha e (F) Nitrato de Potássio $(\mathrm{p}<0,01)$. 82 
Figura 24. Padrões de variação de ATR da cana em função do tempo após a aplicação dos tratamentos. (A) Boro $50 \mathrm{~g} / \mathrm{ha}$, (B) Boro $150 \mathrm{~g} / \mathrm{ha}$, (C) Boro $250 \mathrm{~g} / \mathrm{ha}$, (D) Nitrato de Potássio + Boro 150 g/ha, (E) Complexo de micronutrientes, (F) Complexo de micronutrientes + Biorregulador $(\mathrm{p}<0,01)$.

Figura 25. Padrões de variação de ATR da cana em função do tempo após a aplicação dos tratamentos. (A) Sulfometuron metil + Complexo de micronutrientes, (B) Sulfometuron metil + Complexo de micronutrientes/ Biorregulador $(\mathrm{p}<0,01)$.

Figura 26. Número de dias antecipados pelos tratamentos em relação ao controle, aos 30 (a) e 45 dias (b). (1) Controle, (2) Orthosulfamuron, (3) Etil-Trinexapac, (4) Sulfometuron metil, (5) Sulfometuron metil/ Boro $150 \mathrm{~g} / \mathrm{ha}$, (6) Nitrato de Potássio, (7) Boro $50 \mathrm{~g} / \mathrm{ha}$, (8) Boro 150 g/ha, (9) Boro 250 g/ha, (10) Nitrato de Potássio + Boro 50 g/ha, (11) Complexo de micronutrientes, (12) Complexo de Micronutriente + Biorregulador, (13) Sulfometuron metil + Complexo de micronutrientes, (14) Sulfometuron metil + Complexo de micronutrientes + Biorregulador.

Figura 27. Padrão de variação do brix em função do tempo após a aplicação dos tratamentos e equação e $\mathrm{r}^{2}(\mathrm{p}<0,01)$. _....Tempo (dias) para atingir o nível máximo Brix\%. 86

Figura 28. Padrão de variação de fibra em função do tempo após a aplicação dos tratamentos, equação e $\mathrm{r}^{2} .(\mathrm{p}<0,01)$. _...Tempo (dias) para atingir o nível máximo de fibra.. 88 Figura 29. Padrão de variação de pol do caldo em função do tempo após a aplicação dos tratamentos, equação e $\mathrm{r}^{2}(\mathrm{p}<0,01)$. _.... Tempo (dias) para atingir o nível máximo de pol do caldo. 90

Figura 30. Padrão de variação do pol da cana em função do tempo após a aplicação dos tratamentos, equação e $\mathrm{r}^{2} \cdot(\mathrm{p}<0,01)$. _... Tempo (dias) para atingir o nível de pol da cana $=$ $13 \%$. .92

Figura 31. Padrão de variação de pureza em função do tempo após a aplicação dos tratamentos, equação e $\mathrm{r}^{2}(\mathrm{p}<0,01) . \ldots$ Tempo (dias) para atingir o nível de pureza $=85 \% .94$ Figura 32. Padrão de variação de açúcares redutores do caldo em função do tempo após a aplicação dos tratamentos, equação e $\mathrm{r}^{2}(\mathrm{p}<0,01)$. .95

Figura 33. Padrão de variação de açúcares redutores do caldo em função do tempo após a aplicação dos tratamentos, equação e $\mathrm{r}^{2}$. $(\mathrm{p}<0,01)$.

Figura 34. Padrão de variação de açúcar total recuperável em função do tempo após a aplicação dos tratamentos, equação e $\mathrm{r}^{2}(\mathrm{p}<0,01)$......Tempo (dias) para atingir o máximo nível de ATR por tonelada de cana. .98 


\section{LISTA DE TABELAS}

Tabela 1. Tratamentos experimentais utilizados, princípios ativos, nomes comerciais e doses dos produtos comerciais por hectare.

Tabela 2. Atributos químicos da área experimental obtidos mediante análise química do solo. Primeira época de aplicação dos tratamentos.

Tabela 3 Atributos químicos da área experimental obtidos mediante análise química do solo. Segunda época de aplicação dos tratamentos. 50

Tabela 4. Fontes de variação e significância do valor F para a variável Brix. 56

Tabela 5. Teor de Brix \%, referente a primeira época de aplicação dos tratamentos, avaliado aos $0,15,30,45$ e 60 dias após a aplicação. .57

Tabela 6. Fontes de variação e significância do valor F para a variável fibra. 61

Tabela 7. Porcentagem de fibra referente a primeira época de aplicação dos tratamentos. .... 62

Tabela 8. Fontes de variação e significância do valor F para a variável pol do caldo.

Tabela 9. Porcentagem de Pol do caldo referente a primeira época de aplicação dos tratamentos, avaliada aos 0,15,30, 45 e 60 dias após a aplicação. Em cada época de avaliação as letras comparam os tratamentos. Médias seguidas por mesma letra não diferem estatisticamente entre si $(\mathrm{P}<05)$.

Tabela 10. Fontes de variação e significância do valor $F$ para a variável pol da cana.

Tabela 11. Porcentagem de pol (cana) referente a primeira época de aplicação dos tratamentos, avaliada aos 0,15, 30, 45 e 60 dias após a aplicação.

Tabela 12. Fontes de variação e significância do valor F para a variável pureza. 73

Tabela 13. Porcentagem de pureza referente a primeira época de aplicação dos tratamentos. Médias seguidas por mesma letra não diferem estatisticamente entre si $(\mathrm{p}<05)$. 74

Tabela 14. Fontes de variação e significância do valor F para a variável açúcares redutores do caldo.

Tabela 15. Porcentagem de açúcares redutores (caldo) referente a primeira época de aplicação dos tratamentos. Médias seguidas por mesma letra não diferem estatisticamente entre si $(\mathrm{p}<05)$.

Tabela 16. Fontes de variação e significância do valor $F$ para a variável açúcares redutores da cana.

Tabela 17. Porcentagem de açúcares redutores da cana referente a primeira época de aplicação dos tratamentos. 
Tabela 18. Fontes de variação e significância do valor $F$ para a variável açúcar total recuperável.

Tabela 19. Quilogramas de açúcar total recuperável por tonelada de cana referente a primeira época de aplicação dos tratamentos.

Tabela 20. Fontes de variação e significância do valor $F$ para a variável brix 85

Tabela 21.Porcentagem de brix referente a segunda época de aplicação dos tratamentos...... 85

Tabela 22. Fontes de variação e significância do valor F para a variável fibra. .87

Tabela 23. Porcentagem de fibra referente a segunda época de aplicação dos tratamentos.... 87

Tabela 24. Fontes de variação e significância do valor F para a variável pol do caldo. 88

Tabela 25. Porcentagem de pol do caldo referente a segunda época de aplicação dos tratamentos. Médias seguidas por mesma letra não diferem estatisticamente entre si ( $p<01) .89$

Tabela 26. Fontes de variação e significância do valor F para a variável pol da cana.

Tabela 27. Porcentagem de pol da cana referente a segunda época de aplicação dos tratamentos.

Tabela 28. Fontes de variação e significância do valor F para a variável pureza. .92

Tabela 29. Porcentagem de pureza referente a segunda época de aplicação dos tratamentos. Médias seguidas por mesma letra não diferem estatisticamente entre si $(\mathrm{p}<01)$. 93

Tabela 30. Fontes de variação e significância do valor F para a variável açúcares redutores do caldo

Tabela 31. Porcentagem de açúcares redutores referentes a segunda época de aplicação dos tratamentos. 95

Tabela 32. Fontes de variação e significância do valor F para a variável açúcares redutores da cana.

Tabela 33. Porcentagem de açúcares redutores (cana) referente a segunda época de aplicação dos tratamentos. Médias seguidas por mesma letra não diferem estatisticamente entre si $(\mathrm{p}<01)$. 96

Tabela 34. Fontes de variação e significância do valor $F$ para a variável açúcar total recuperável. 97

Tabela 35. Quilogramas de açúcar total recuperável por tonelada de cana referente a segunda época de aplicação dos tratamentos. 


\section{LISTA DE ABREVIATURAS E SIGLAS}

ART Açúcares redutores totais

ATR Açúcar total recuperável.

ATP Trifosfato de adenosina

DAA Dias após a aplicação.

IAC Instituto Agronômico de Campinas

Inc Certificate of incorporation

MTC Milhões de toneladas de cana.

NC North Carolina

PC Pol da cana

PIB Produto Interno Bruto

Proálcool Programa Nacional do Álcool.

PUI Período útil de utilização.

RB Variedade de cana de açúcar RB (República do Brasil).

SAS Statistical Analysis System

SP São Paulo

USA United States of America

US\$ United States Dollar. 


\section{LISTA DE UNIDADES E SÍMBOLOS}

$\% \quad$ Porcentagem

$\circ \quad$ Grau

6 $\quad$ Minutos

$<\quad$ Menor

B Boro

$\mathrm{B}_{4} \mathrm{O}_{7}^{-2}$ Ânion tetraborato

${ }^{\circ} \mathbf{C}$ Graus Celsius

Ca Cálcio

$\mathbf{C a C l}_{2}$ Cloreto de cálcio

CaO Óxido de cálcio

Cl Cloro

cm Centímetros

$\mathbf{C O}_{2}$ Dióxido de Carbono

CTC Capacidade de troca catiônica

Cu Cobre

DTPA Ácido dietilenotriaminopentaacético

Fe Ferro

GAs Giberelinas

$\mathbf{G A}_{3}$ Ácido Giberélico

g/ha Gramas por hectare

H+Al Hidrogênio+Alumínio

ha Hectares

kg p.c. ha Quilogramas do produto comercial por hectare

K Potássio

$\mathbf{K}_{2} \mathbf{O}$ Óxido de potássio

$\mathrm{KNO}_{3}$ Nitrato de potássio 
L ha Litros por hectare

M Molar

m Metros

$\mathbf{m}^{2} \quad$ Metros quadrados

Mg Magnésio

$\mathbf{m g} \mathbf{d m}^{\mathbf{3}}$ Miligramas por decímetro cúbico de solo

mmol $\mathbf{c}_{\mathbf{d m}} \mathbf{d m}^{\mathbf{3}}$ Milimol de carga por decímetro cúbico

MgO Óxido de magnésio

mL Mililitro

Mm Milímetros

Mn Manganês

MO Matéria orgânica

Mo Molibdênio

N Nitrogênio

P Fósforo

p p-valor

p.c. ha Produto comercial por hectare

pH Potencial hidrogeniônico

ppm Parte por milhão

S Enxofre

SB Soma de bases

$\mathrm{SiO}_{2} \quad$ Dióxido de silício

V\% Porcentagem de saturação por bases

Zn Zinco 


\section{SUMÁRIO}

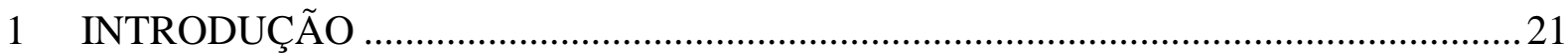

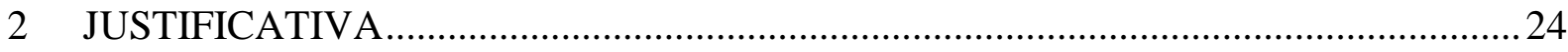

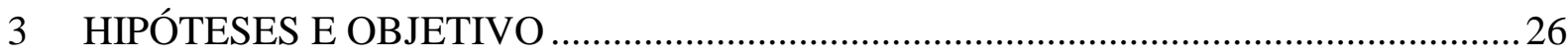

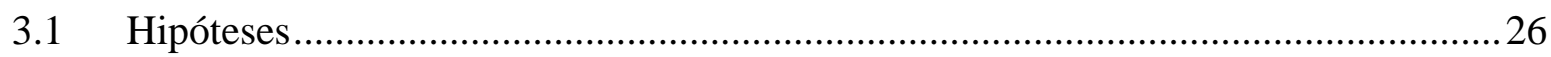

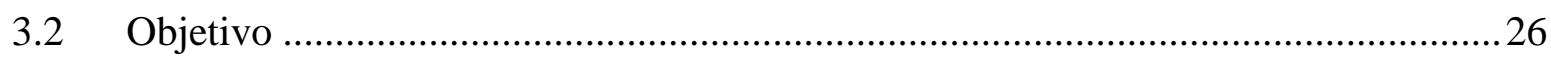

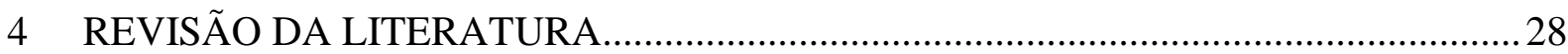

4.1 Histórico e produção brasileira da cana-de-açúcar ...................................................28

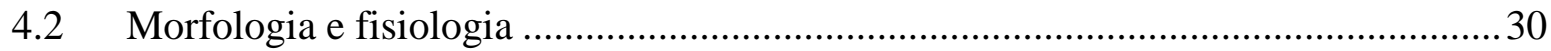

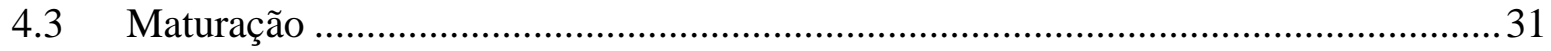

4.4 Função dos nutrientes e dos hormônios na maturação.............................................33

4.5 Qualidade da matéria prima e indicadores industriais ............................................ 37

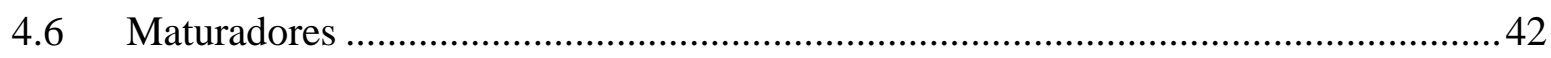

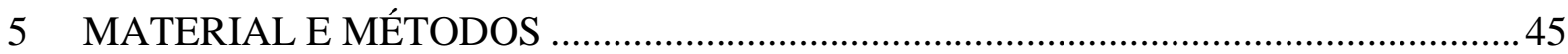

5.1 Caracterização da área experimental e condições climáticas .................................45

5.2 Tratamentos, delineamento experimental e atributos do solo..................................48

5.3 Aplicação dos tratamentos e amostragens .............................................................51

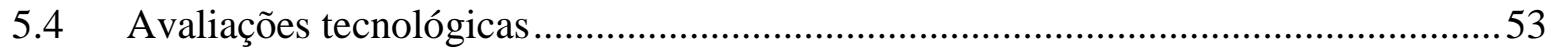

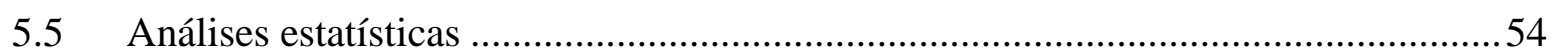

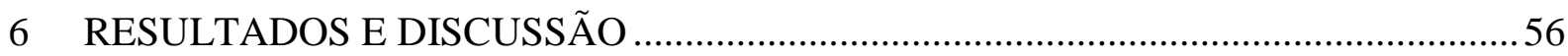

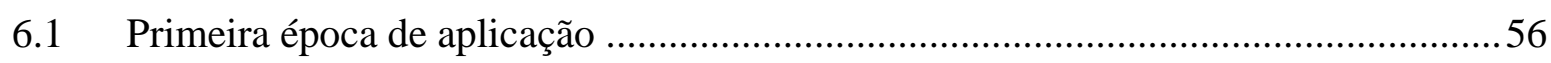

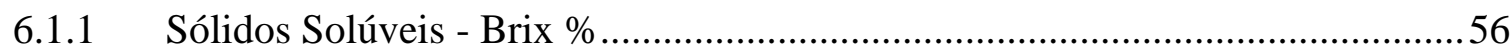

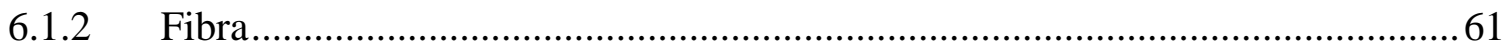

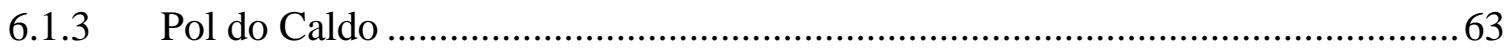

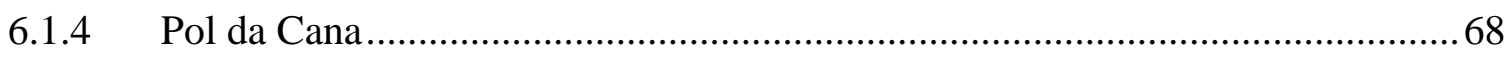

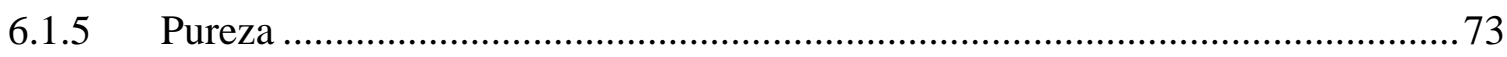

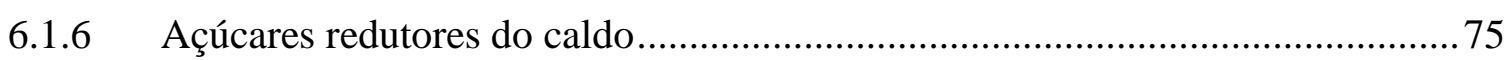

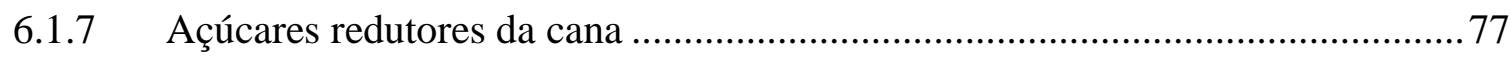

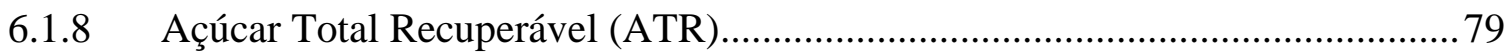

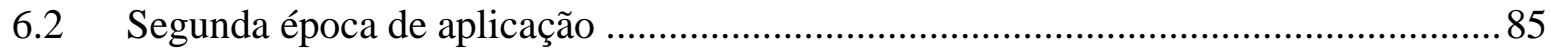

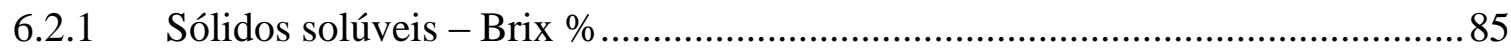

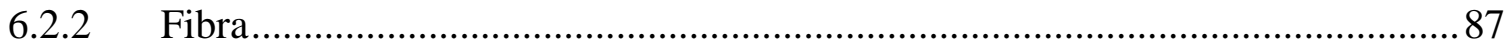

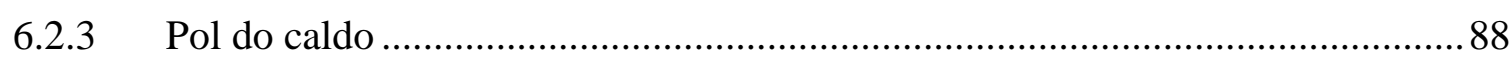

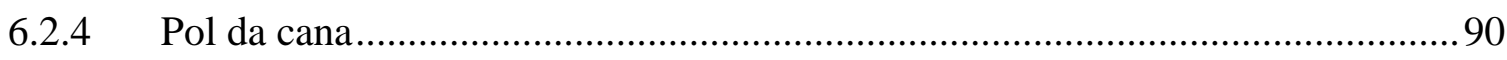

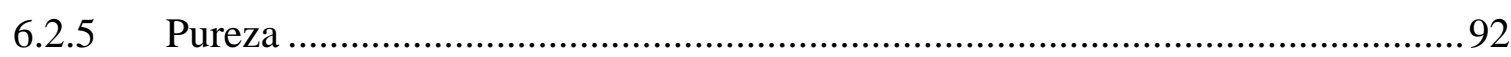

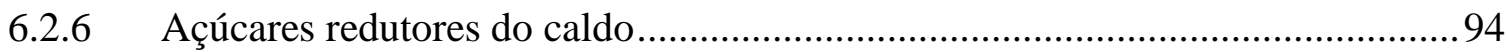




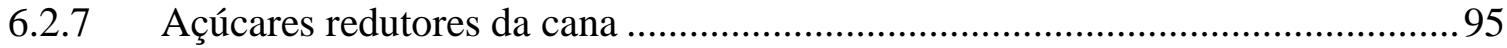

6.2.8 Açúcar Total Recuperável (ATR) ................................................................ 97

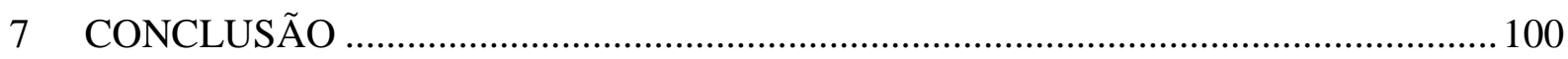


1. INTRODUÇÃ̃ 


\section{INTRODUÇÃO}

Introduzida no Brasil no período colonial, a cana-de-açúcar transformou-se em uma das principais culturas do agronegócio brasileiro, com grande importância econômica, social e ambiental. A produção do país é considerada referência mundial, devendo atingir na safra 2015/2016 654,6 milhões de toneladas, em pouco mais de 9 milhões de hectares (CONAB, 2015). Contudo, a produtividade média ainda é baixa, o que denota grande potencial a ser explorado. Isto posto, buscam-se novas tecnologias capazes de proporcionar incrementos em produtividade e melhorias na qualidade tecnológica da cana-de-açúcar.

Com a tendência de antecipação do início da safra pela ocorrência de safras maiores, devido às dificuldades financeiras das empresas, que buscam fazer caixa no período em que a oferta é aquém da demanda, aproveitando os melhores preços no mercado interno e, a crise de produtividade em função do clima e expansão do cultivo, recorrente das dificuldades de adaptação das variedades (solo x clima) o emprego de tecnologias que otimizem o potencial genético de acúmulo de sacarose, elevando a qualidade tecnológica do canavial, são imprescindíveis.

Entre as estratégias utilizadas para o fornecimento de matéria prima de qualidade tecnológica está a utilização de maturadores, que permitem o manejo da cultura em seu sistema de produção. Atualmente, nove produtos químicos estão registrados no Brasil para o uso como reguladores de crescimento vegetal. Estudos demonstram que a ação dos reguladores/ maturadores influenciam de forma significativa a produtividade de açúcar aumentando o retorno econômico por hectare, promovem melhorias na qualidade tecnológica e antecipam a colheita da cana (LEITE et al., 2009; CAPUTO et al., 2008; LEITE e CRUSCIOL, 2008).

A associação de maturadores com boro (B) pode fornecer à indústria matéria prima de qualidade, bem como a aplicação de produtos cuja composição química apresentam o nitrato de potássio. Segundo Siqueira (2014) a aplicação do Boro revelou efeito promissor em elevar o teor de sacarose dos colmos em início de safra. Leite et al. (2011) verificaram que o nitrato de potássio apresentou efeito maturador na cultura da cana-de-açúcar, possibilitando acúmulo de sacarose nos colmos.

Ainda que progressos tecnológicos tenham sido obtidos, muitas questões ainda necessitam ser estudadas em relação ao cultivo desta cultura objetivando maximizar a quantidade de açúcar e álcool produzido por tonelada de cana. É importante continuar 
estudando o uso de substâncias químicas como maturadores, pois, existem muitas áreas onde a produção pode variar significativamente se essas substâncias forem introduzidas em seu sistema de cultivo com sucesso. Novos estudos que visam antecipar para o início da safra o processo de maturação da cana-de-açúcar e propiciar melhorias na qualidade tecnológica são importantes para determinar novas ferramentas para serem utilizadas no planejamento da colheita. Nesse sentido, o emprego de maturadores com diferentes princípios ativos, o uso de nutrientes e hormônios, associações entre estes produtos e o manejo em diferentes épocas, permitirão identificar novas alternativas para os incrementos na produção. 
2. JUSTIFICATIVA 


\section{JUSTIFICATIVA}

Projeções para a safra brasileira de cana-de-açúcar em 2023/2024 demostram que haverá a necessidade de o país atingir uma área plantada de 10,5 milhões de hectares e um processamento na ordem de 862 milhões de toneladas para atender o crescimento do consumo e das exportações de açúcar e etanol. Para atender a demanda, a produtividade deverá crescer $11 \%$ e a produção $32,5 \%$.

Com tamanha proporção de produção, a qualidade da cana-de-açúcar, como matériaprima, será um dos fatores cruciais para proporcionar aumentos de desempenho, com pequeno aumento na área plantada. A recuperação da vitalidade da indústria canavieira depende de investimentos para aumentar a eficiência agrícola e industrial.

Por estar envolvida diretamente com o desempenho das operações de extração, fermentação e destilação, a matéria prima é a razão fundamental da obtenção de altos rendimentos e da qualidade do produto final, tendo reflexo positivo em toda a cadeia produtiva.

Segundo Morgan et al. (2007), os custos de produção e a viabilidade econômica da industrialização da cana-de-açúcar estão fortemente correlacionados com a quantidade de açúcares presentes nos colmos industrializáveis enviados para o processamento. Estratégias e tecnologias que proporcionem uma matéria-prima mais produtiva e mais rentável devem continuar sendo estudadas.

Nesse contexto o estudo do desempenho de maturadores, com diferentes princípios ativos, associados com nutrientes com potencial maturador e épocas de aplicação, são viáveis para a determinação de novas ferramentas de utilização no planejamento e no manejo da colheita da cana-de-açúcar. 
3. HIPÓTESES E OBJETIVO 


\section{HIPÓTESES E OBJETIVO}

\subsection{Hipóteses}

As hipóteses desta pesquisa foram:

A utilização de maturadores e nutrientes (Boro (B), Zinco (Zn) e Potássio (K)) em précolheita promovem melhorias na qualidade tecnológica da cana-de-açúcar.

A associação dos nutrientes ( $\mathrm{B}, \mathrm{Zn}$ e $\mathrm{K}$ ) com maturadores potencializam a ação dos maturadores.

Diferentes épocas de aplicação de maturadores e nutrientes, em início de safra, implicam em melhorias na qualidade tecnológica da cana-de-açúcar.

\subsection{Objetivo}

Com a finalidade de avaliar as hipóteses em referência, conduziu-se esta pesquisa com o objetivo de avaliar o efeito de maturadores, nutrientes e hormônios sobre os parâmetros tecnológicos da cana-de-açúcar em início de safra. 
4. REVISÃO DA LITERATURA 


\section{REVISÃO DA LITERATURA}

\subsection{Histórico e produção brasileira da cana-de-açúcar}

A hipótese mais aceita sobre a origem e expansão da cana-de-açúcar é que ela tenha sido cultivada inicialmente na Ásia e se difundido juntamente com as migrações náuticas para vários lugares do Oceano Pacífico e Golfo de Bengala, aparecendo como planta produtora de açúcar na Índia tropical, país no qual, ao que tudo indica, a história do açúcar teve seu início (RIPOLI et al., 2007; MIRANDA, 2008).

Típica de climas tropicais e subtropicais, a planta não correspondeu às tentativas para cultivá-la na Europa. Foi, contudo, a América que ofereceu à cana-de-açúcar excelentes condições para o seu desenvolvimento (SEGATO et al., 2006 b).

Há indícios de que o cultivo da cultura no Brasil seja anterior à época do descobrimento, mas, seu desenvolvimento se deu, posteriormente, com a criação de engenhos e plantações com mudas trazidas pelos portugueses (SEGATO et al., 2006 a). A cultura foi introduzida no país com o objetivo de desfazer domínio comercial exercido pela França na comercialização do açúcar produzido nas Ilhas do Caribe. Oficialmente, foi Martim Afonso de Souza que, em 1532, trouxe a primeira muda de cana ao Brasil (AZANIA, 2003).

Nos primórdios do estabelecimento da cultura canavieira nas terras brasileiras, seu desenvolvimento foi maior no Nordeste, nos Estados de Pernambuco, Bahia e Alagoas. Fatores climáticos e características de solo permitiram o florescimento da cultura da cana-deaçúcar e a proximidade a Portugal viabilizou o aproveitamento do seu potencial exportador fazendo dessa atividade o núcleo econômico central do Brasil Colônia (CORRÊA, 1935; WEHLING, 1994). Este foi o princípio de uma agroindústria das mais sofisticadas da época, que encontrou no Brasil condições de solo e clima ideais, tornando-o um dos locais mais férteis para a expansão da cultura da cana-de-açúcar (MIRANDA, 2008).

Com a criação do Programa Nacional do Álcool (Proálcool), em 1975, incentivou-se as inovações tecnológicas, modernas práticas empresariais e ganhos de escala ao setor, os quais acabaram por reduzir o custo de produção do etanol a preços compatíveis com a gasolina. O Proálcool foi o maior programa mundial de energia renovável, congregou incentivos múltiplos ao aumento da capacidade instalada: canaviais, usinas, destilarias e infraestrutura de armazenagem. Essa política ensejou rápida implantação de canaviais e vertiginoso crescimento da produção de álcool sem, entretanto, perturbar o abastecimento de açúcar (MAPA, 2015). 
Hoje o Brasil destaca-se como uma potência mundial quando se discute cana-deaçúcar, açúcar e etanol, consolidando-se o maior produtor de cana-de-açúcar e exportador de açúcar e álcool (NEVES e OLIVEIRA, 2007). Atualmente, 2\% das terras agrícolas brasileiras são utilizadas para esta cultura, com produção correspondente a aproximadamente a $41 \%$ da produção mundial, seguido da Índia e China, com $18 \%$ e $7 \%$ respectivamente, da produção global (CONAB, 2013).

Nas últimas três safras, 2012/2013, 13/14, 14/15, a produção nacional girou em torno de 627 milhões de toneladas de cana (MTC), atingindo seu recorde de 658 MTC na safra 2013-2014. O Brasil deverá produzir na safra 2015/2016 654,6 MTC. A estimativa é de que a produção tenha um incremento de $3,1 \%$ em relação à safra passada, que só não será maior devido ao aumento na área plantada no país ser relativamente pequeno $(0,7 \%)$ e, pela produtividade nos canaviais do estado de São Paulo, maior estado produtor, que se recuperam de um impacto hídrico da safra passada (CONAB, 2014; CONAB, 2015).

A área cultivada com cana-de-açúcar que deverá ser colhida e destinada à atividade sucroalcooleira na safra 2015/16 é de 9.070,4 mil hectares, distribuídas em todos estados produtores. São Paulo permanece como o maior produtor com 51,7\% (4.687,6 mil hectares) da área plantada, seguido por Goiás, com 9,8\% (891,6 mil hectares), Minas Gerais, com 8,9\% (808 mil hectares), Mato Grosso do Sul, com 7,5\% (682,3 mil hectares), Paraná, com 6,8\% (620,1 mil hectares), Alagoas, com 4,3\% (386 mil hectares) e Pernambuco com 3\% (276,3 mil hectares). Estes sete estados são responsáveis por 92,1\% da produção nacional, os outros dezesseis estados produtores possuem áreas menores, com representações abaixo de 2,5\%, totalizando 8\% da área total do país (MAPA, 2015).

O PIB do setor sucroenergético foi de cerca de US\$ 43,4 bilhões na safra de 2013/2014 (NEVES e TROMBIN, 2014). Entretanto, o Brasil está perdendo competitividade no setor o qual já foi considerado um dos mais promissores do país. O setor vem atravessando uma das mais graves crises de rentabilidade da história, motivada pela escalada dos custos de produção, sobretudo, a despesa com insumos e mão de obra. Os preços dos produtos não acompanharam o aumento dos custos, por isso, a rentabilidade média das usinas caiu mais de $50 \%$ nos últimos anos. A ausência de políticas para os biocombustíveis entrava novos investimentos (AGRIANUAL, 2013).

Verifica-se que a cana-de-açúcar teve sempre um importante papel para a economia nacional, desde o período dos engenhos até os dias atuais. Em virtude da importância e expressividade do mercado sucroenergético, é necessário que ocorram novos incentivos e 
alterações nesse setor para que, desta maneira, o mesmo persista desempenhando papel relevante para o agronegócio brasileiro.

\subsection{Morfologia e fisiologia}

A cana-de-açúcar (Saccharum officinarum) é uma planta monocotiledônea, C4, alógama e perene, pertence à família Poaceae e ao gênero Saccharum, que abrange várias espécies. As canas altamente cultivadas, na sua maioria, são híbridas, nas quais procurou-se aliar a rusticidade de espécies, como $S$. spontaneum, às boas qualidades das variedades nobres de S. officinarum (FIGUEIREDO, 2008; GOMES e LIMA, 1964; GUPTA et al., 2010; SEGATO et al.,2006 b).

Seu desenvolvimento se dá em forma de touceira, a parte aérea é composta por colmos (caule típico das gramíneas), folhas, inflorescências e sementes e a subterrânea por raízes e rizomas, sendo as raízes fasciculadas e os rizomas constituídos por nódios, internódios e gemas, as quais são responsáveis pela formação dos perfilhos na touceira (MOZAMBANI et al., 2006).

Em função do seu ciclo perene, sofre a influência das variações climáticas durante todo o ano. Para atingir alta produção de sacarose, a planta necessita de temperatura e umidade adequadas, para permitir o máximo crescimento na fase vegetativa, seguida de restrição hídrica ou térmica, para favorecer o acúmulo de sacarose no colmo na época do corte. A cultura encontra suas melhores condições quando ocorre um período quente e úmido, com intensa radiação solar durante a fase de crescimento, seguida de um período seco durante as fases de maturação e colheita (ALFONSI et al., 1987).

A temperatura noturna influi mais no crescimento da cana-de-açúcar que a diurna, sendo que quando as noites são frias, o desenvolvimento é lento, e ocorre maior concentração de sacarose nos colmos (FAUCONIER e BASSEREAU, 1975). A sacarose e os açúcares redutores (glicose e frutose) translocam-se dia e noite para todas as partes da planta através do floema, sendo armazenados, principalmente, nos entrenós mais velhos, crescendo, portanto, do topo para a base da planta (LUCCHESI, 2008).

O regime hídrico anual mínimo para a cana-de-açúcar é de $1200 \mathrm{~mm}$, concentrados na primavera e verão, com inverno seco e/ou frio bem característico, sem geadas frequentes. 
Tolera temperaturas elevadas desde que o solo seja profundo e com boa disponibilidade de água (FIGUEIREDO et al., 1998).

Na cana-de-açúcar são definidos quatro estádios de desenvolvimento, conhecidos por brotação, perfilhamento, máximo crescimento e maturação (GASCHO e SHIH, 1983). Tal como as demais gramíneas, a cana floresce, frutifica e morre, garantindo a perpetuação da espécie. A floração é fenômeno normal e indispensável para a sobrevivência da espécie não interessando, no entanto, ao produtor, pelo fato de causar prejuízos, principalmente em relação ao armazenamento de açúcar (RODRIGUES, 1995).

O conhecimento do desenvolvimento da cana-de-açúcar, em suas diferentes fases fisiológicas, possibilita discernir as relações e a interferência dos fatores envolvidos no processo de produção, favorecendo o manejo e as tomadas de decisão.

\subsection{Maturação}

Define-se a maturação como o processo fisiológico de carregamento e armazenamento de sacarose nas células do parênquima dos colmos. É o momento de acumulação máxima de produtos fotoassimilados nos órgãos de reserva da planta. O ponto de maturação é determinado principalmente pelos teores de sacarose, açúcares redutores e umidade do colmo durante o ciclo da cultura (SEGATO et al., 2006 b; DIOLA e SANTOS, 2010; LAVANHOLI, 2008).

A maturação é um dos aspectos mais importantes da cultura da cana-de-açúcar por estar diretamente relacionada ao momento de industrialização (GHELLER, 2001). Na fase de maturação a cana entra em repouso fisiológico e ocorre o acúmulo de sacarose nos colmos, precisando de clima seco e frio. Se faz necessária uma redução da temperatura de 10 a $20^{\circ} \mathrm{C}$, com redução na taxa de crescimento e maior acúmulo de sacarose (ANDRADE e ANDRADE, 2007; DOOREMBOS e CASSAM, 1979).

Verifica-se nesta fase o decréscimo de umidade no colmo que é contrabalanceado pelo ganho de sacarose e de fibras. $\mathrm{O}$ amadurecimento prossegue da parte inferior para a superior (LISSON et al., 2005).

Do ponto de vista agroindustrial, a maturação é definida como aquele estádio de desenvolvimento em que a cultura apresenta melhor produtividade quali-quantitativa de açúcares ou como aquele cuja produtividade agroindustrial e o resultado econômico se 
encontram maximizados (MUTTON, 1993). Sob o ponto de vista econômico, a cana é considerada apta a ser industrializada a partir do momento em que apresenta teor mínimo de sacarose de $13 \%$ do peso do colmo (VIANA et al., 2007).

O rendimento industrial em açúcar e álcool é decorrente do teor de açúcares da cana, como a sacarose (para a produção de açúcar) e sacarose, glicose e frutose (para a produção de álcool). Nesse aspecto, a maturação é de fundamental importância, uma vez que os teores de sacarose são mais elevados quando a cana se encontra em plena maturação (LAVANHOLI, 2008).

Em condições normais, a cana-de-açúcar tem a sua maturação influenciada por diversos fatores que induzirão as plantas a acumular sacarose nos colmos, sendo estes: umidade do solo, temperatura, nutrientes minerais, tratos culturais e diferenças entre variedades. Desses, a temperatura e a umidade dos solos são as que maiores influências exercem sobre a planta, pois, os períodos de intensa umidade e alta temperatura correspondem aos de maior atividade vegetativa (MARAFON, 2012; GUELLER, 1999).

Considerando-se a época em que as variedades acumulam açúcar, elas podem ser classificadas quanto aos diferentes períodos de maturação. Esses períodos iniciam-se quando a cana atinge o teor de sacarose acima do padrão, apresenta valores crescentes e após atingido o pico os teores decrescem, encerrando-se quando o teor de sacarose atinge 16\% (AUDE, 1993; LAVANHOLI, 2008). Segundo Barbosa e Silveira (2006), as variedades são classificadas da seguinte forma:

Precoces: apresentam teor de sacarose superior a outros cultivares no início da safra (abril e maio). Considerando somente a maturação, normalmente possuem longo Período Útil de Industrialização - PUI;

Médias: apresentam teor de sacarose superior a outros cultivares no meio da safra (junho, julho e agosto) possuindo PUI médio;

Tardias: apresentam elevado teor de sacarose de meados para o final da safra, possuindo PUI curto (70 a 120 dias).

Uma cana é considerada madura, para início de safra, quando atinge os seguintes valores mínimos: Brix (Sólidos Solúveis) 18\%; POL\% Caldo 15,3\% ou POL\% Cana 13,0; Pureza 85\% e Açúcares Redutores de 1\%, no máximo (BRIEGER, 1968). 
A maturação por estar diretamente relacionada aos resultados que serão obtidos na indústria, e, por ser a fase fisiológica que proporciona retorno econômico, é um dos aspectos de maior importância da cultura da cana-de-açúcar.

\subsection{Função dos nutrientes e dos hormônios na maturação}

Os fatores mais importantes para o crescimento e desenvolvimento da cana-de-açúcar são a água, nutrientes e hormônios vegetais (CAMARGO, 1976). Segundo Lucchesi (1995) a adubação e a nutrição da cana-de-açúcar têm influência na qualidade e na maturação da matéria-prima.

O potássio $(\mathrm{K})$ é o macronutriente requerido em maior quantidade pela cana-deaçúcar. Desempenha papel importante no crescimento, produtividade de colmos e na produtividade de açúcar. Quando suprido adequadamente o mesmo aumenta os teores de sacarose, bem como possibilita maior resistência das plantas a doenças (aumenta a espessura da cutícula) e pragas, além de evitar o acamamento (ROSSETTO et al., 2008; OTTO, VITTI e LUZ, 2010).

O K é vital para a fotossíntese e têm elevada contribuição para o potencial osmótico da planta. A concentração de $\mathrm{K}$ nas células guarda regula o processo de abertura e fechamento dos estômatos, sua deficiência provoca limitado controle sobre a perda de água das plantas (DECHEN e NACHTIGALL, 2007).

Atua na síntese de proteínas, como cofator da ativação de aminoácidos e indiretamente no suprimento de ATP (LUCCHESI, 2008). Absorvido pelas plantas na forma de $\mathrm{K}^{+}$, o potássio é usualmente o cátion mais abundante nas células vegetais (MALAVOLTA, 1964).

A ação bioquímica do K na cana-de-açúcar está presente no metabolismo de hexoses e transporte de sacarose (devido a sua influência no crescimento, fotossíntese ou teor de umidade) seja no transporte do floema, seja no transporte célula a célula da sacarose em direção ao floema, ou deste, no sentido de armazenamento, havendo relação entre o nível de $\mathrm{K}$ e a síntese proteica nas folhas e nos colmos, bem como diminuição da fotossíntese em plantas deficientes desse elemento. Há relatos da influência direta e indireta do $\mathrm{K}$ no transporte de sacarose em cana-de-açúcar (FRANZÉ, 2010; RODRIGUES, 1995).

Condições de deficiência potássica resultam em acumulação de carboidratos solúveis e diminuição na síntese de amido. O primeiro efeito pode ser explicado de dois modos 
complementares, a saber: impedimento no desdobramento glicolítico do carboidrato e impedimento na síntese do amido (MALAVOLTA et al, 1974).

Segundo Malavolta e Crócomo (1982), o K tem grande importância na redução do acamamento das plantas. Sampaio (1945), estudando os efeitos das adubações na composição do caldo da cana-de-açúcar, verificou que o $\mathrm{K}$ foi sempre um elemento muito favorável no que se refere a sacarose no caldo.

Malavolta et al. (1974), citaram que as canas deficientes em K apresentam teor mais baixo de açúcar, o que pode ser devido a uma diminuição na atividade fotossintética ou na translocação das folhas para o colmo - ou ambas as coisas. A deficiência de potássio reduz grandemente a translocação do açúcar nas folhas e não há acumulação de nitrogênio não proteico nas mesmas (CAMARGO e SILVA, 1990).

Em plantas deficientes em potássio ocorrem aumentos na percentagem de açúcares redutores e diminuição na de sacarose, aumento na atividade da invertase e amilase, aumento na taxa de respiração foliar, diminuição na fotossíntese, redução no movimento da sacarose das folhas para os tecidos e diminuição da síntese e translocação de proteínas, devendo essa ser causada pela necrose do floema. Portanto, teores adequados do nutriente aumentam a sacarose na cana-de-açúcar (HARTT, 1929; HARTT, 1993).

Hauch e Dickison (1954) demonstraram que em plantas deficientes em potássio a atividade hidrolítica da invertase é aumentada, acarretando, portanto, na maior quantidade de açúcares redutores que sacarose.

Produtos cuja composição química apresentam o nitrato de potássio têm sido sugeridos para cana-de-açúcar, uma vez que atuam como indutores da maturação (HARO et al., 2001). O nitrato de potássio $\left(\mathrm{KNO}_{3}\right)$ se agrupa como retardador de crescimento por ser menos estressante à cana e obter o mesmo objetivo de reduzir o crescimento vegetativo da planta em favor da translocação e acúmulo de sacarose (CRUSCIOL et al., 2010). O $\mathrm{KNO}_{3}$ puro contém $13,68 \%$ de $\mathrm{N}$ e $46,58 \%$ de $\mathrm{K}_{2} \mathrm{O}$. Os produtos comerciais têm variação em sua a composição média (CAMARGO e SILVA, 1990).

Leite et al. (2011) observaram efeito maturador do nitrato de potássio na cultura da cana-de-açúcar, possibilitando o acúmulo de sacarose nos colmos. 
Até o advento do ProÁlcool, o cultivo da cana-de-açúcar estava restrito às terras de elevada fertilidade na região sul do país. Com a expansão do cultivo para solos de baixa fertilidade dos cerrados, as deficiências dos micronutrientes passaram a ser observadas.

Entre os micronutrientes, o boro (B) é o que mais frequentemente se encontra deficiente em solos brasileiros (SILVA e FERREYRA, 1998). É um elemento essencial ao crescimento das plantas, participando como constituinte de diversos compostos e ativadores de enzimas, e de diversos processos, como absorção iônica, transporte de carboidratos, síntese de lignina, celulose, ácidos nucléicos e proteínas (ALLEONI, CAMARGO e CASAGRANDE, 1998).

O B está relacionado a muitos processos fisiológicos da planta que são afetados pela sua deficiência, como o transporte de açúcares, síntese da parede celular, lignificação, estrutura da parede celular, metabolismo de carboidratos, metabolismo de RNA, respiração, metabolismo fenólico, metabolismo de ascorbato, integridade da membrana plasmática e metabolismo de AIA (CAKMAC e RÖMHELD, 1997).

$\mathrm{O} \mathrm{B}$ é absorvido pelas plantas nas formas aniônicas $\mathrm{B}_{4} \mathrm{O}_{7}{ }^{2-}, \mathrm{HBO}_{3}{ }^{2-}, \mathrm{BO}_{3}{ }^{2-}$ e na forma $\mathrm{H}_{3} \mathrm{BO}_{3}$ (CAMARGO e SILVA, 1990). Embora geralmente seja imóvel no floema, em espécies que o sorbitol é o principal açúcar, o boro é móvel (BROWN e HU, 1996). Tem sido atribuído ao B um papel na translocação dos açúcares, o que é explicado de diversos modos. Para alguns os íons borato formam uniões com os OHs dos açúcares dando complexos ionizáveis capazes de atravessar membranas de modo mais rápido que as moléculas não ionizadas do açúcar propriamente dito (GAUCH, 1957).

O efeito do boro na translocação do açúcar é secundário: faltando o elemento, ficaria dificultada a formação de pectatos da parede celular ocorrendo necrose do floema e daí menor transporte de carboidrato (NICHOLAS, 1961). A falta de B diminui a formação dos complexos do borato com açúcares que facilita o transporte dos últimos dentro da planta (MALAVOLTA, 2006).

Os sintomas de deficiência de boro são, na realidade, sintomas de deficiência de glucídeos, visto que as regiões das plantas onde a atividade metabólica é elevada necessitam também de maiores quantidades de açúcares e essas regiões são as primeiras a serem afetadas pelas condições de deficiência do elemento (SOBRAL e WEBER 1983). 
Leite et al. (2009), utilizando os maturadores $\mathrm{KNO}_{3}+$ Boro, em condições climáticas desfavoráveis ao processo de maturação natural, verificaram que a utilização destes produtos promoveu antecipação da colheita em 5 dias em relação ao controle.

O Zinco ( $\mathrm{Zn}$ ) é absorvido pelo sistema radicular das plantas como $\mathrm{Zn}^{+2}$. A cana-deaçúcar com carência desse elemento apresenta diminuição na elongação dos internódios. O Zn é essencial para a síntese do triptofano, um precursor da auxina responsável pelo aumento do volume celular, participa também como constituinte e ativador de várias enzimas (SOBRAL \&WEBER, 1983). Segundo TAIZ \& ZEIGER, 2013, o elemento se se concentra nas zonas de crescimento devido à maior concentração auxínica.

A maior disponibilidade de $\mathrm{Zn}$ ocorre na faixa de $\mathrm{pH}$ 5,0 a 6,5. A associação de baixas temperaturas e excesso de umidade podem fazer com que as deficiências de $\mathrm{Zn}$ sejam pronunciada (ABREU et al., 2007).

A adubação com Zn em canaviais cultivados em solos com baixo teor deste nutriente pode proporcionar maior crescimento dos internódios, aumentar o crescimento do topo da cana-de-açúcar e, consequentemente, aumentar o comprimento e produtividade de colmos (TEIXEIRA FILHO et. al, 2013).

O desenvolvimento e o crescimento das plantas são regulados por fatores endógenos e externos. Os fatores endógenos são ativos não somente a nível celular e molecular, afetando os processos metabólicos via transcrição e transdução, mas, também, têm a função de coordenação do organismo como um todo, realizada por meio dos hormônios vegetais (LARCHER, 2000).

Os hormônios são biomoléculas produzidas pelas plantas, cuja função, é proporcionar crescimento das estruturas do vegetal e que em baixas concentrações promovem, inibem ou modificam processos morfológicos e fisiológicos do vegetal. Entre essas biomoléculas estão as auxinas, citocininas, giberelina, entre outras. Porém, é possível a produção dessas biomoléculas sinteticamente, chamados reguladores de crescimento, cuja função é semelhante à dos hormônios (CID, 2010; CASTRO et al., 1998).

A auxina foi o primeiro hormônio vegetal a ser descoberto e estudado. Ela regula muitos aspectos do desenvolvimento vegetal, incluindo o alongamento do caule, a dominância apical, iniciação de raízes, o desenvolvimento dos frutos e meristemas e o crescimento 
trópico, podendo atuar com outros hormônios vegetais. As auxinas vêm sendo utilizadas comercialmente na agricultura há mais de 50 anos (TAIZ \& ZEIGER, 2013). Em face da estrutura relativamente simples do Ácido Indol-3-Acético, os laboratórios foram capazes de sintetizar várias moléculas com atividade de auxina.

A giberelina é um hormônio vegetal que tem sido utilizado experimentalmente em canade-açúcar desde 1956 para aumentar a produção de sacarose (SIEMER, 1969). Exerce um importante papel na mediação dos efeitos dos estímulos ambientais no desenvolvimento do vegetal. A luz e a temperatura podem ter efeitos profundos no metabolismo das GAs e nas respostas a esses hormônios. Os principais usos comerciais das giberelinas (principalmente $\mathrm{GA}_{3}$ ) estão relacionados à promoção de crescimento de frutíferas, a maltagem da cevada e ao aumento da produção de açúcar em cana-de-açúcar (TAIZ \& ZEIGER, 2013).

A citocinina é um hormônio que, além do seu papel na proliferação celular, afeta muitos outros processos, incluindo o desenvolvimento vascular, a dominância apical, a aquisição de nutrientes e a senescência foliar. As citocininas influenciam a mobilização de nutrientes para as folhas a partir de outras partes da planta (TAIZ \& ZEIGER, 2013).

Martins e Castro (1999) verificaram que a giberelina, aplicada para aumentar o desenvolvimento e a produtividade sob condições invernais promove atividade meristemática nos feixes vasculares, diminui a quantidade de fibras e provoca a diferenciação dos elementos condutores. O ethephon aplicado para inibir o florescimento e antecipar a maturação da canade-açúcar restringe a atividade do meristema intercalar (provocando a formação de um entrenó mais curto, denominado carretel, no momento de sua aplicação) e aumenta a frequência de pêlos ao longo das nervuras, uma característica da senescência induzida.

O conhecimento das múltiplas funções metabólicas e estruturais exercidas pelos nutrientes e suas exigências durante o ciclo da cultura, bem como a utilização de hormônios, podem facilitar o manejo e proporcionar melhorias na qualidade tecnológica e produtividade da cultura.

\subsection{Qualidade da matéria prima e indicadores industriais}

Segundo Camara (1993), o processo produtivo canavieiro visa três objetivos básicos: qualidade (riqueza em açúcar dos colmos industrializáveis, caracterizando matéria-prima de 
qualidade) produtividade (elevado rendimento agrícola de colmos industrializáveis, em cujas células parenquimatosas é armazenada a sacarose) e longevidade do canavial.

A eficiência do processo industrial de recuperação do açúcar depende da qualidade da matéria-prima entregue na unidade industrial (VIANA, 2007). A qualidade da cana-de-açúcar enquanto matéria-prima industrial pode ser definida por uma série de características intrínsecas da própria planta, como maior riqueza e pureza em açúcares, menor presença de impurezas vegetais (folhas verdes, palha, palmitos) e minerais (terras e pedras), que definem seu potencial para a produção de açúcar e etanol (FERNANDES, 2003; ALONSO, 2006).

Os dados referentes à qualidade da matéria-prima são importantes fatores que repercutem diretamente na qualidade e na quantidade dos produtos derivados da cana, sendo que os principais parâmetros analisados para especificar essa qualidade são a Pol\% da cana (percentual de sacarose na composição da cana) o teor de fibra e a pureza do caldo. Além de impactarem na qualidade dos produtos, esses fatores também são utilizados como base para cálculo da quantidade de ART (Açúcares Redutores Totais) da cana-de-açúcar processada pelas indústrias (PECEGE, 2011).

Dentre os fatores que influenciam a composição química e tecnológica da cana-deaçúcar, destacam-se variedades, ambientes de produção e manejo adotado (SEGATO et al., 2006a). As variedades apresentam composição química muito variável quantitativamente, porém, qualitativamente são semelhantes (FERNANDES, 1984).

As características agronômicas e agroindustriais refletem as diferenças genéticas entre os cultivares. Atualmente, encontram-se variedades melhoradas, com baixos valores de fibras e altos teores de sacarose, o que proporciona maiores produtividades agrícolas e industriais. No entanto, ainda existe o problema de precocidade e florescimento da cultura, não conseguindo atender as demandas com os mesmos teores de pol exigidos pelas indústrias (RAMALHO, 2001; MASCHEDE et al., 2009).

Deve-se destacar que o custo da matéria prima em uma unidade produtora de açúcar e etanol é em torno de dois terços do custo final dos produtos (açúcar e etanol). Esse número reflete a importância do setor agrícola no setor sucroenergético (MARGARIDO e SANTOS, 2013). O rendimento econômico da cana-de-açúcar é dado pela produção de sacarose, além de açúcares não redutores utilizados para formar o melaço e também a fibra, que pode ser utilizada como fonte de energia para a própria usina. $\mathrm{O}$ processamento industrial da cana pode 
também ser dirigido para a produção de álcool, para utilização como combustível e a partir daí toda a alcoolquímica (RODRIGUES, 1995).

A cana-de-açúcar contém cerca de $75 \%$ de água, $25 \%$ de matéria orgânica e $0,5 \%$ de material mineral. Altos teores de açúcares redutores indicam cana "verde" enquanto baixos teores indicam cana "madura". O caldo contém cerca de $82 \%$ de água e $18 \%$ de sólidos solúveis (Brix), glicose, aproximadamente, 0,4\%, frutose, aproximadamente, 0,2 \% e sacarose, aproximadamente, 14\% (VASCONCELOS, 2006). Alguns dos diversos atributos considerados para indicar a qualidade são: Pol \% Cana, Pol \% Caldo, Brix do Caldo, Brix da Cana, Açúcares Redutores, Pureza, Umidade e Fibra (CONSECANA, 2006).

Em relação a composição tecnológica dos colmos, estes apresentam cerca de 10 a $16 \%$ de fibra e o restante equivale ao caldo absoluto. Desse percentual, 75 a $82 \%$ equivale a água e o restante é representado pela presença de sólidos solúveis, destacando-se os açúcares (sacarose, glicose e frutose) e não açúcares (orgânicos: aminoácidos, gorduras, ceras e pigmentos) além de componentes não orgânicos: $\mathrm{SiO}_{2}, \mathrm{CaO}, \mathrm{MgO}, \mathrm{Cl}$ e $\mathrm{K}_{2} \mathrm{O}$ (CESAR e SILVA, 1993).

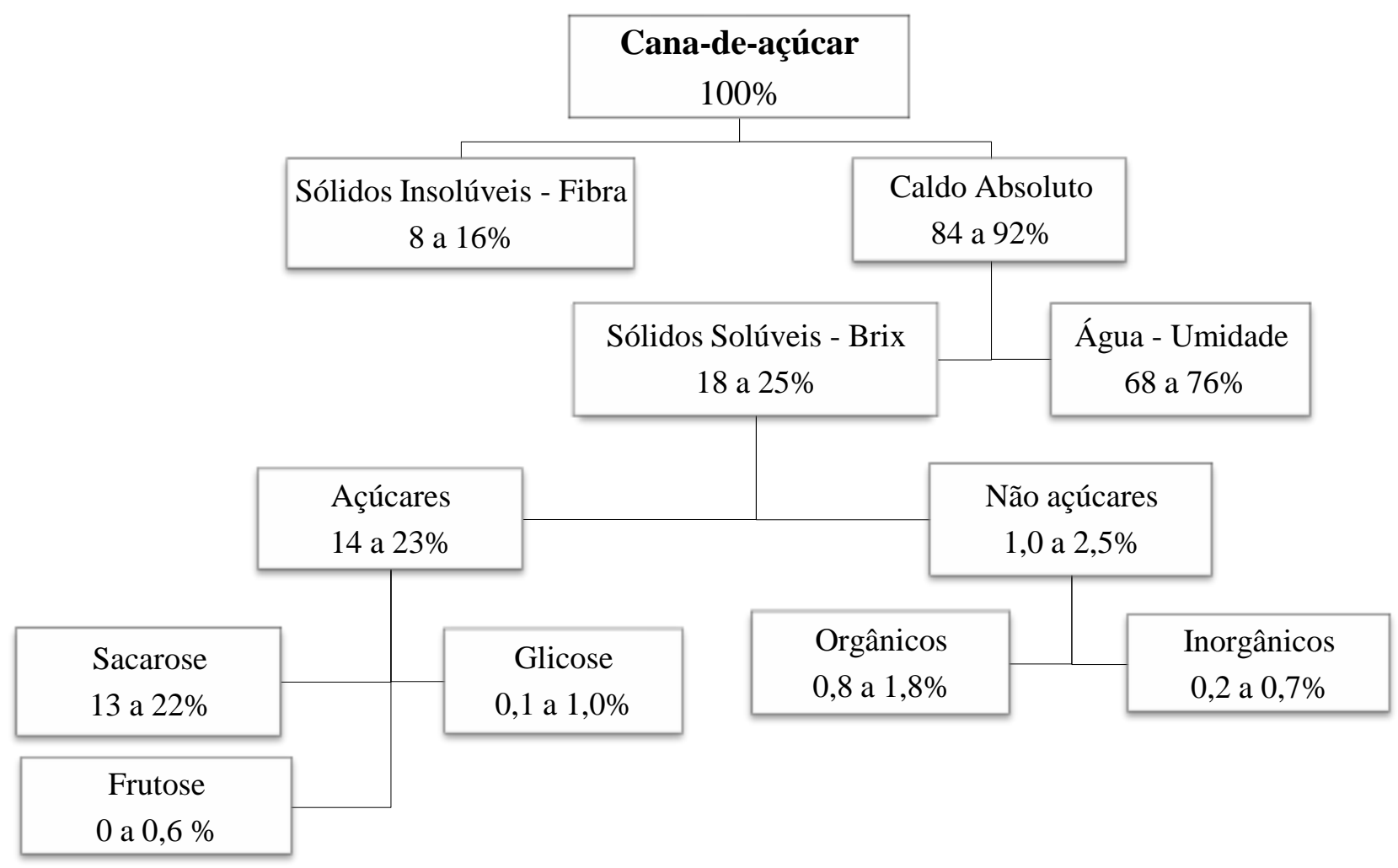

Figura 1. Composição química da cana-de-açúcar. 
Fonte: SANTOS et al., 2013.

O caldo da cana contém em sua composição basicamente três açúcares: sacarose, glicose e frutose. Para o caldo de cana madura, o teor de glicose e frutose é geralmente baixo, menor que $0,5 \%$, comparado ao teor de sacarose, acima de $14 \%$ na média da safra (FERNANDES, 2000).

A cana-de-açúcar apresenta capacidade de sintetizar açúcares, com destaque para a sacarose, em sua estrutura através de fotossíntese (COPERSUCAR, 1999). A sacarose, de fórmula química $\mathrm{C}_{12} \mathrm{H}_{22} \mathrm{O}_{11}$, é um dissacarídeo e constitui o principal parâmetro de qualidade tecnológica da cana-de-açúcar. É o açúcar diretamente cristalizável no processo de fabricação (FERNANDES, 2000).

A sacarose é a forma na qual o açúcar é transportado a partir das células fotossintetizantes (principalmente nas folhas) onde ele é produzido, para outras partes da planta (RAVEN et al., 2007). A síntese de sacarose ocorre em vários órgãos e tecidos, e a acumulação ocorre nos vacúolos (CASTRO, KLUGE e PERES, 2005).

É o componente atualmente mais valioso pois dela se obtém os dois produtos de maior exploração, o açúcar e o álcool etílico (DIOLA e SANTOS, 2010). O teor de sacarose está diretamente relacionado com o ponto de maturação da cana, e, é fundamental para um bom processamento e rendimento. Sua quantidade depende do estádio de maturação, do estado sanitário e das condições de conservação dos colmos (LAVANHOLI, 2008; MARAFON, 2012). O acúmulo máximo de sacarose ocorre quando a planta encontra condições que restringem seu crescimento forçando-a a parar seu desenvolvimento e amadurecer (ROSSETTO, 2015).

A Pol representa a porcentagem aparente de sacarose contida numa solução de açúcares, sendo determinada por métodos sacarimétricos (polarimétricos ou sacarimétricos). A pol na cana determinada por sacarimetria no caldo pode ser expressa em porcentagem de cana através de fórmula utilizando a fibra \% cana. No Estado de São Paulo, uma cana para ser considerada madura deve apresentar Pol\% cana variando de 14,4 (início da safra) a 15,3 (transcorrer da safra) (FERNANDES, 2000). 
Os açúcares redutores são compostos principalmente por glicose e frutose. São produtos precursores de cor no processo industrial, isto é, aumentam a cor do açúcar, depreciando a qualidade do produto (FERNANDES, 2000).

Os açúcares totais recuperáveis (ATR) representam a quantidade de ATR recuperados da cana até o xarope, ou seja, é obtido pela diferença entre o ATR da cana e as perdas na lavagem da cana, bagaço final das moendas, torta dos filtros e indeterminadas, considerandose uma eficiência média padrão (FERNANDES, 2000).

O brix é o parâmetro mais utilizado na indústria do açúcar e álcool. Estritamente, expressa a porcentagem peso/peso dos sólidos solúveis contidos em uma solução pura de sacarose, ou seja, mede o teor de sacarose na solução. Admite-se o brix como a porcentagem aparente de sólidos solúveis contidos em uma solução açucarada impura. A indústria sucroalcooleira, no Estado de São Paulo, considera que uma cana para ser industrializada deve ter, entre outras características, um caldo que contenha, no mínimo $18^{\circ}$ Brix, ou seja, $18 \%$ de sólidos solúveis (FERNANDES, 2000).

A fibra é a matéria insolúvel em água contida na cana. Corresponde a aproximadamente de 10 a $16 \%$ do total formado por celulose, hemicelulose, lignina, pectina e outros componentes da parede celular (BARBOSA e SILVEIRA, 2010; FERNANDES, 2000). O teor de fibras deve estar entre 10 e $11 \%$ para que seja recomendada a industrialização da cana (FERNANDES, 2000). Em início de safra é de fundamental importância que as variedades tenham teores mais elevados de fibra para garantir o suprimento de combustível para as caldeiras (LAVANHOLI, 2008). O teor de fibra da cana é uma característica varietal, mas é também influenciado por diversos fatores, como clima, solo, época de corte e método de determinação (FERNANDES, 2000).

A pureza é um dos principais parâmetros na fabricação do açúcar (DELGADO e CÉSAR, 1977). É a porcentagem de sacarose contida nos sólidos solúveis, sendo denominada pureza real. Quando se utilizam pol e brix, diz-se pureza aparente (FERNANDES, 2000). Quando a cana está madura, a pureza é maior do que quando a cana está verde pelo fato de refletir a relação entre o teor de sacarose e todos os demais sólidos solúveis (LAVANHOLI, 2008).

A qualidade da cana-de-açúcar é imprescindível na busca de resultados positivos industriais e econômicos por estar totalmente vinculada ao desempenho dos processos 
industriais, os quais são fundamentais para a obtenção de rendimentos satisfatórios e qualidade do produto final.

\subsection{Maturadores}

Uma estratégia considerável para evitar o florescimento, antecipar o processo de maturação ou promover melhorias na qualidade da matéria-prima a ser processada é o emprego de maturadores, que são produtos químicos que possuem a propriedade de paralisar o desenvolvimento da cana, induzindo a translocação e armazenamento dos açúcares (RODRIGUES, 1995; TOPPA, 2010; SEGATO e PEREIRA, 2006).

Os reguladores vegetais agem alterando a morfologia e a fisiologia da planta, podendo levar a modificações qualitativas e quantitativas na produção (MARTINS e CASTRO, 1999). O modo de ação é inerente a cada um, uma vez que atuam diretamente na fisiologia da planta, interferindo na síntese, degradação ou emprego de moléculas importantes do metabolismo básico (CASTRO, 1992).

Podem promover a diminuição do crescimento da planta, possibilitando incrementos no teor de sacarose, precocidade de maturação e também atuar sobre enzimas (invertases) que catalisam o acúmulo de sacarose nos colmos (SEGATO e PEREIRA, 2006).

A aplicação de maturadores na cultura da cana-de-açúcar tornou-se uma prática cada vez mais comum no setor sucroalcooleiro (GHELLER, 2001). A ausência de cultivares produtivos, com maturação precoce, pode ser contornada com a utilização de maturadores químicos para o suprimento da usina com cana madura durante o ano todo (RODRIGUES, 1995).

O início de safra é a época mais explorada por todas as unidades produtoras com o uso de produtos químicos, ou seja, de modo-geral, é a época que a matéria prima está mais pobre. Dessa forma, o uso de tais produtos propicia melhoria nas curvas de maturação (ROSA, 2008). Entretanto, a época de aplicação dos produtos químicos e a época de corte da matériaprima são alguns dos fatores que podem interferir na eficiência dos maturadores da cana-deaçúcar (LEITE, 2005).

Leite et al. (2010), aplicando os maturadores glifosato e sulfometuron metil, verificaram melhorias na qualidade tecnológica da matéria-prima. A utilização dos 
tratamentos contribuiu para o processo de maturação e possibilitaram antecipar o corte em relação à maturação natural (controle).

O Orthosulfamuron, produto comercial denominado de Strada 50WG®, apresenta ação sistêmica, após a sua absorção pelas folhas da cultura. Atua nas regiões meristemáticas afetando tanto o crescimento como inibindo a divisão celular. Com a paralisação temporária do crescimento, ocorre o processo de armazenamento de sacarose no colmo, cessando a emissão de novas folhas e impedindo o florescimento, quando aplicado antes da indução floral, o que acarreta em redução no índice de chochamento ou isoporização.

O Sulfometuron metil, produto comercial denominado Curavial ${ }^{\circledR}$, caracteriza-se como inibidor de crescimento vegetal. Apresenta ação sistêmica, atuando nas regiões meristemáticas afetando tanto o crescimento como inibindo a divisão celular. Ocorre processo de armazenamento de sacarose no colmo ao invés de emissão de novas folhas, o que acarreta em redução no índice de chochamento ou isoporização. $\mathrm{O}$ acúmulo de sacarose em decorrência da aplicação, acarreta em matéria-prima de melhor qualidade.

O Etil-Trinexapac, produto comercial denominado Moddus®, uma vez aplicado, é absorvido pela planta e, passa a atuar seletivamente através da redução do nível de giberelina ativa, induzindo a planta a uma inibição temporária ou redução do ritmo de crescimento, sem afetar, porém, o processo de fotossíntese e a integridade da gema apical.

Para cada situação deve-se verificar as ferramentas de manejo disponíveis, pois, através do manejo correto da matéria-prima obtém-se melhores resultados. Os maturadores são uma importante ferramenta para se planejar a safra de cana-de-açúcar. Sua utilização pode resultar em acréscimos (início da safra) ou conservação (final de safra) dos teores de açúcar na cana, sem desservir outros atributos, principalmente a produtividade. 
5. MATERIAL E MÉTODOS 


\section{MATERIAL E MÉTODOS}

\subsection{Caracterização da área experimental e condições climáticas}

O experimento foi conduzido na safra 2013/2014 na Fazenda Nova Aliança, pertencente à Abengoa Bioenergia, localizada no município de Pirassununga (SP), apresentando como coordenadas geográficas $47^{\circ} 21^{\prime}$ de longitude Oeste de Greenwich e $21^{\circ}$ 54' de latitude Sul, com altitude de 602 metros.

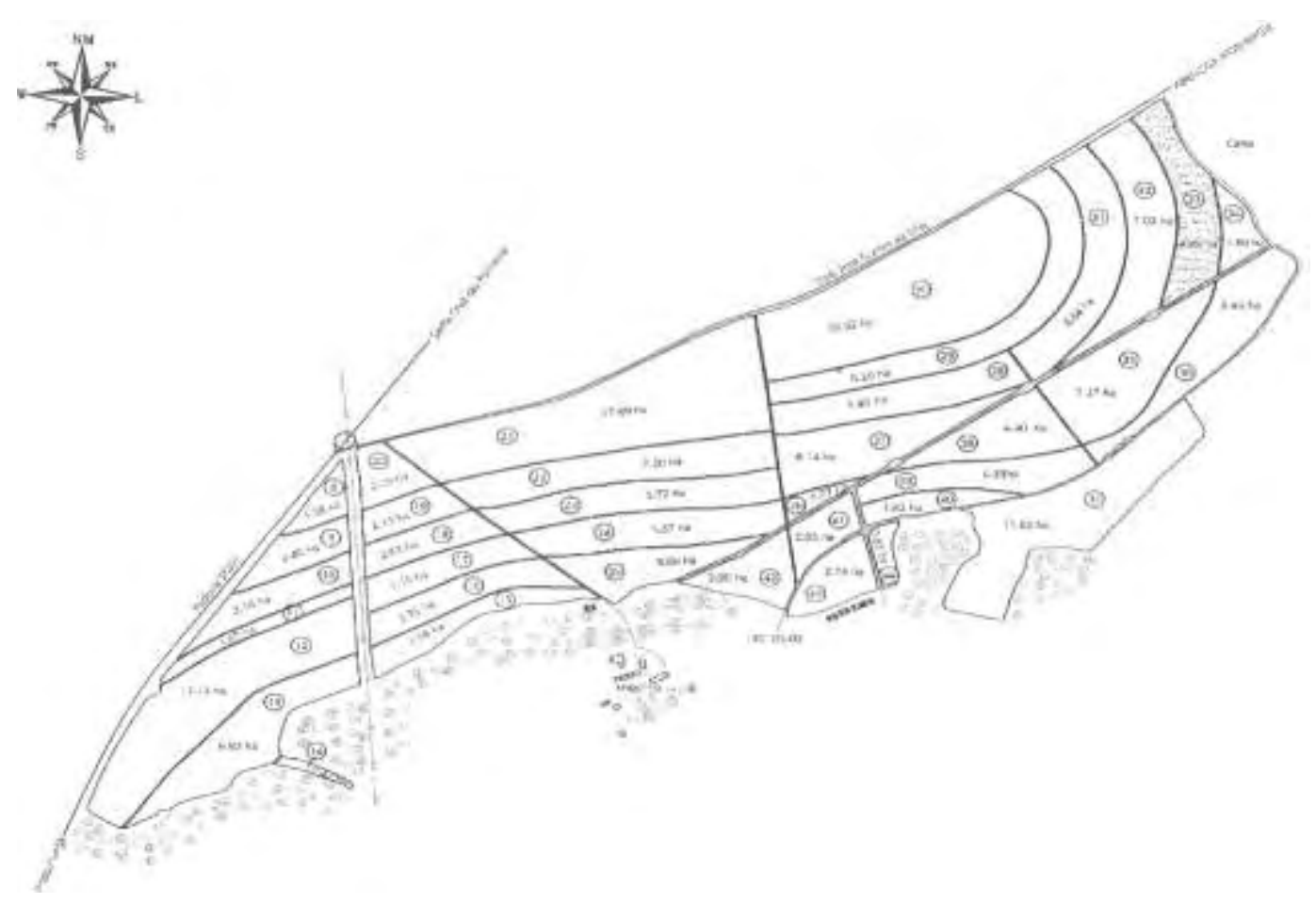

Figura 2. Localização da área experimental (talhão 33).

De acordo com a classificação de Köeppen, o clima predominante da região é do tipo Cwa que caracteriza clima tropical de altitude, com inverno seco e verão quente e chuvoso (KÖPPEN e GEIGER, 1928). O monitoramento agrometeorológico, com o objetivo de demonstrar as condições no ano de 2013, contendo os dados diários referentes à precipitação pluvial, à temperatura, radiação solar, umidade e temperatura do solo estão apresentados nas figuras 3 e 4 respectivamente. Os dados foram coletados na estação meteorológica da Universidade de São Paulo-FZEA, localizada a 13 quilômetros da área experimental.

Durante o ciclo da cultura, do plantio ao término da primeira e da segunda época de aplicação dos tratamentos, os níveis de precipitação foram de 1868,8 e 1909,60 mm respectivamente. A produção média do talhão foi de 122 toneladas de colmos por hectare. 


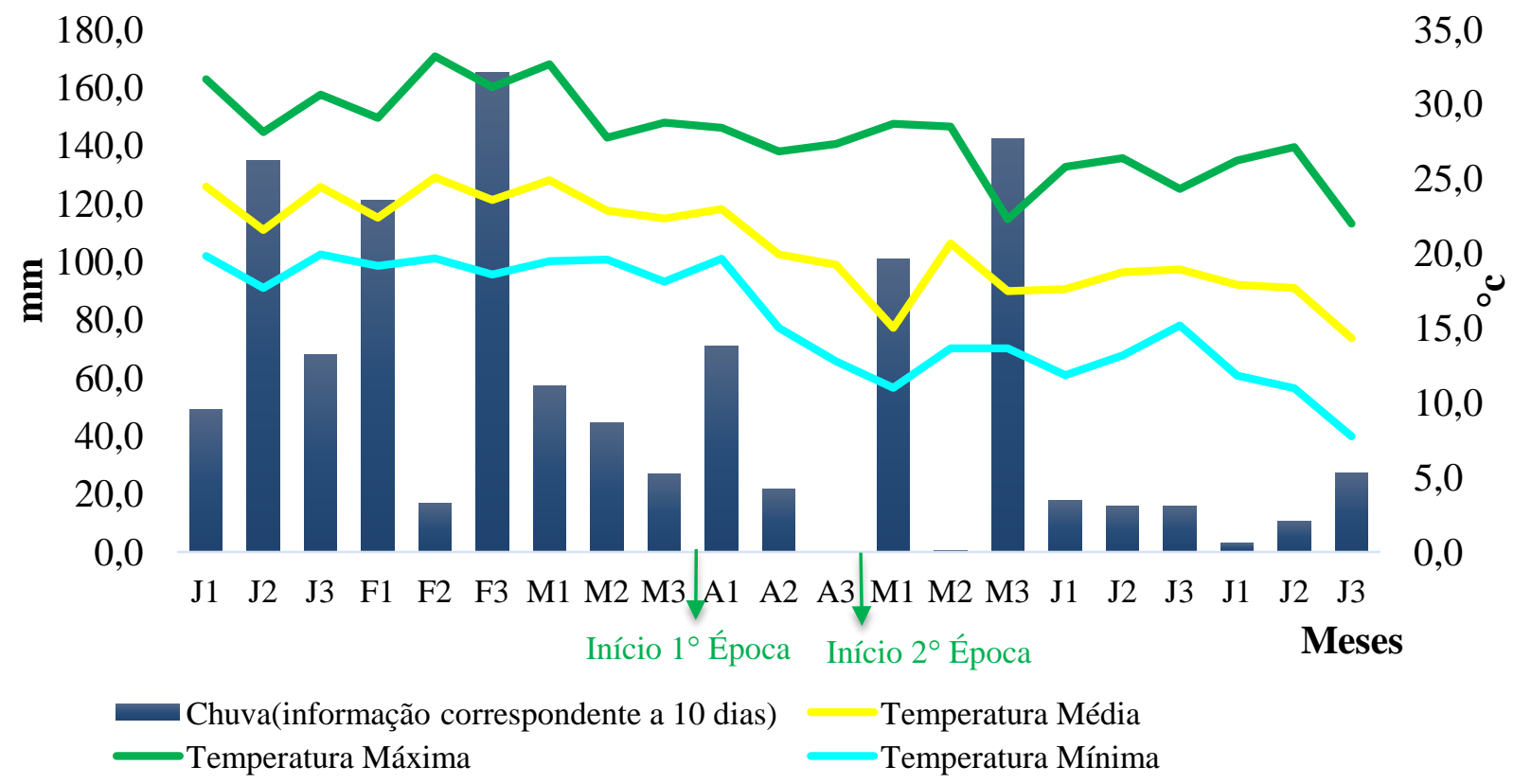

Figura 3. Precipitação $\left(\mathrm{mm}\right.$ mês $\left.{ }^{-1}\right)$ e temperaturas $\left({ }^{\circ} \mathrm{C}\right)$ máxima, mínima e média registradas durante o período experimental na estação meteorológica localizada na Universidade de São Paulo (Pirassununga-SP).

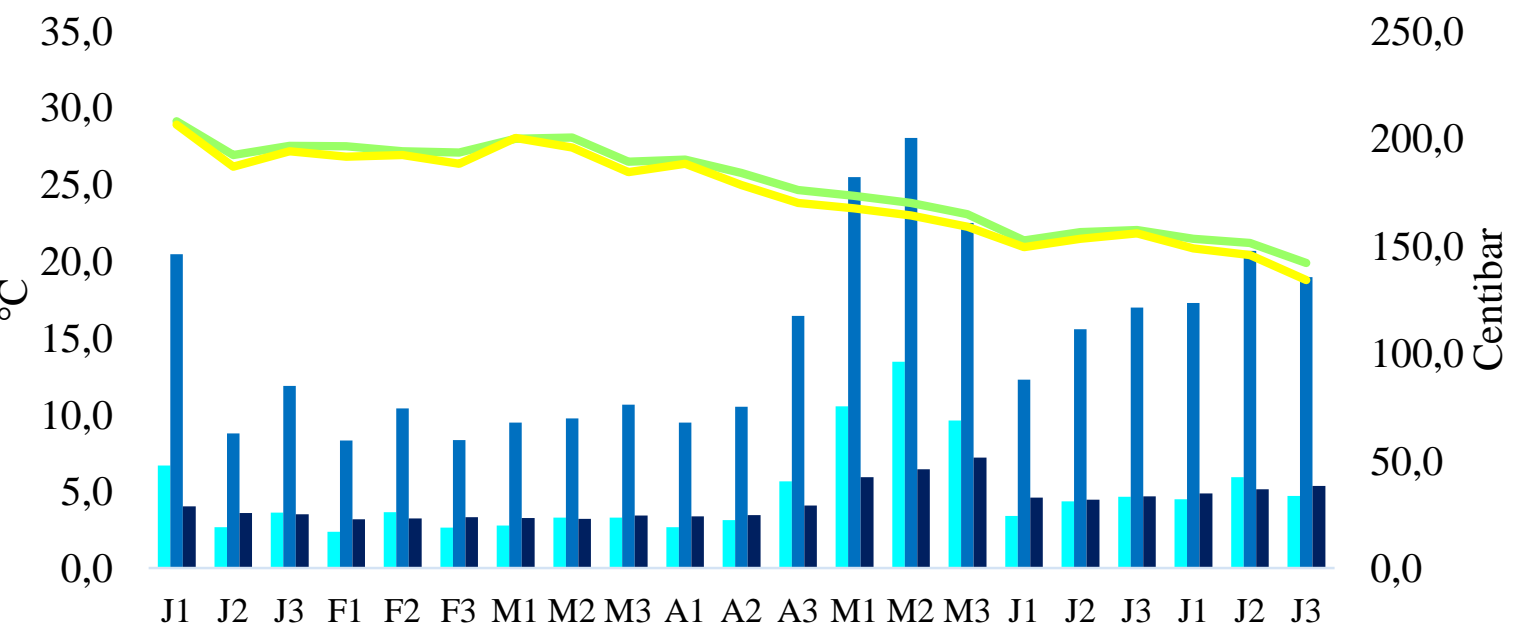

Meses

\footnotetext{
Umidade do Solo $20 \mathrm{~cm} \quad$ Umidade do Solo $40 \mathrm{~cm} \quad$ Umidade do Solo $60 \mathrm{~cm}$ Temperatura do solo $20 \mathrm{~cm}$ Temperatura do solo $40 \mathrm{~cm}$
}

Figura 4. Umidade do solo (Centibar) e temperaturas $\left({ }^{\circ} \mathrm{C}\right)$ média, máxima e mínima registradas durante o período experimental na estação meteorológica localizada na Universidade de São Paulo (Pirassununga-SP). 


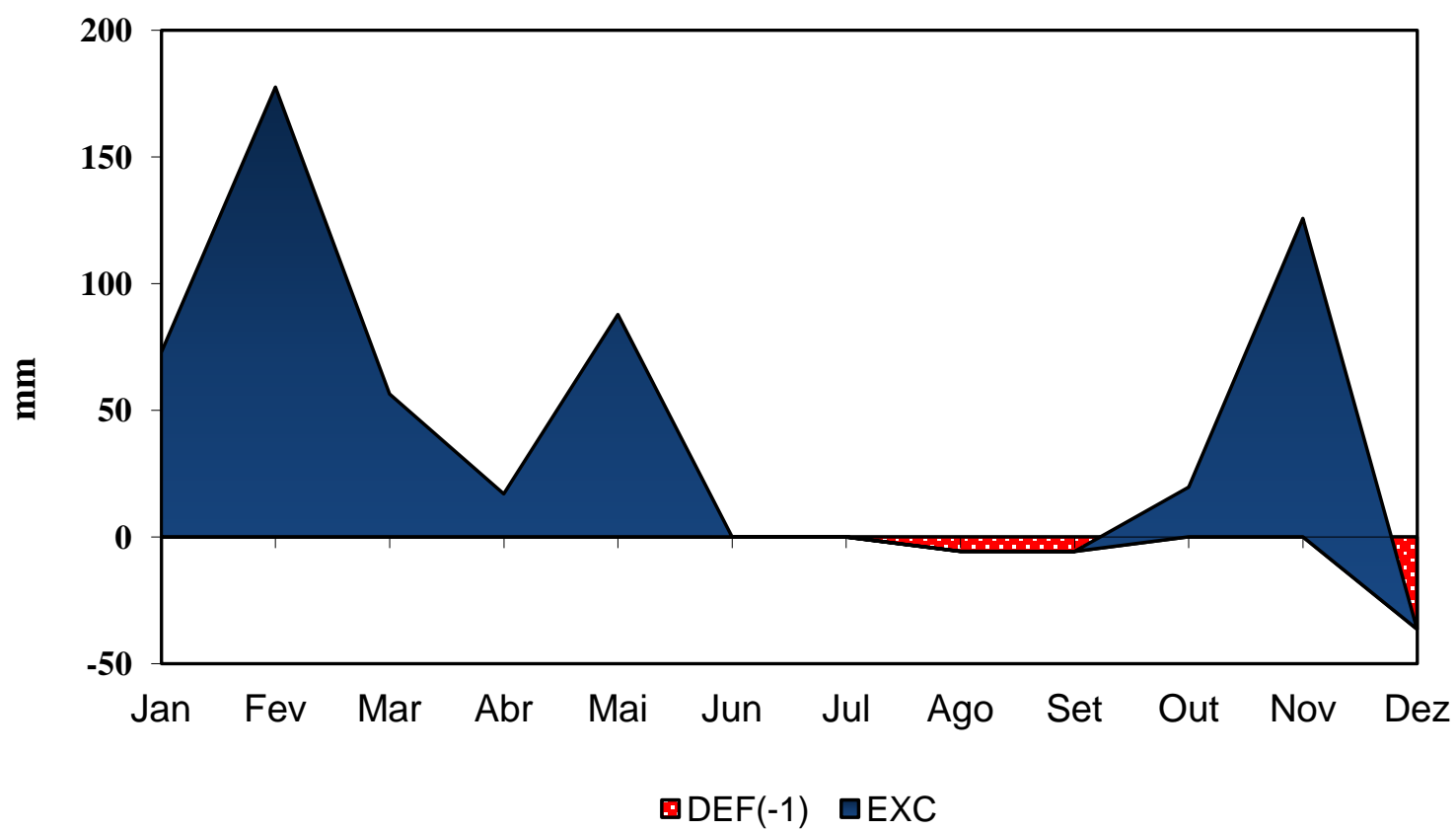

Figura 5. Extrato do balanço hídrico ao longo do ano de 2013. Calculado com base nos dados da estação meteorológica localizada na Universidade de São Paulo (Pirassununga-SP).

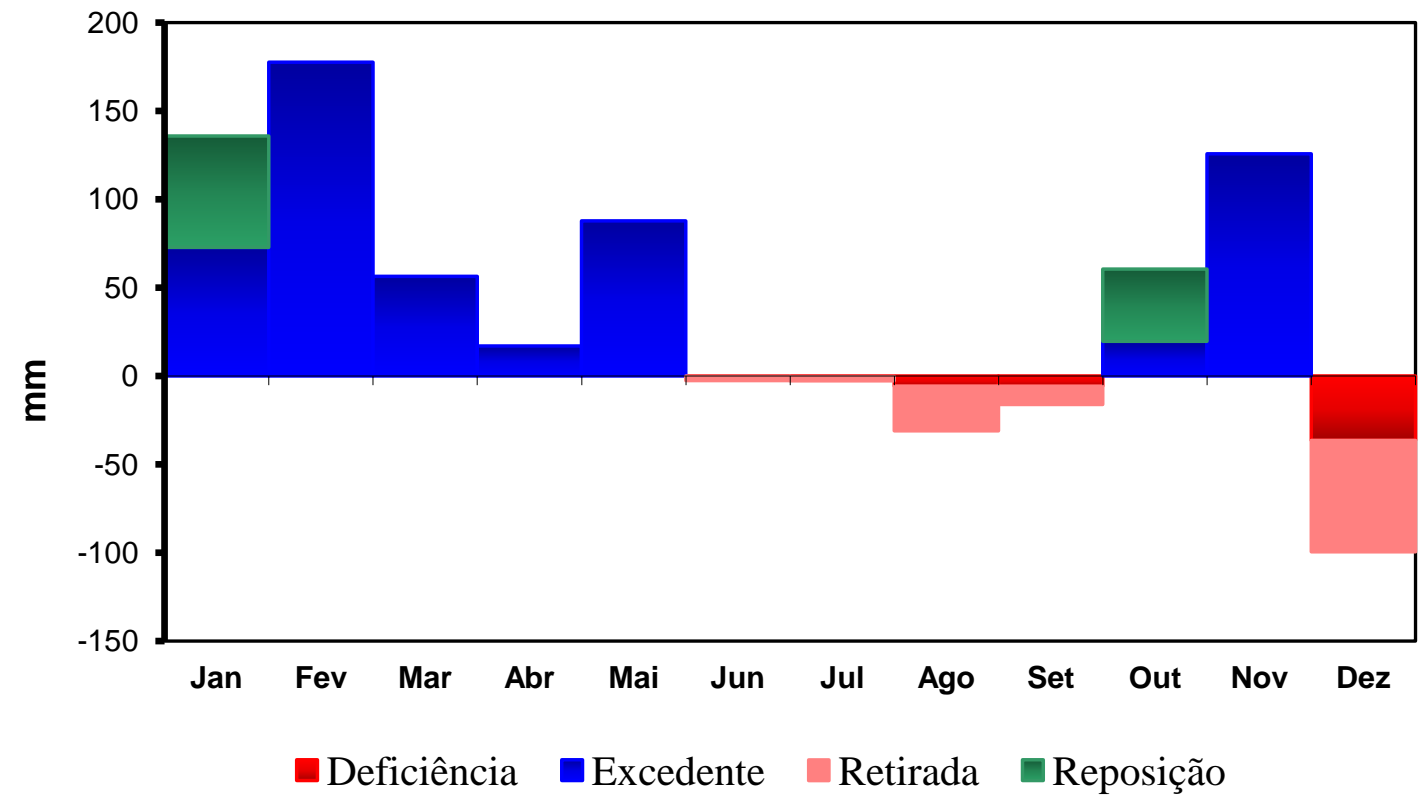

Figura 6. Deficiência, excedente, retirada e reposição hídrica ao longo do ano de 2013. Calculados com base nos dados da estação meteorológica localizada na Universidade de São Paulo (Pirassununga-SP). 
O plantio da área experimental foi realizado em 15 de maio de 2012, utilizando-se o espaçamento de 1,5m entre linhas. Utilizou-se a variedade RB 855453 que corresponde a 7,6\% da área brasileira plantada, e apresenta como características precocidade e riqueza. É uma variedade de maturação precoce, PUI curto, teor de sacarose muito alto, médio teor de fibra, alta produtividade agrícola e período de colheita de maio a julho.

\subsection{Tratamentos, delineamento experimental e atributos do solo}

O experimento foi composto por 14 tratamentos, apresentados na tabela 1. A dosagem dos produtos químicos seguiu as especificações recomendadas pelos fabricantes.

Tabela 1. Tratamentos experimentais utilizados, princípios ativos, nomes comerciais e doses dos produtos comerciais por hectare.

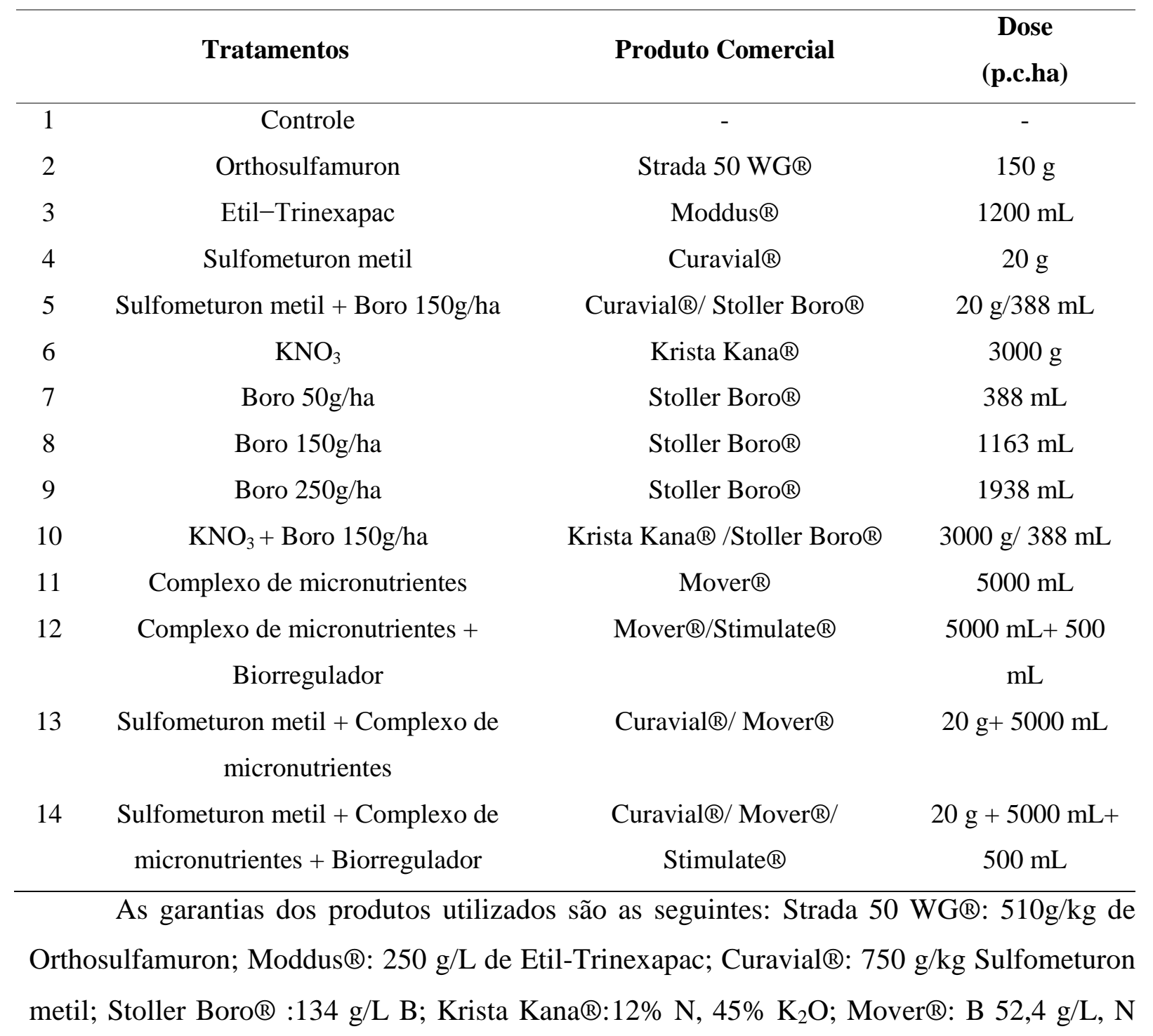


65,5 g/L, Cu 2,23 g/L, Mo 0,19 g/L, Zn:59,0 g/L; Stimulate®: Cinetina:0,09 g/L, Ácido Giberélico 0,05 g/L, Ácido 4-Indol-3-Ilbutírico 0,05g/L.

A demarcação das unidades experimentais foi realizada com estacas identificadas. Cada unidade experimental foi composta por cinco linhas com dez metros lineares, totalizando $75 \mathrm{~m}^{2}$. Uma bordadura de 3 metros foi utilizada entre parcelas a fim de se evitar contaminação. A área útil do ensaio foi de $8,400 \mathrm{~m}^{2}$.

Foram conduzidos dois experimentos, um para cada época de aplicação, utilizando-se o delineamento experimental em blocos casualizados com quatro repetições. O croqui experimental encontra-se na figura 7.

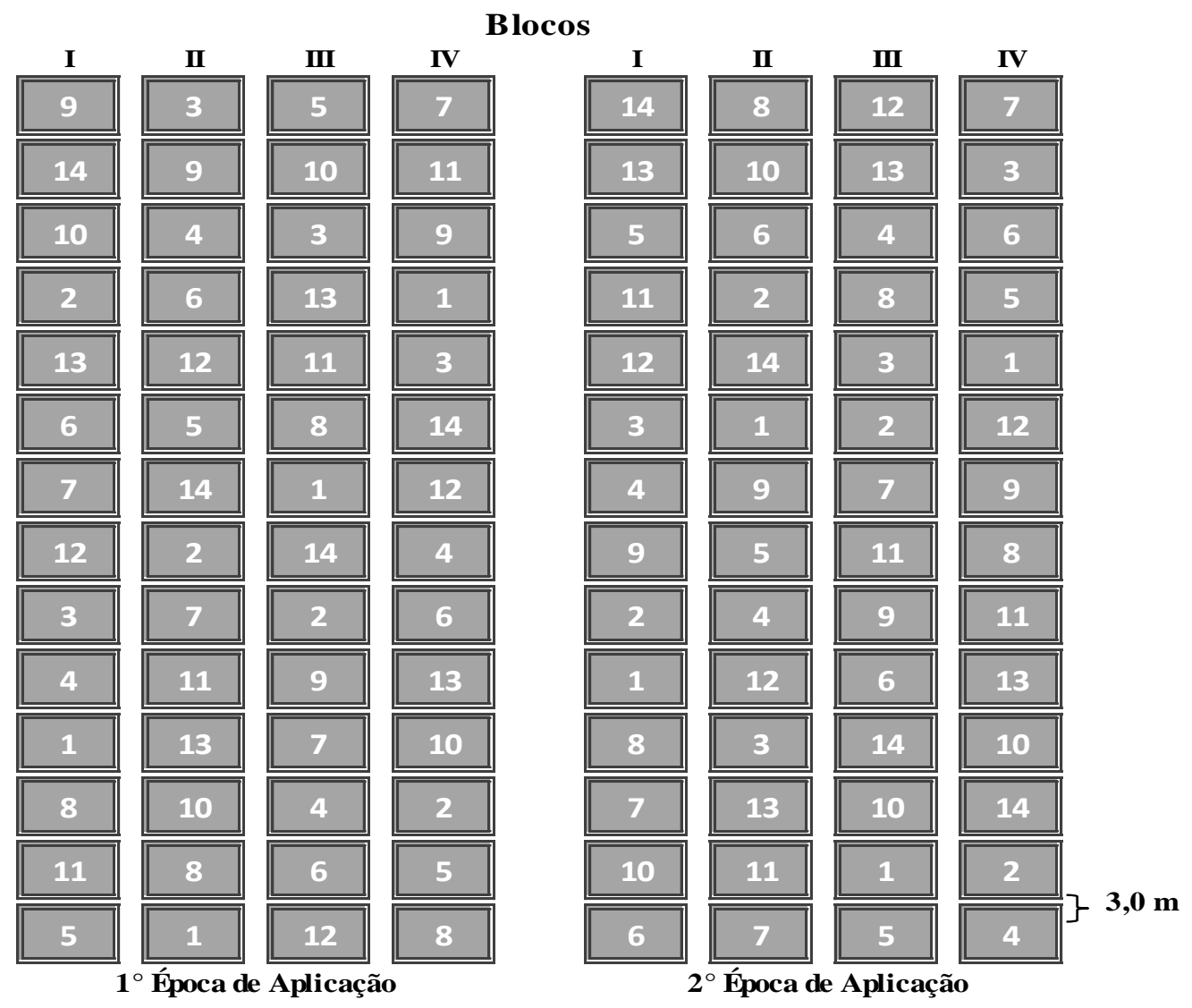

Figura 7. Disposição dos tratamentos no campo.

O solo da área experimental é classificado como Latossolo Vermelho Distroférrico. Ao término do experimento foram coletadas amostras de solo nas profundidades de $0-20 \mathrm{~cm}$ e 20-40 cm nas entrelinhas da cana-de-açúcar. As análises de solo foram realizadas segundo método proposto por Raij et al., (2001). Os dados referentes a análise química encontram-se nas tabelas 
Tabela 2. Atributos químicos da área experimental obtidos mediante análise química do solo. Primeira época de aplicação dos tratamentos.

\begin{tabular}{|c|c|c|c|c|c|c|c|c|c|c|c|c|c|c|c|c|c|}
\hline \multirow[t]{2}{*}{ Bloco } & \multirow{2}{*}{$\begin{array}{l}\text { Profundidade } \\
\qquad(\mathrm{cm})\end{array}$} & \multirow{2}{*}{$\frac{\mathbf{p H}}{\mathrm{CaCl}_{2}}$} & $\frac{\mathbf{P}}{\text { resina }}$ & $\mathbf{S}$ & $\mathbf{K}$ & $\mathbf{C a}$ & Mg & $\mathbf{H}+\mathbf{A l}$ & \multirow{2}{*}{$\begin{array}{l}\text { MO } \\
\mathrm{g} / \mathrm{Kg}\end{array}$} & SB & CTC & \multirow{2}{*}{$\begin{array}{l}\mathbf{V} \\
\%\end{array}$} & B & $\mathbf{C u}$ & $\mathbf{F e}$ & Mn & $\mathbf{Z n}$ \\
\hline & & & \multicolumn{2}{|c|}{ mg.dm ${ }^{-3}(\mathrm{ppm})$} & \multicolumn{4}{|c|}{$\mathrm{mmol}_{\mathrm{c}} \cdot \mathrm{dm}^{-3}$} & & \multicolumn{2}{|c|}{$\mathrm{mmol}_{\mathrm{c}} \cdot \mathrm{dm}^{-3}$} & & \multicolumn{5}{|c|}{ mg.dm ${ }^{-3}(\mathrm{ppm})$} \\
\hline I & $0-20$ & 5,8 & 55 & 7 & 6,8 & 25 & 9 & 22 & 25 & 41 & 63 & 65 & 0,30 & 4,7 & 20 & 10,2 & 1,5 \\
\hline II & $0-20$ & 5,6 & 23 & 36 & 4,5 & 22 & 9 & 25 & 23 & 36 & 60 & 59 & 0,83 & 4,5 & 21 & 9,30 & 0,9 \\
\hline III & $0-20$ & 5,3 & 78 & 31 & 6,8 & 18 & 9 & 30 & 26 & 34 & 64 & 53 & 0,89 & 4,5 & 23 & 14,3 & 1,5 \\
\hline IV & $0-20$ & 5,5 & 24 & 19 & 8,4 & 28 & 11 & 27 & 27 & 47 & 75 & 63 & 0,41 & 4,3 & 21 & 13,8 & 0,8 \\
\hline I & $20-40$ & 5,6 & 25 & 92 & 6,1 & 17 & 8 & 24 & 22 & 31 & 56 & 56 & 0,84 & 4,2 & 19 & 5,8 & 1,1 \\
\hline II & $20-40$ & 4,9 & 17 & 111 & 2,8 & 14 & 9 & 41 & 22 & 26 & 67 & 38 & 0,46 & 4,5 & 21 & 8,2 & 0,70 \\
\hline III & $20-40$ & 4,7 & 19 & 40 & 3,3 & 15 & 8 & 48 & 24 & 26 & 74 & 36 & 1,9 & 4 & 20 & 6,8 & 0,6 \\
\hline IV & $20-40$ & 5,2 & 17 & 93 & 4,5 & 15 & 9 & 32 & 22 & 28 & 61 & 47 & 0,16 & 4 & 19 & 6,9 & 0,6 \\
\hline
\end{tabular}

Tabela 3 Atributos químicos da área experimental obtidos mediante análise química do solo. Segunda época de aplicação dos tratamentos.

\begin{tabular}{|c|c|c|c|c|c|c|c|c|c|c|c|c|c|c|c|c|c|}
\hline \multirow[t]{2}{*}{ Bloco } & \multirow{2}{*}{$\begin{array}{l}\text { Profundidade } \\
\qquad(\mathrm{cm})\end{array}$} & \multirow{2}{*}{$\begin{array}{c}\mathbf{p H} \\
\mathrm{CaCl}_{2}\end{array}$} & $\frac{\mathbf{P}}{\text { resina }}$ & $\mathbf{S}$ & $\mathbf{K}$ & $\mathbf{C a}$ & Mg & $\mathbf{H}+\mathbf{A l}$ & \multirow{2}{*}{$\begin{array}{c}\text { MO } \\
\mathrm{g} / \mathrm{Kg}\end{array}$} & SB & CTC & \multirow{2}{*}{$\begin{array}{l}\mathbf{V} \\
\%\end{array}$} & \multirow[t]{2}{*}{$\mathbf{R}$} & \multirow[t]{2}{*}{$\mathbf{C u}$} & $\mathbf{F e}$ & \multirow{2}{*}{ Mn } & \multirow[t]{2}{*}{ Zn } \\
\hline & & & \multicolumn{2}{|c|}{ mg.dm ${ }^{-3}(\mathrm{ppm})$} & & \multicolumn{2}{|c|}{$\mathrm{mmol}_{\mathrm{c}} \cdot \mathrm{dm}^{-3}$} & & & $\mathrm{~mm}$ & $1_{c} \cdot \mathrm{dm}^{-3}$ & & & & mg.dm ${ }^{-3}(\mathrm{ppm})$ & & \\
\hline I & $0-20$ & 6,2 & 27 & 20 & 3,8 & 40 & 12 & 19 & 24 & 56 & 75 & 74 & 0,35 & 4,2 & 20 & 11,8 & 0,7 \\
\hline II & $0-20$ & 5,5 & 15 & 24 & 5,5 & 15 & 8 & 27 & 24 & 28 & 56 & 51 & 0,46 & 4,0 & 21 & 12,6 & 0,6 \\
\hline III & $0-20$ & 5,8 & 17 & 26 & 4,4 & 18 & 8 & 21 & 23 & 30 & 51 & 60 & 0,19 & 3,6 & 17 & 9,3 & 0,7 \\
\hline IV & $0-20$ & 5,5 & 28 & 38 & 4,6 & 21 & 9 & 24 & 24 & 35 & 59 & 59 & 0,23 & 4 & 19 & 8,7 & 0,7 \\
\hline I & $20-40$ & 5,3 & 22 & 14 & 1,5 & 26 & 11 & 31 & 23 & 38 & 70 & 55 & 0,14 & 4,2 & 19 & 7,4 & 0,6 \\
\hline II & $20-40$ & 5,1 & 14 & 37 & 3,7 & 11 & 7 & 32 & 22 & 22 & 54 & 40 & 0,77 & 3,6 & 19 & 8,6 & 0,6 \\
\hline III & $20-40$ & 4,9 & 12 & 91 & 2,3 & 13 & 7 & 32 & 19 & 22 & 55 & 40 & 0,33 & 3,4 & 17 & 2,9 & 0,5 \\
\hline IV & $20-40$ & 4,7 & 13 & 97 & 2,0 & 12 & 8 & 44 & 21 & 22 & 66 & 33 & 0,59 & 3,5 & 19 & 3,8 & 0,5 \\
\hline
\end{tabular}

Extratores: pH: $\mathrm{CaCl}_{2}$; P, K, Ca e Mg: Resina trocadora de íons; S: Fosfato de cálcio; B: Água quente; $\mathrm{Cu}, \mathrm{Fe}, \mathrm{Mn}$ e Zn: DTPA. 


\subsection{Aplicação dos tratamentos e amostragens}

Os tratamentos foram aplicados em duas épocas distintas, 28 de março e 30 de abril de 2013, utilizando-se equipamento de pulverização costal pressurizado $\left(\mathrm{CO}_{2}\right)$, acoplado a uma garrafa contendo a solução preparada e uma barra de $2,5 \mathrm{~m}$ de comprimento com bico de pulverização do tipo leque, proporcionando aplicação em uma linha. Para a correta aplicação foi realizada prévia calibração com água.
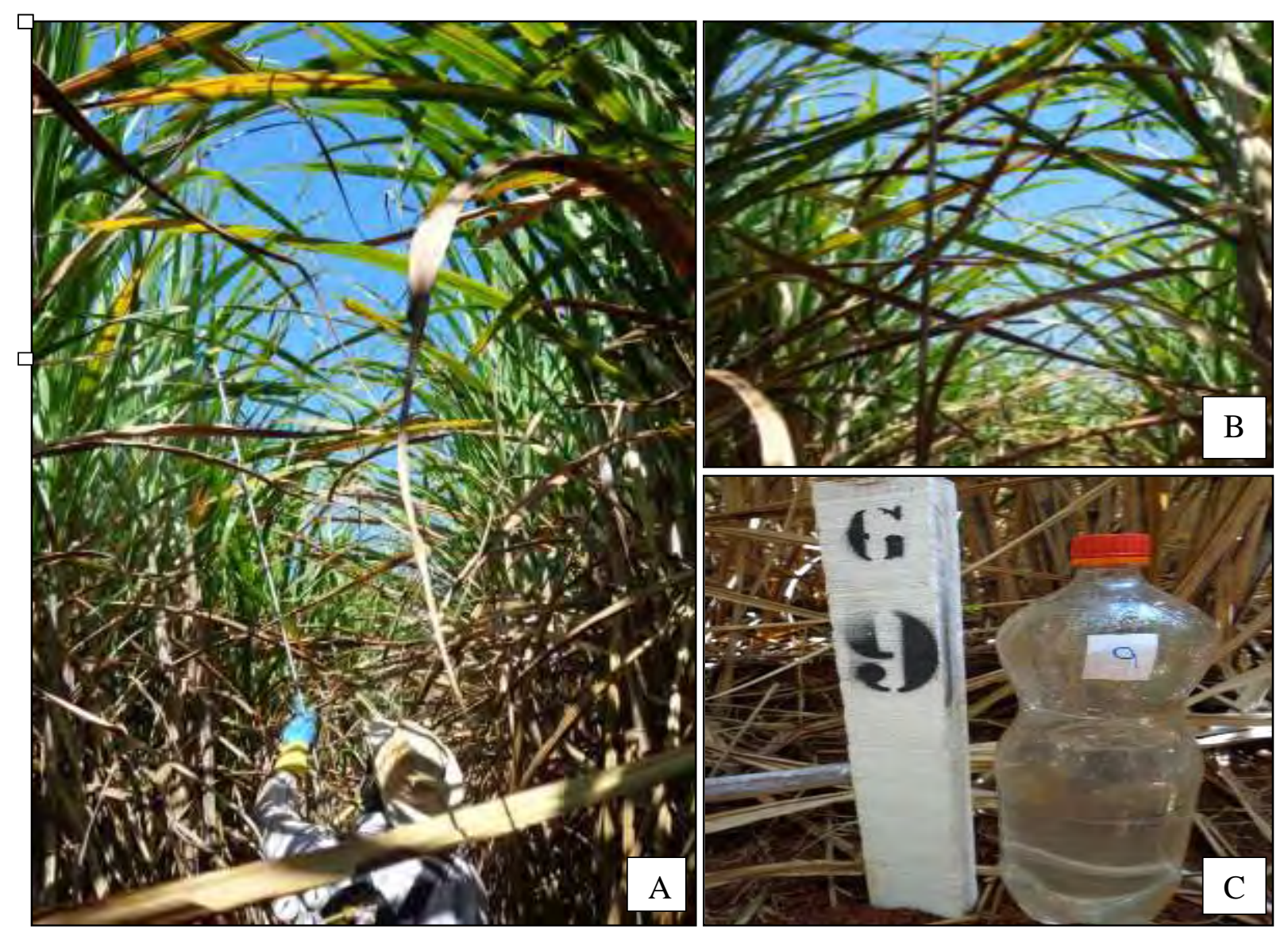

Figura 8. (A) Aplicação dos tratamentos; (B) Barra aplicadora; (C) Solução preparada para aplicação na parcela correspondente.

Realizou-se a caracterização da área um dia antes da aplicação dos tratamentos $\left(1^{\circ}\right.$ amostragem) e amostragens periódicas, com intervalos quinzenais, para o monitoramento dos parâmetros tecnológicos. As amostragens consistiram na coleta de dez colmos industrializáveis por parcela, os quais foram cortados rente ao solo, despalhados e despontados no último entrenó maduro. Posterior a estes procedimentos, os feixes contendo os dez colmos foram amarrados e identificados (Figura 9). 

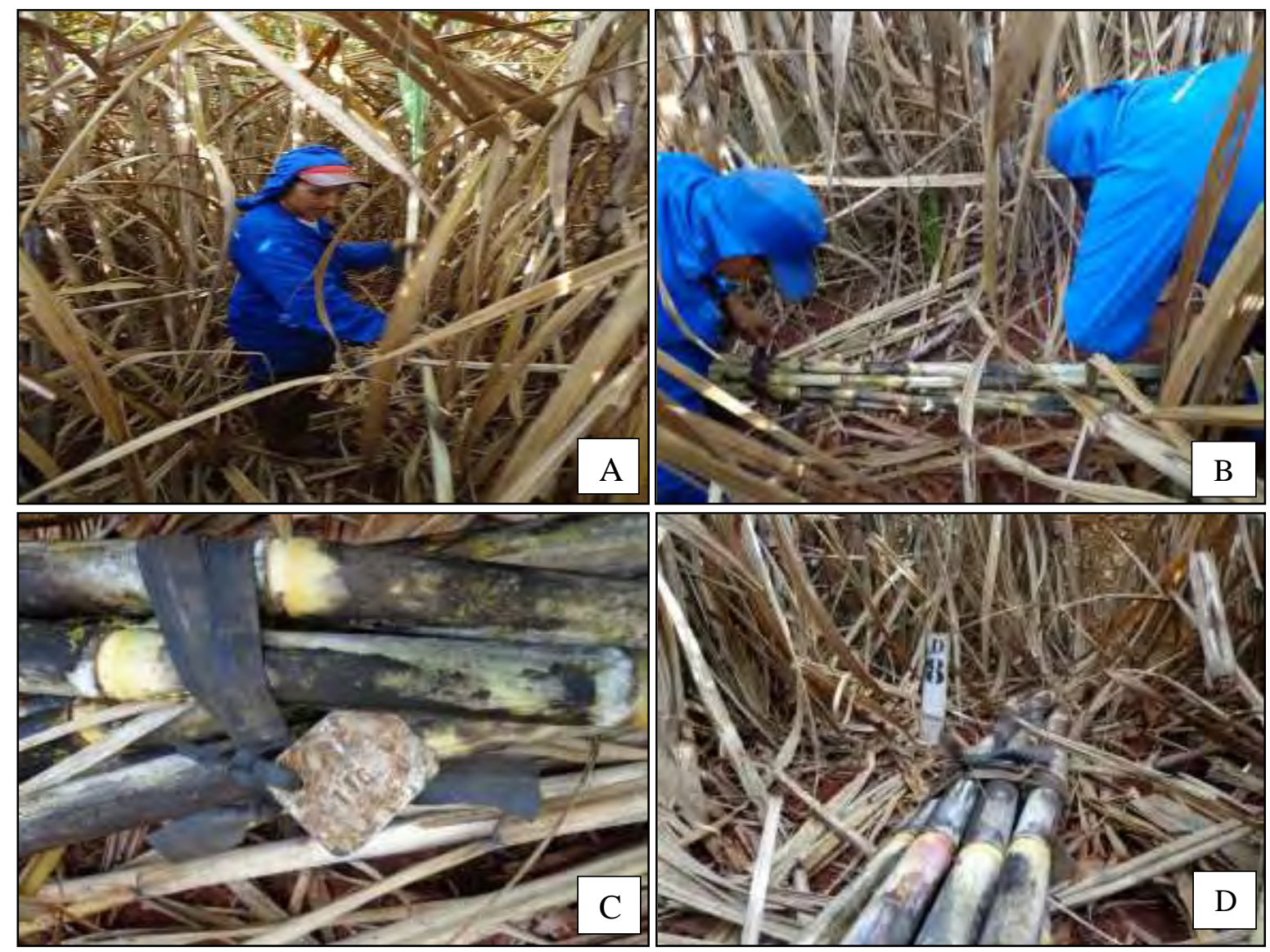

Figura 9. Amostragens periódicas realizadas: (A) Corte e despalha; (B) Preparo dos feixes; (C) Identificação; (D) Feixes na parcela correspondente.

As aplicações e amostragens ocorreram nas seguintes datas:

Primeira época: Aplicação em 28 março de 2013 - 1Amostragem: 27 março (caracterização da área); $2^{\circ}$ Amostragem: 12 abril (15 dias após a aplicação, DAA); $3^{\circ}$ Amostragem: 29 abril (30 dias após a aplicação, DAA); $4^{\circ}$ Amostragem: 14 maio (45 dias após a aplicação, DAA); $5^{\circ}$ Amostragem: 28 maio (60 dias após a aplicação, DAA);

Segunda época: Aplicação em 30 abril de 2013 - $1^{\circ}$ Amostragem: 29 abril (caracterização da área); $2^{\circ}$ Amostragem: 15 maio (15 dias após a aplicação, DAA); $3^{\circ}$ Amostragem: 31 maio (32 dias após a aplicação, DAA); $4^{\circ}$ Amostragem: 14 junho (45 dias após a aplicação, DAA); $5^{\circ}$ Amostragem: 01 julho (60 dias após a aplicação, DAA). No decorrer desta época experimental houve a ocorrência de ventos fortes na região que levaram ao acamamento da área experimental. 


\subsection{Avaliações tecnológicas}

Após as amostragens, os feixes foram encaminhados ao laboratório de análises de canade-açúcar da unidade industrial da Abengoa Bioenergia - Unidade São Luiz para realização das análises tecnológicas. Os procedimentos foram realizados de acordo com as diretrizes contidas no Manual de Instruções do Consecana (2006).

A extração do caldo, pesagem do bagaço úmido e as leituras ocorreram imediatamente após a desintegração e homogeneização das amostras. Foram efetuadas as seguintes determinações:

Brix (Bj): a determinação do brix (teor de sólidos solúveis por cento, em peso, de caldo) foi realizada através de um refratômetro digital de leitura automática.

Fibra (F): a fibra da cana foi calculada através da equação: $F=0,08 * P B U+0,876$. Onde: PBU = Peso úmido do bagaço da prensa.

Pol do caldo (S): foi determinada através de sacarímetro digital automático. A pol do caldo (teor de sacarose aparente por cento, em peso, de caldo) foi calculada pela seguinte equação $S=L P o l *\left(0,26047-0,0009882 * B_{J}\right)$. Onde: $L P o l=$ Leitura sacarimétrica do caldo clarificado; e, $B_{j}=$ Brix do caldo.

Pol da cana (PC): A pol da cana foi calculada através da equação: $P O L=S *(1-0,01 * F) * C$. Onde: $\mathrm{S}=\mathrm{Pol}$ no caldo $\mathrm{F}=$ Fibra $; \mathrm{C}=$ Coeficiente utilizado para a transformação da pol do caldo extraído pela prensa (S) em pol de cana (PC).

Pureza no caldo (Q): A pureza aparente do caldo (Q) por ser definida como a porcentagem de pol em relação ao brix, foi calculada pela equação: $Q=100 * \frac{S}{B_{j}}$. Onde: $\mathrm{S}=$ Pol no caldo $; \mathrm{B}_{\mathrm{j}}=$ Brix no caldo

Açúcares redutores do caldo \% (AR): O teor de açúcares redutores (AR) por cento, em peso, de caldo foi calculado pela equação: $A R=3,641-0,0343 * Q$. Onde: $\mathrm{Q}=$ pureza no caldo.

Açucares Redutores da cana \% (ARC): O cálculo dos açúcares redutores da cana (ARC) foi realizado pela equação: $A R C=A R *(1-0,01 * F) * C$. Onde: $\mathrm{AR}=$ açúcares redutores do caldo 
Açúcar total recuperável (ATR): Obtidos a pol da cana (PC) e os açúcares redutores da cana (ARC), o ATR foi calculado pela equação: $A T R=9,526 * P C+9,05 * A R$.

\subsection{Análises estatísticas}

As análises estatísticas foram realizadas segundo um DBC com tratamentos em esquema fatorial 14x5, sendo: 14 tratamentos (Controle, Orthosulfamuron, Etil-Trinexapac, Sulfometuron metil, Sulfometuron metil + Boro $150 \mathrm{~g} / \mathrm{ha}, \mathrm{KNO}_{3}$, Boro $50 \mathrm{~g} / \mathrm{ha}$, Boro 150 $\mathrm{g} / \mathrm{ha}$, Boro $250 \mathrm{~g} / \mathrm{ha}, \mathrm{KNO}_{3}+$ Boro $50 \mathrm{~g} / \mathrm{ha}$, Complexo de micronutrientes, Complexo de Micronutriente + Biorregulador, Sulfometuron metil + Complexo de Micronutrientes, Sulfometuron metil + Complexo de Micronutrientes + Biorregulador) e 5 épocas de coleta $(0$, $15,30,45$ e 60 dias).

Utilizou-se o procedimento MIXED do programa SAS (SAS Institute Inc., Cary, NC, USA, 2012), considerando os efeitos fixos de Tratamento, Época de Coleta e Interação Tratamento x Época de Coleta, além dos efeitos aleatórios de Blocos e Resíduo.

Em caso de efeito principal de tratamentos significativos, utilizou-se o teste de Tukey. Em caso de efeito principal de época de coleta, utilizou-se as análises de regressão. Em caso de interação significativa realizou-se análises de regressão do tempo dentro de cada tratamento. 
6. RESULTADOS E DISCUSSÃO 


\section{RESULTADOS E DISCUSSÃO}

\subsection{Primeira época de aplicação}

\subsubsection{Sólidos Solúveis - Brix \%}

Na tabela quatro verifica-se a análise de variância para a variável Brix. Houve efeito significativo para tratamentos e para época de avaliação, ambos ao nível de $1 \%$ de probabilidade $(\mathrm{p}<0,01)$ e, interação entre tratamento e época de avaliação, ao nível de $5 \%$ de probabilidade $(\mathrm{p}<0,05)$ pelo teste $\mathrm{F}$.

Tabela 4. Fontes de variação e significância do valor F para a variável Brix.

\begin{tabular}{cccc}
\hline Efeito $^{1}$ & Gl & $\mathrm{F}$ & $\mathrm{Pr}>\mathrm{F}^{2}$ \\
\hline $\mathrm{T}$ & 13 & 8,5 & $<0001^{* *}$ \\
$\mathrm{E}$ & 4 & 542,98 & $<0001^{* *}$ \\
$\mathrm{~T}$ x E & 52 & 1,5 & $0,0249^{*}$ \\
\hline
\end{tabular}

${ }^{1} \mathrm{~T}=$ efeito de tratamento; $\mathrm{E}=$ efeito de época de coleta; $\mathrm{T}$ x $\mathrm{E}=$ interação tratamento $\mathrm{x}$ época de coleta.

${ }^{2}$ Teste $\mathrm{F}$ para probabilidade de efeito significativo e discriminatório para os fatores.

Os símbolos ** e * representam $\mathrm{p}<0,01$ e 0,05 respectivamente.

Na tabela cinco estão demonstrados os desdobramentos da interação dos tratamentos $\mathrm{x}$ épocas de avaliação aos 0, 15, 30, 45 e 60 dias após a aplicação. Aos 15 DAA os tratamentos não induziram alterações nos teores de brix. Os efeitos significativos iniciaram-se aos 30 DAA, sendo que os teores foram crescentes ao longo do tempo e atingiram níveis máximos aos 60 DAA para todos os tratamentos. O teor médio de Brix foi de 16,72\%.

Aos 45 DAA os tratamentos que proporcionaram maiores amadurecimentos da cana foram o maturador sulfameturon metil isolado e nas combinações com boro, complexo de micronutrientes, o maturador etil-trinexapac, o boro na dose $150 \mathrm{~g} / \mathrm{ha}$ isolado ou associado ao nitrato de potássio, e, complexo de micronutrientes + biorregulador, fazendo com que a cana atingisse o mínimo de $18 \%$ de brix.

Aos 60 DAA os maiores teores de brix foram proporcionados pelos maturadores etiltrinexapac e sulfameturon metil, isolado ou em combinações, porém, não houve diferença significativa entre estes tratamentos com o controle. 
Tabela 5. Teor de Brix\%, referente a primeira época de aplicação dos tratamentos, avaliado aos $0,15,30,45$ e 60 dias após a aplicação.

\begin{tabular}{lccccccccccc}
\hline \multirow{2}{*}{ Tratamento } & \multicolumn{8}{c}{ Tempo após a aplicação (d) } \\
\cline { 2 - 11 } & $0^{2}$ & & 15 & & 30 & & 45 & & \\
\hline Controle & 13,9 & a & 15,6 & a & 16,3 & cd & 17,6 & cdef & 19,1 & abcd \\
Orthosulfamuron & 14,7 & a & 15,8 & a & 16,8 & bc & 17,5 & ef & 18,8 & bcd \\
Etil-Trinexapac & 13,8 & a & 15,5 & a & 17,3 & ab & 18,3 & abcd & 19,5 & abc \\
Sulfometuron metil & 14,4 & a & 15,8 & a & 17,6 & a & 18,3 & abcd & 19,6 & ab \\
Sulfometuron metil + Boro 150 g/ha & 14,1 & a & 15,7 & a & 17,5 & ab & 18,4 & abc & 19,7 & a \\
KNO $_{3}$ & 14,4 & a & 15,8 & a & 16,7 & bc & 17,6 & def & 18,6 & d \\
Boro 50 g/ha & 14,4 & a & 15,3 & a & 16,4 & cd & 17,4 & ef & 18,4 & d \\
Boro 150 g/ha & 14,4 & a & 15,5 & a & 17,3 & ab & 18,0 & bcde & 18,4 & d \\
Boro 250 g/ha & 14,1 & a & 15,4 & a & 15,7 & d & 17,1 & f & 17,4 & e \\
KNO + Boro 150 g/ha & 14,3 & a & 15,6 & a & 16,8 & abc & 18,0 & bcde & 18,9 & bcd \\
Complexo de Micronutrientes & 14,8 & a & 15,6 & a & 16,5 & cd & 17,6 & cdef & 18,3 & d \\
Complexo de Micronutrientes & & & & & & & & & & \\
Biorregulador & 14,4 & a & 15,4 & a & 16,3 & cd & 17,3 & & 18,7 & cd \\
Sulfometuron metil + Complexo de & & & & & & & & & & \\
Micronutrientes & 14,7 & a & 16,2 & a & 17,5 & ab & 19,1 & a & 19,8 & a \\
Sulfometuron metil + Complexo de & & & & & & & & & & \\
Micronutrientes + Biorregulador & 14,6 & a & 15,6 & a & 17,1 & abc & 18,4 & ab & 19,5 & abc \\
\hline
\end{tabular}

Coeficiente de Variação: 10,53\%. Desvio Padrão: 1,76. Média: 16,72.

1. Amostragens realizadas aos $0,15,30,45$ e 60 dias após a aplicação dos tratamentos.

2. Em cada época de avaliação as letras comparam os tratamentos. Médias seguidas por mesma letra não diferem estatisticamente entre si $(\mathrm{p}<05)$.

Os tratamentos contendo maturadores promoveram em média aumento de 0,43 pontos percentuais no Brix em relação ao controle, e os tratamentos contendo o maturador Sulfometuron metil promoveram aumento de 0,95 pontos percentuais. Estes resultados corroboram com os alcançados por Oliveira (1993) que, trabalhando com a variedade SP 701143 e utilizando os maturadores sulfometuron-methyl e ethephon relataram aumento de 0,9 pontos no Brix.

Os resultados foram inferiores aos encontrados por Inoue et al. (2015), que, trabalhando com bispyribac-sodium, sulfometuron-methyl e ethyl-trinexapac, em aplicação realizada em 9 de abril na variedade RB 86-751, verificaram que sulfometuron-methyl e ethyl-trinexapac foram eficientes na melhoria da qualidade tecnológica. Observaram que, em 
média, os maturadores promoveram acréscimo de 1,31 pontos percentuais no Brix, em relação à testemunha. Essa diferença entre resultados pode estar relacionada a resposta varietal ou às condições climáticas ocorridas durante os períodos experimentais.

Os resultados obtidos neste trabalho podem estar relacionados com a dose do produto utilizada. Viana et al. (2007), trabalhando com a variedade RB72454 realizando a aplicação dos maturadores em final de safra (20/10/2005) verificaram que os maturadores químicos, com destaque para o sulfometuron-metil na dose de $20 \mathrm{~g} /$ há e glifosate na dose de $0,4 \mathrm{~L}$ de p.c $/$ ha $^{-1}$, promoveram um incremento significativo sobre o Brix (\%) e sobre outras características tecnológicas da planta. Almeida, Leite e Souza (2005) utilizando o sulfometuron-methyl na dose de $15 \mathrm{~g}$ ha e o ethephon na dose de $480 \mathrm{~g}$ ha, observaram que a aplicação dos maturadores não proporciou aumento significativo do brix com relação a testemunha na quase totalidade das épocas avaliadas com exceção da realizada a 21 DAA.

Oliveira Filho (2011) concluiu que a aplicação de etil-trinexapac, sulfometuron metil e $\mathrm{KNO}_{3}$ na variedade de maturação média RB 86 7515, conferiram aumentos médios de $13 \%$ para a variável Brix em relação a testemunha, resultados muito superiores aos verificados neste trabalho.

Os padrões de variação dos tratamentos em função das épocas de coleta e as respectivas representações gráficas das equações encontram-se nas figuras 10, 11 e 12 . Houve efeito quadrático $(\mathrm{p}<0,01)$ das épocas de coleta no teor de brix para o boro (dose $150 \mathrm{~g} / \mathrm{ha}$ ), e, para os demais tratamentos, houve efeito linear $(\mathrm{p}<0,01)$.

A maior antecipação do amadurecimento da cana foi resultante do tratamento do tratamento Sulfometuron metil/Complexo de micronutrientes, que atingiu $18 \%$ de brix aos 36 DAA, 12 dias antes da maturação natural (controle). Baseando-se no teor de Brix, os tratamentos Sulfometuron metil, Sulfometuron metil/Boro, Etil-Trinexapac anteciparam a colheita em 8 dias e os Sulfometuron metil + Complexo de micronutrientes + Biorregulador, com base no teor de brix, anteciparam a colheita 7 dias. 


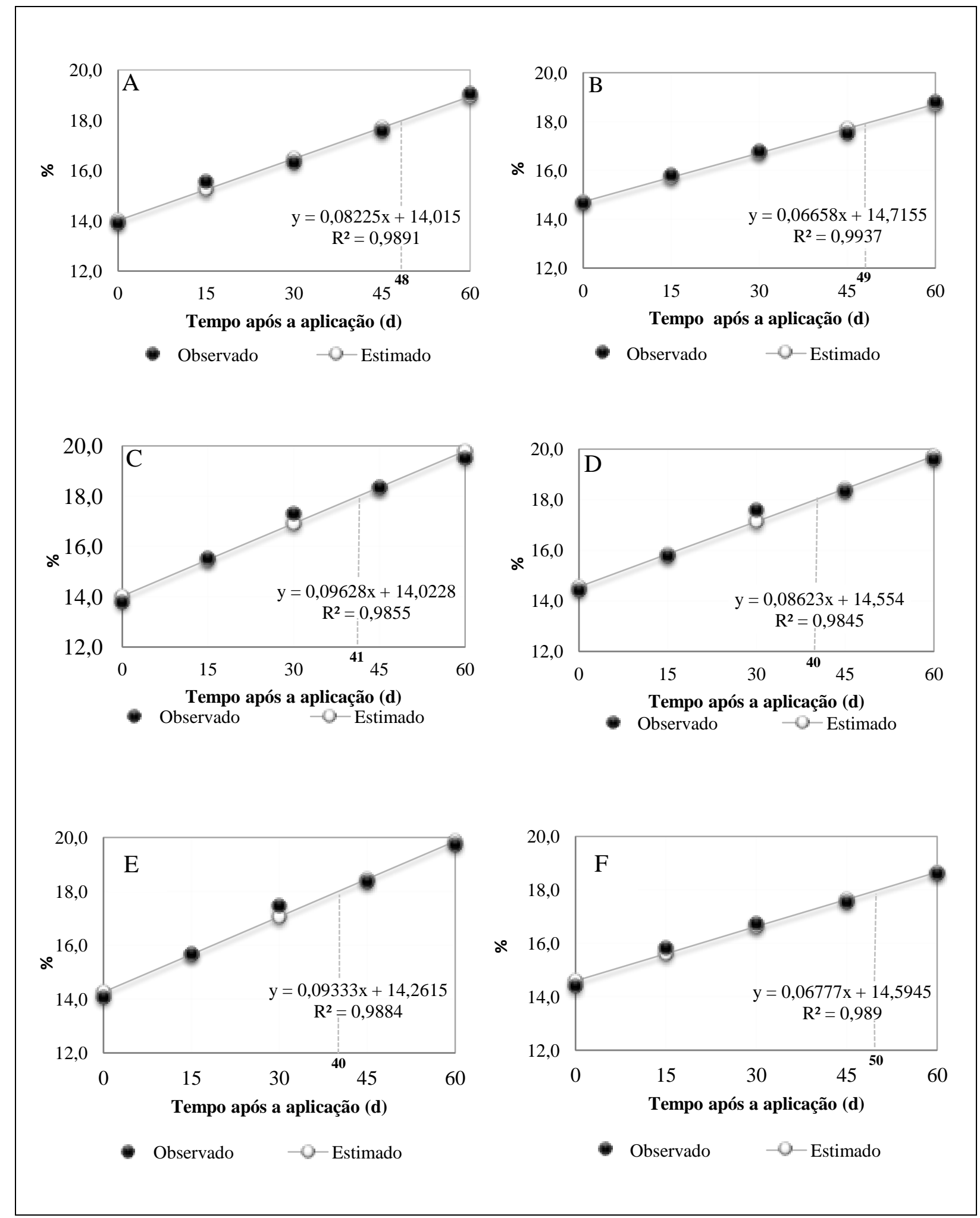

Figura 10. Padrões de variação do teor de Brix\% em função do tempo após a aplicação dos tratamentos. (A) Controle, (B) Orthosulfamuron, (C) Etil-trinexapac, (D) Sulfometuron metil, (E) Sulfometuron metil + Boro $150 \mathrm{~g} / \mathrm{ha}$ e (F) Nitrato de Potássio. $(\mathrm{p}<0,01)$. _....- Tempo (dias) para o tratamento atingir Brix $=18 \%$. 


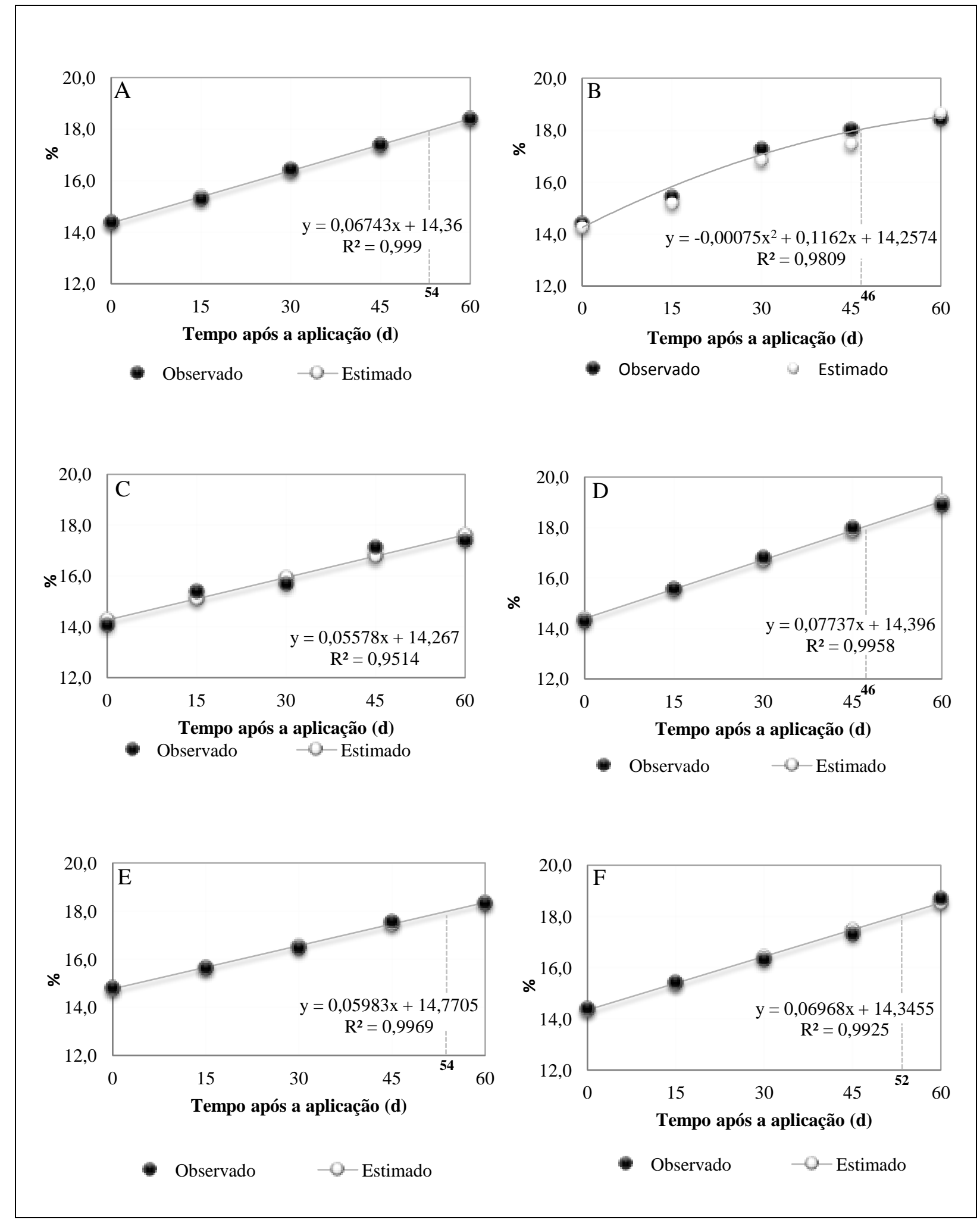

Figura 11. Padrões de variação do teor de Brix\% em função do tempo após a aplicação dos tratamentos. (A) Boro 50g/ha, (B) Boro $150 \mathrm{~g} / \mathrm{ha}$, (C) Boro $250 \mathrm{~g} / \mathrm{ha}$, (D) Nitrato de Potássio + Boro 150 g/ha, (E) Complexo de micronutrientes, (F) Complexo de micronutrientes + Biorregulador. $(\mathrm{p}<0,01)$. . Tempo (dias) para o tratamento atingir Brix $=18 \%$. 


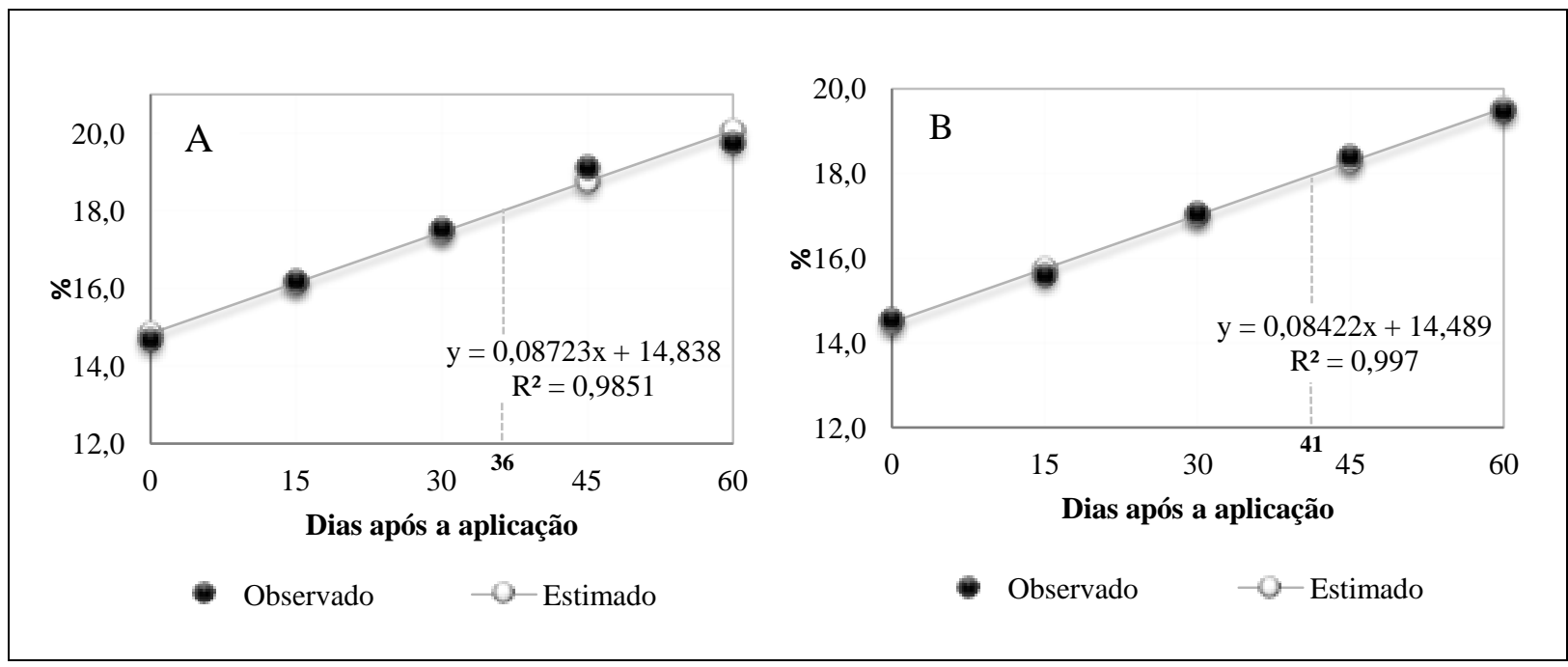

Figura 12. Padrões de variação do teor de Brix\% em função do tempo após a aplicação dos tratamentos. (A) Sulfometuron metil + Complexo de micronutrientes, (B) Sulfometuron metil + Complexo de micronutrientes + Biorregulador $(\mathrm{p}<0,01)$. . Tempo (dias) para o tratamento atingir Brix $=18 \%$.

\subsubsection{Fibra}

Para o parâmetro fibra houve efeito significativo para tratamentos $(p<0,01)$ e para época de coleta $(\mathrm{p}<0,01)$ não ocorrendo interação entre tratamentos e época de coleta. A análise de variância encontra-se na tabela 6.

Tabela 6. Fontes de variação e significância do valor F para a variável fibra.

\begin{tabular}{cccc}
\hline Efeito $^{1}$ & Gl & F & $\operatorname{Pr}>\mathrm{F}^{2}$ \\
\hline $\mathrm{T}$ & 13 & 2,75 & $<0013^{* *}$ \\
$\mathrm{E}$ & 4 & 90,22 & $<0001^{* *}$ \\
$\mathrm{~T} \times \mathrm{E}$ & 52 & 0,74 & $0,8966^{\mathrm{ns}}$
\end{tabular}

${ }^{1} . \mathrm{T}=$ efeito de tratamento; $\mathrm{E}=$ efeito de época de coleta; $\mathrm{T} \times \mathrm{E}=$ interação tratamento $\mathrm{x}$ época de coleta.

${ }^{2}$.Teste $\mathrm{F}$ para probabilidade de efeito significativo e discriminatório para os fatores.

ns $=$ não significativo. Os símbolos $* *$ e $*$ representam $\mathrm{p}<0,01$ e 0,05 respectivamente.

Os teores de fibra dos tratamentos encontram-se na tabela 7. As maiores porcentagens de fibra foram resultantes da aplicação do maturador Sulfometuron metil, da associação $\mathrm{KNO}_{3}$ e boro e, da associação sulfometuron metil e complexo de micronutrientes. Dentre os maturadores, a menor porcentagem de fibra foi proporcionada pela aplicação do Etiltrinexapac, não diferindo estatisticamente do Orthosulfamuron. 
Tabela 7. Porcentagem de fibra referente a primeira época de aplicação dos tratamentos.

\begin{tabular}{|c|c|c|}
\hline Tratamento & \multicolumn{2}{|c|}{ Médias } \\
\hline Controle & 9,4135 & cde \\
\hline Orthosulfamuron & 9,4981 & bcd \\
\hline Etil-Trinexapac & 9,4158 & cde \\
\hline Sulfometuron metil & 9,6714 & $\mathrm{a}$ \\
\hline Sulfometuron metil + Boro Boro $150 \mathrm{~g} / \mathrm{ha}$ & 9,4748 & bcd \\
\hline $\mathrm{KNO}_{3}$ & 9,3866 & de \\
\hline Boro $50 \mathrm{~g} / \mathrm{ha}$ & 9,3786 & de \\
\hline Boro $150 \mathrm{~g} / \mathrm{ha}$ & 9,4592 & bcde \\
\hline Boro $250 \mathrm{~g} / \mathrm{ha}$ & 9,2894 & $\mathrm{e}$ \\
\hline $\mathrm{KNO}_{3}+$ Boro $150 \mathrm{~g} / \mathrm{ha}$ & 9,5786 & $\mathrm{abc}$ \\
\hline Complexo de micronutrientes & 9,4655 & bcd \\
\hline $\begin{array}{c}\text { Complexo de Micronutrientes }+ \\
\text { Biorregulador }\end{array}$ & 9,4504 & bcde \\
\hline $\begin{array}{c}\text { Sulfometuron metil + Complexo de } \\
\text { micronutrientes }\end{array}$ & 9,6100 & $a b c$ \\
\hline $\begin{array}{l}\text { Sulfometuron metil + Complexo de } \\
\text { micronutrientes + Biorregulador }\end{array}$ & 9,3896 & de \\
\hline
\end{tabular}

Coeficiente de variação: $4,40 \%$. Desvio padrão: 0,42 . Média: 9,46.

${ }^{1}$ Médias seguidas por mesma letra não diferem estatisticamente entre si $(\mathrm{p}<05)$.

Martins e Castro (1999) estudando a anatomia de plantas de cana-de-açúcar verificaram que giberelina e ethephon reduziram a quantidade de fibras na cana-de-açúcar. Neste experimento a maior redução porcentagem de fibra foi resultado da aplicação do Boro na dose de $250 \mathrm{~g} / \mathrm{ha}$.

Houve resposta quadrática $(\mathrm{p}<0,01)$ das épocas de coleta no teor de fibra, como é demonstrado na figura 13. Os teores de fibra foram crescentes no decorrer do tempo após a aplicação. 


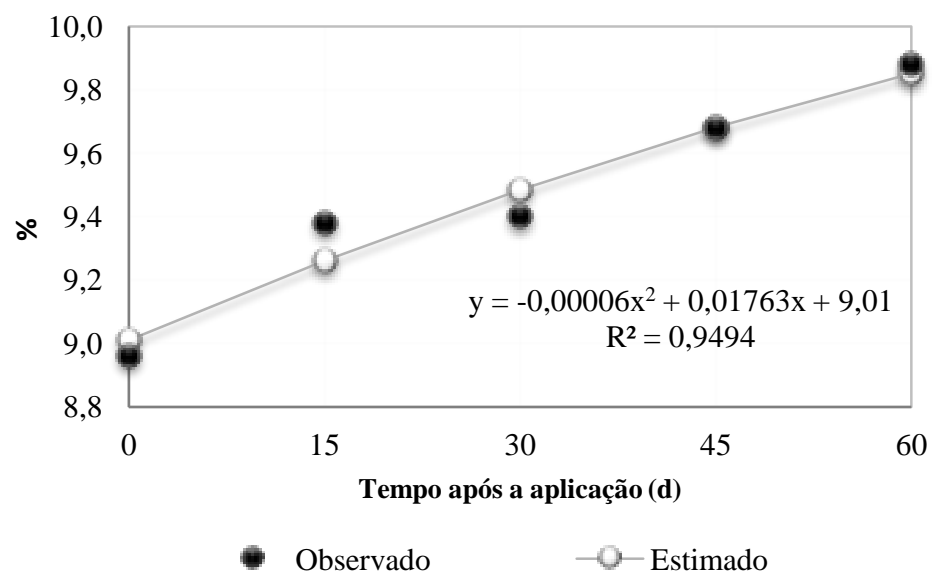

Figura 13. Padrão de variação da porcentagem de fibra em função do tempo após a aplicação dos tratamentos e equação.

\subsubsection{Pol do Caldo}

$\mathrm{Na}$ análise de Pol do caldo verificou-se interação significativa entre tratamentos e época de coleta $(\mathrm{p}<0,05)$, como é demonstrado na tabela 8 .

Tabela 8. Fontes de variação e significância do valor F para a variável pol do caldo.

\begin{tabular}{cccc}
\hline Efeito $^{1}$ & Gl & F & Pr $>\mathrm{F}^{2}$ \\
\hline $\mathrm{T}$ & 13 & 7,54 & $<0001^{* *}$ \\
$\mathrm{E}$ & 4 & 577,68 & $<0001^{* *}$ \\
$\mathrm{~T}$ x E & 52 & 1,52 & $0,0211^{*}$
\end{tabular}

${ }^{1} . \mathrm{T}=$ efeito de tratamento; $\mathrm{E}=$ efeito de época de coleta; $\mathrm{T} \times \mathrm{E}=$ interação tratamento $\mathrm{x}$ época de coleta.

${ }^{2}$.Teste $\mathrm{F}$ para probabilidade de efeito significativo e discriminatório para os fatores.

${ }^{2}$.Os símbolos $* *$ e $*$ representam $\mathrm{p}<0,01$ e 0,05 respectivamente.

Os resultados de pol do caldo apresentaram comportamentos semelhantes aos demonstrados pela variável brix\%, sendo que, os tratamentos afetaram a porcentagem de pol a partir dos 30 DAA, respostas que podem sem verificados na tabela 9.

Tabela 9. Porcentagem de Pol do caldo referente a primeira época de aplicação dos tratamentos, avaliada aos 0, 15, 30, 45 e 60 dias após a aplicação. Em cada época de avaliação as letras comparam os tratamentos. Médias seguidas por mesma letra não diferem estatisticamente entre si $(\mathrm{P}<05)$. 


\begin{tabular}{|c|c|c|c|c|c|}
\hline \multirow{2}{*}{ Tratamento } & \multicolumn{5}{|c|}{ Tempo após a aplicação $(\mathrm{d})^{1}$} \\
\hline & $0^{2}$ & 15 & 30 & 45 & 60 \\
\hline Controle & $10,7 \mathrm{a}$ & 13,0 a & 13,4 ef & 15,2 bcd & 16,7 bcde \\
\hline Orthosulfamuron & $11,7 \mathrm{a}$ & 13,1 a & 14,3 abcde & $15,0 \mathrm{~cd}$ & 16,5 cde \\
\hline Etil-Trinexapac & 10,4 a & $13,0 \mathrm{a}$ & $15,0 \mathrm{ab}$ & $16,0 \mathrm{ab}$ & $17,3 \mathrm{abc}$ \\
\hline Sulfometuron metil & 11,3 a & $13,1 \mathrm{a}$ & $15,2 \mathrm{a}$ & $16,0 \mathrm{ab}$ & 17,7 a \\
\hline Sulfometuron metil + Boro & $10,8 \mathrm{a}$ & 13,0 a & $14,9 \mathrm{ab}$ & $15,9 \mathrm{abc}$ & $17,5 \mathrm{ab}$ \\
\hline $\mathrm{KNO}_{3}$ & $11,3 \mathrm{a}$ & 13,3 a & 14,2 bcde & $15,2 \mathrm{bcd}$ & 16,4 cde \\
\hline Boro $50 \mathrm{~g} / \mathrm{ha}$ & 11,3 a & $12,7 \mathrm{a}$ & 13,9 cdef & $14,7 \mathrm{~d}$ & $16,1 \mathrm{e}$ \\
\hline Boro $150 \mathrm{~g} / \mathrm{ha}$ & $11,2 \mathrm{a}$ & 12,9 a & $14,8 \mathrm{abc}$ & $15,8 \mathrm{bc}$ & 16,3 de \\
\hline Boro $250 \mathrm{~g} / \mathrm{ha}$ & $11,0 \mathrm{a}$ & $12,6 \mathrm{a}$ & $13,0 \mathrm{f}$ & $14,6 \mathrm{~d}$ & $15,9 \mathrm{e}$ \\
\hline $\mathrm{KNO}_{3}+$ Boro $150 \mathrm{~g} / \mathrm{ha}$ & $11,1 \mathrm{a}$ & 12,9 a & 14,2 bcde & $15,5 \mathrm{bcd}$ & 16,7 bcde \\
\hline Complexo de Micronutrientes & 11,9 a & $13,2 \mathrm{a}$ & $13,8 \mathrm{def}$ & $15,1 \mathrm{bcd}$ & $16,0 \mathrm{e}$ \\
\hline \multicolumn{6}{|l|}{ Complexo de Micronutrientes } \\
\hline+ Biorregulador & 11,3 a & $12,7 \mathrm{a}$ & 13,5 ef & $14,8 \mathrm{~d}$ & $16,2 \mathrm{de}$ \\
\hline \multicolumn{6}{|l|}{ Sulfometuron metil + } \\
\hline \multicolumn{6}{|l|}{ Sulfometuron metil + } \\
\hline Complexo de Micronutrientes & & & & & \\
\hline+ Biorregulador & 11,4 a & 12,9 a & 14,5 abcd & $15,9 \mathrm{abc}$ & 17,1 abcd \\
\hline
\end{tabular}

Coeficiente de variação: 14,57\%. Desvio Padrão: 2,06. Média: 14,13.

${ }^{1}$ Amostragens realizadas aos $0,15,30,45$ e 60 dias após a aplicação dos tratamentos.

${ }^{2} \mathrm{Em}$ cada época de avaliação as letras comparam os tratamentos. Médias seguidas por mesma letra não diferem estatisticamente entre si $(\mathrm{p}<05)$.

Aos 30 DAA os resultados superiores foram proporcionados pelos maturadores, boro na dose de $150 \mathrm{~g} / \mathrm{ha}$ e pelas associações do Sulfometuron metil ao complexo de micronutrientes e ao complexo de nutrientes e biorregulador.

Aos 45 DAA os tratamentos Etil-trinexapac e o Sulfometuron metil isolado ou em associação com boro, ou complexo de micronutrientes ou complexo de micronutrientes + biorregulador apresentaram maiores porcentagens de pol no caldo, resultados verificados também aos 60 DAA. 
Aos 60 DAA os resultados proporcionados pelos tratamentos compostos por complexo de nutrientes, dos nutrientes $\mathrm{KNO}_{3}$ e Boro, do biorregulador e do Orthosulfamuron não diferiram estatisticamente do controle. Verifica-se tendência de desaparecimento de efeito dos tratamentos, pela ocorrência da maturação natural da cana-de-açúcar.

No início do experimento o teor médio de Pol era de 10,2\% e ao término $16,7 \%$, com incremento médio de $1,4 \%$ de pol no intervalo de 15 dias, ou seja, $0,09 \%$ por dia.

Os resultados de utilização do nitrato de potássio diferenciam-se dos resultados encontrados por Leite et al., (2011) em que a utilização do nitrato de potássio apresentou efeito maturador na cultura da cana-de-açúcar, possibilitando o acúmulo de sacarose nos colmos, porém, isso pode ser justificado pelas condições climáticas que afetaram sua eficiência agronômica, tendo em vista que atua como indutor do processo de maturação, como é explicado pelos próprios autores.

Leite et al., (2009) verificaram que os maturadores $\mathrm{KNO}_{3}+$ Boro, Etefon e Etiltrinexapac, sob condição climática desfavorável ao processo de maturação natural (safra 2004), permitiram antecipar a colheita em 5, 8 e 25 dias, respectivamente, em relação ao controle. Os resultados encontrados podem ter apresentado comportamento diferenciado pelo fato das condições climáticas nesta época estarem favoráveis a maturação natural.

Silva, Cato e Costa, (2010) trabalhando com as variedades IAC 87-3396, IAC 912218, IAC 91-4216, IAC 91-5155 e IAC/SP 93-6006 e realizando a aplicação dos tratamentos 70 dias após a quarta colheita concluiram que os genótipos de cana-de-açúcar respondem diferentemente ao emprego de biorreguladores, associados ou não a fertilizantes foliares, e que a aplicação do biorregulador não proporcionou efeitos na qualidade tecnológica da canade-açúcar. Observando-se os resultados do biorregulador, verifica-se que os resultados corroboram com os encontrados por Silva, Cato e Costa, (2010) para o biorregulador, não ocorreram efeitos sob a qualidade tecnológica, observando que as épocas de aplicação foram diferentes - 70 dias após a colheita e pré-colheita.

Almeida et al., (2003) relataram que o sulfometuron-methyl foi eficiente como maturador antecipando em 15 dias a colheita da cana-de-açúcar, inclusive tendo o pico de maturação antecipado em relação aos outros maturadores. 
Os padrões de variação de pol em função do tempo após a aplicação dos tratamentos encontram-se nas figuras 14, 15 e 16. Houve resposta quadrática $(p<0,01)$ para os tratamentos Etil-trinexapac e Boro $150 \mathrm{~g} / \mathrm{ha}$ das épocas de coleta na porcentagem de Pol do caldo, para os demais tratamentos houve resposta linear crescente $(\mathrm{p}<0,01)$.

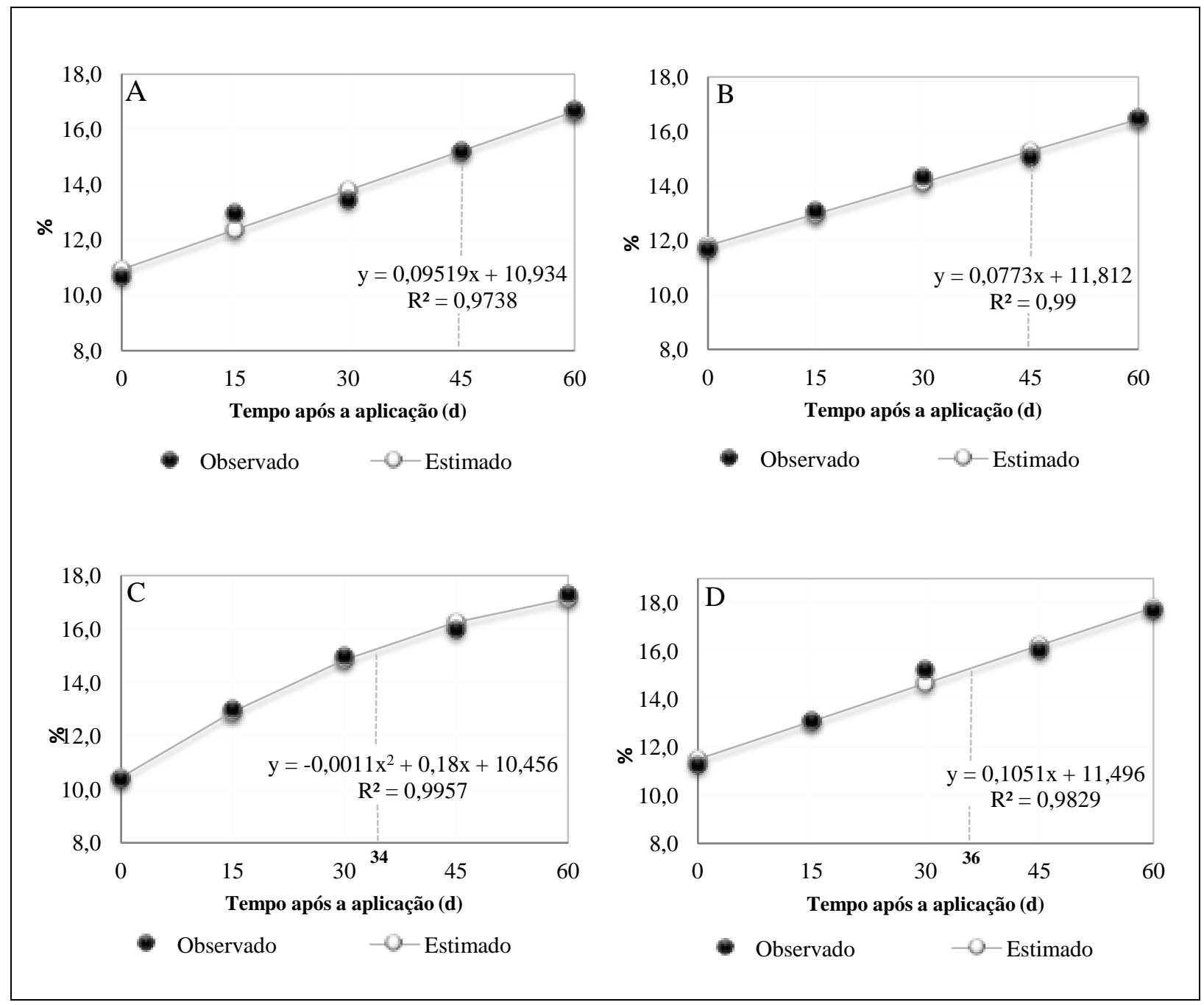

Figura 14. Padrões de variação de Pol do Caldo em função do tempo após a aplicação dos tratamentos. (A) Controle, (B) Orthosulfamuron, (C) Etil-trinexapac, (D) Sulfometuron metil. $(\mathrm{p}<0,01) \ldots \quad$ Tempo (dias) para o tratamento atingir Pol do caldo=15,3\%. 


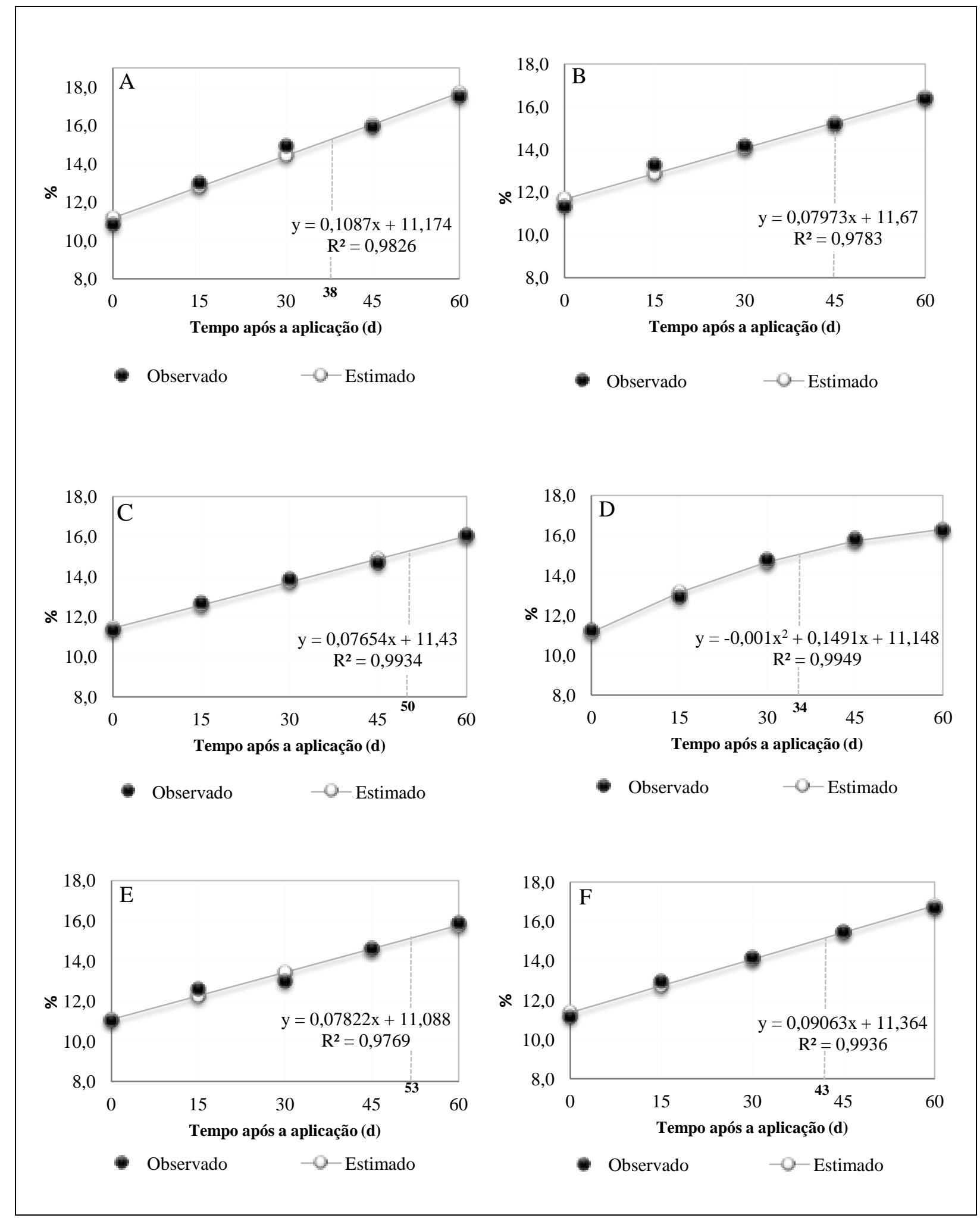

Figura 15. Padrões de variação de Pol do caldo em função do tempo após a aplicação dos tratamentos. (A) Sulfometuron metil + Boro $150 \mathrm{~g} / \mathrm{ha}$, (B) Nitrato de Potássio; (C) Boro 50g/ha, (D) Boro $150 \mathrm{~g} / \mathrm{ha}$, (E) Boro $250 \mathrm{~g} / \mathrm{ha}$, (F) Nitrato de Potássio + Boro $150 \mathrm{~g} / \mathrm{ha}$. $(\mathrm{p}<0,01) \ldots$ Tempo (dias) para o tratamento atingir Pol do caldo=15,3\%. 


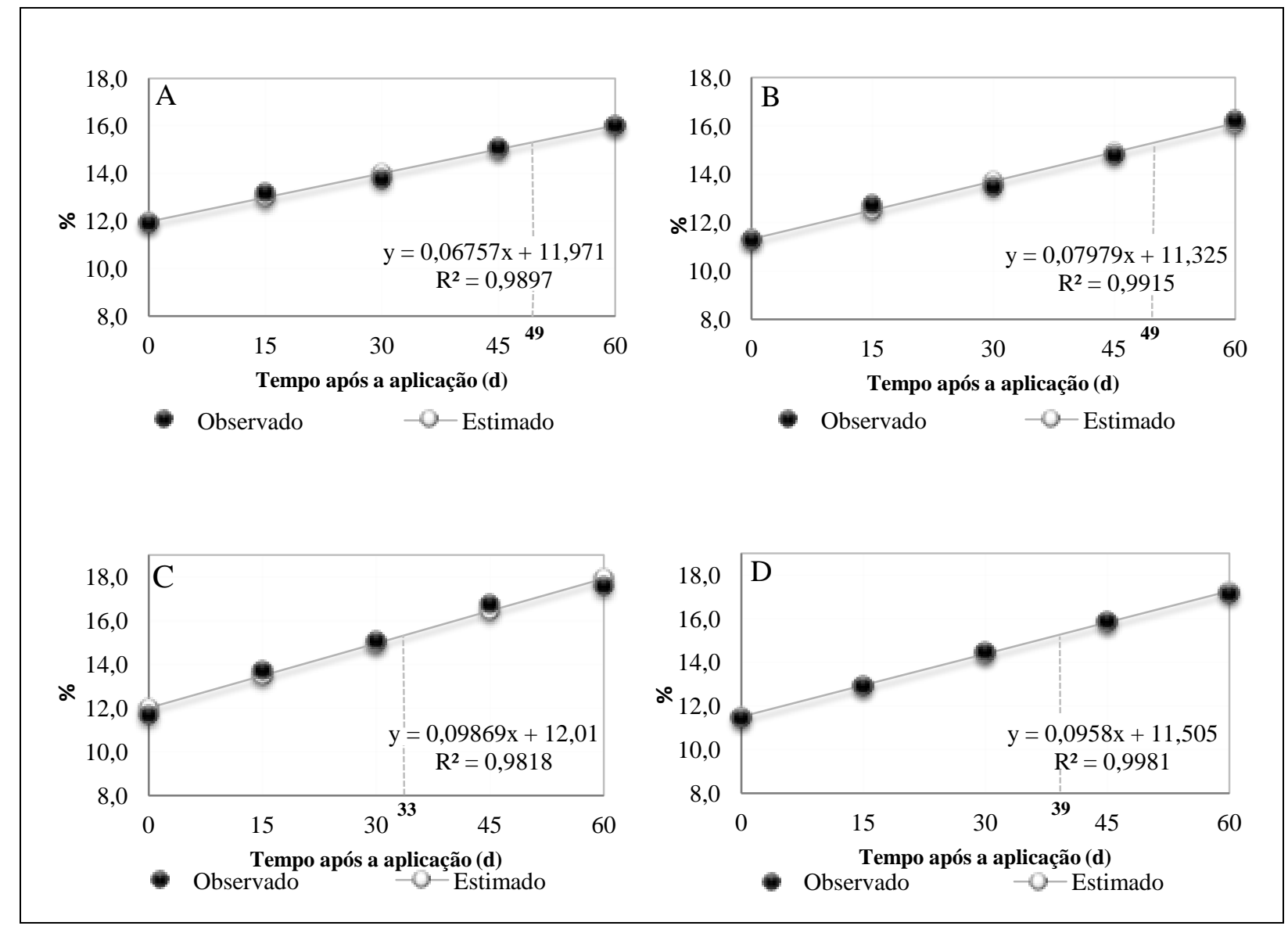

Figura 16 Padrões de variação de Pol do caldo em função do tempo após a aplicação dos tratamentos. (A) Complexo de micronutrientes, (B) Complexo de micronutrientes + biorregulador (C) Sulfometuron metil + Complexo de micronutrientes, (D) Sulfometuron metil + Complexo de micronutrientes + Biorregulador. $(\mathrm{p}<0,01)$. -..-Tempo (dias) para o tratamento atingir Pol do caldo $=15,3 \%$.

Para a variável pol do caldo, o tratamento Sulfometuron metil/ Complexo de micronutrientes antecipou a colheita em 12 dias em relação ao controle. O tratamento boro na $250 \mathrm{~g} / \mathrm{ha}$ proporcionou atraso de 8 dias na colheita da cana. Ambos os casos considerando-se Pol do caldo ideal para colheita $=15,3 \%$.

\subsubsection{Pol da Cana}

Houve interação significativa entre tratamento e época de coleta para o parâmetro pol da cana $(\mathrm{p}<0,05)$ e efeitos significativos para tratamento e época de coleta, ambos com $\mathrm{p}<0,01$. A análise de variância encontra-se na tabela 10 . 
Tabela 10. Fontes de variação e significância do valor F para a variável pol da cana.

\begin{tabular}{cccc}
\hline Efeito $^{1}$ & Gl & $\mathrm{F}$ & $\mathrm{Pr}>\mathrm{F}^{2}$ \\
\hline $\mathrm{T}$ & 13 & 7,34 & $<0001^{* *}$ \\
$\mathrm{E}$ & 4 & 573,98 & $<0001^{* *}$ \\
$\mathrm{~T}$ x E & 52 & 1,55 & $0,0164^{*}$ \\
\hline
\end{tabular}

${ }^{1} \cdot \mathrm{T}=$ efeito de tratamento; $\mathrm{E}=$ efeito de época de coleta; $\mathrm{T} \times \mathrm{E}=$ interação tratamento $\mathrm{x}$ época de coleta.

${ }^{2}$.Teste $\mathrm{F}$ para probabilidade de efeito significativo e discriminatório para os fatores.

Os símbolos $* *$ e $*$ representam $\mathrm{p}<0,01$ e 0,05 respectivamente.

Diferenças entre tratamentos para a porcentagem de pol da cana foram verificadas a partir dos 30 DAA, como demonstrado na tabela 11.

Tabela 11. Porcentagem de pol (cana) referente a primeira época de aplicação dos tratamentos, avaliada aos 0, 15, 30, 45 e 60 dias após a aplicação.

\begin{tabular}{|c|c|c|c|c|c|c|c|}
\hline \multirow{2}{*}{ Tratamento } & \multicolumn{7}{|c|}{ Tempo após a aplicação (d) } \\
\hline & \multicolumn{2}{|l|}{0} & \multicolumn{2}{|l|}{15} & 30 & 45 & 60 \\
\hline Controle & 9,51 & $\mathrm{a}$ & 11,50 & $\mathrm{a}$ & $11,93 \mathrm{de}$ & 13,41 bcd & 14,6 bcdef \\
\hline Orthosulfamuron & 10,41 & $\mathrm{a}$ & 11,61 & a & $12,68 \mathrm{abcd}$ & $13,25 \mathrm{~cd}$ & $14,5 \mathrm{def}$ \\
\hline Etil-Trinexapac & 9,29 & $\mathrm{a}$ & 11,49 & $\mathrm{a}$ & $13,28 \mathrm{ab}$ & $14,08 \mathrm{ab}$ & 15,2 abcd \\
\hline Sulfometuron metil & 10,04 & $\mathrm{a}$ & 11,53 & $\mathrm{a}$ & 13,41 a & $14,07 \mathrm{ab}$ & 15,4 a \\
\hline Sulfometuron metil/Boro $150 \mathrm{~g} / \mathrm{ha}$ & 9,64 & $\mathrm{a}$ & 11,55 & $\mathrm{a}$ & $13,22 \mathrm{ab}$ & $13,98 \mathrm{abc}$ & $15,4 \mathrm{abc}$ \\
\hline $\mathrm{KNO}_{3}$ & 10,09 & $\mathrm{a}$ & 11,77 & $\mathrm{a}$ & 12,54 bcd & 13,42 bcd & 14,4 def \\
\hline Boro $50 \mathrm{~g} / \mathrm{ha}$ & 10,13 & $\mathrm{a}$ & 11,25 & a & 12,24 cde & $12,98 \mathrm{~d}$ & $14,1 \mathrm{f}$ \\
\hline Boro $150 \mathrm{~g} / \mathrm{ha}$ & 10,03 & $\mathrm{a}$ & 11,41 & $\mathrm{a}$ & $13,11 \mathrm{ab}$ & $13,94 \mathrm{abc}$ & 14,3 ef \\
\hline Boro $250 \mathrm{~g} / \mathrm{ha}$ & 9,83 & $\mathrm{a}$ & 11,22 & $\mathrm{a}$ & $11,56 \mathrm{e}$ & $12,94 \mathrm{~d}$ & $14,0 \mathrm{f}$ \\
\hline $\mathrm{KNO}_{3} /$ Boro $150 \mathrm{~g} / \mathrm{ha}$ & 9,94 & a & 11,42 & $\mathrm{a}$ & 12,55 bcd & $13,60 \mathrm{bcd}$ & 14,6 cdef \\
\hline Complexo de Micronutrientes & 10,59 & a & 11,69 & a & 12,18 cde & $13,33 \mathrm{bcd}$ & $14,1 \mathrm{f}$ \\
\hline \multicolumn{8}{|l|}{ Complexo de Micronutrientes } \\
\hline /Biorregulador & 10,08 & $\mathrm{a}$ & 11,26 & a & 11,95 de & $13,07 \mathrm{~d}$ & 14,3 ef \\
\hline \multicolumn{8}{|l|}{ Sulfometuron metil/Complexo de } \\
\hline Micronutrientes & 10,41 & a & 12,15 & a & $13,31 \mathrm{ab}$ & 14,72 a & $15,4 \mathrm{ab}$ \\
\hline \multicolumn{8}{|l|}{ Sulfometuron metil/ Complexo de } \\
\hline Micronutrientes/ Biorregulador & 10,22 & a & 11,48 & $\mathrm{a}$ & 12,87 abc & 14,00 abc & 15,1 abcde \\
\hline
\end{tabular}

Coeficiente de variação: 14,03\%. Desvio Padrão: 1,75. Média:12,48. 
${ }^{1}$ Amostragens realizadas aos $0,15,30,45$ e 60 dias após a aplicação dos tratamentos.

${ }^{2}$ Em cada época de avaliação as letras comparam os tratamentos. Médias seguidas por mesma letra não diferem estatisticamente entre si $(\mathrm{p}<05)$.

Os tratamentos Etil-trinexapac e os compostos por Sulfometuron metil, isolado ou em qualquer associação, apresentaram maiores porcentagens de pol aos $30 \mathrm{DAA}$, resultados que se perpetuaram até os 60 DAA. O Orthosulfamuron não diferiu destes tratamentos aos 30 DAA, porém, os resultados nas demais épocas de avaliação foram inferiores, assim como o boro $150 \mathrm{~g} / \mathrm{ha}$ que não manteve seus resultados até os $60 \mathrm{DAA}$.

Fernandes et al., (2000) trabalhando com as variedades SP80-1816, SP80-1842 e SP81-3250, em condições altamente restritivas para o desenvolvimento vegetativo, verificaram que as variedades responderam significativamente à aplicação de Curavial@ com ganhos de pol (colmos + ponteiros) e aumentos da pureza do caldo, resultados que corroboram com os verificados. Todos os tratamentos contendo o sulfometuron metil, a partir dos 30 DAA, foram superiores aos demais e ao resultado proveniente da maturação natura (controle).

Caputo et. al (2008) trabalhando com as variedades IAC87-3410 (tardia), IAC893124 (precoce), IAC91-2195 (precoce), IAC91-5155 (média/tardia), PO88-62 (média) e SP80-1842 (precoce) e dois maturadores sulfometuron metil e etefon, aplicados em 10 de março de 2004 verificou que o emprego dos maturadores antecipou a colheita de cana-deaçúcar em pelo menos 21 dias, em relação à testemunha, podendo-se efetuá-la entre 42 e 84 dias após a aplicação do etefon e entre 105 e 126 dias após a aplicação de sulfometuron metil.

Admitindo-se o valor de pol indicado para a colheita de 13,0 \%, os tratamentos Etiltrinexapac, sulfometuron metil, e a associação sulfometuron metil/complexo de micronutrientes, proporcionariam a colheita antes dos 45 dias após a aplicação resultados que corroboram com os encontrados por Viana et al. (2008) que verificaram que o tratamento ethyl trinexapac, a partir dos 46 d.a.a., apresentou ganhos em Pol (\%) cana de 0,5 pontos percentuais em relação à testemunha.

As regressões dos tratamentos em função das épocas de coleta e suas respectivas representações gráficas das equações encontram-se nas figuras 17, 18 e 19 . Houve efeito linear $(\mathrm{p}<0,01)$ das épocas de coleta no teor de pol da cana para todos os tratamentos, exceto o etil-trinexapac e boro na dose de $250 \mathrm{~g} / \mathrm{ha}$ que apresentaram comportamento quadrático $(\mathrm{p}<0,01)$. 


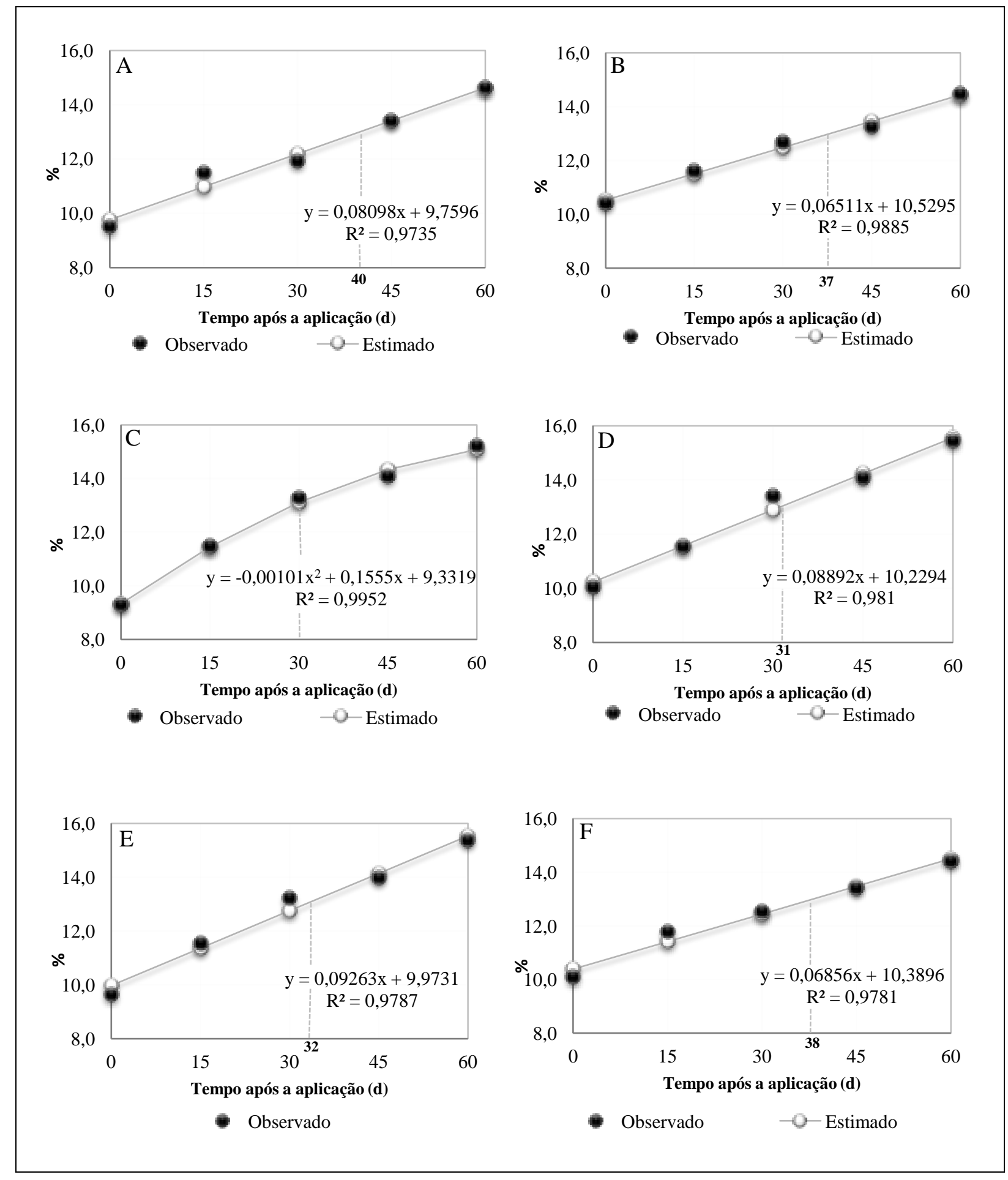

Figura 17. Padrões de variação de Pol da Cana em função do tempo após a aplicação dos tratamentos. (A) Controle, (B) Orthosulfamuron, (C) Etil-trinexapac, (D) Sulfometuron metil, (E) Sulfometuron metil + Boro 150g/ha e (F) Nitrato de Potássio. (p<0,01). _... Tempo (dias) para o tratamento atingir Pol da Cana $=13,0 \%$. 


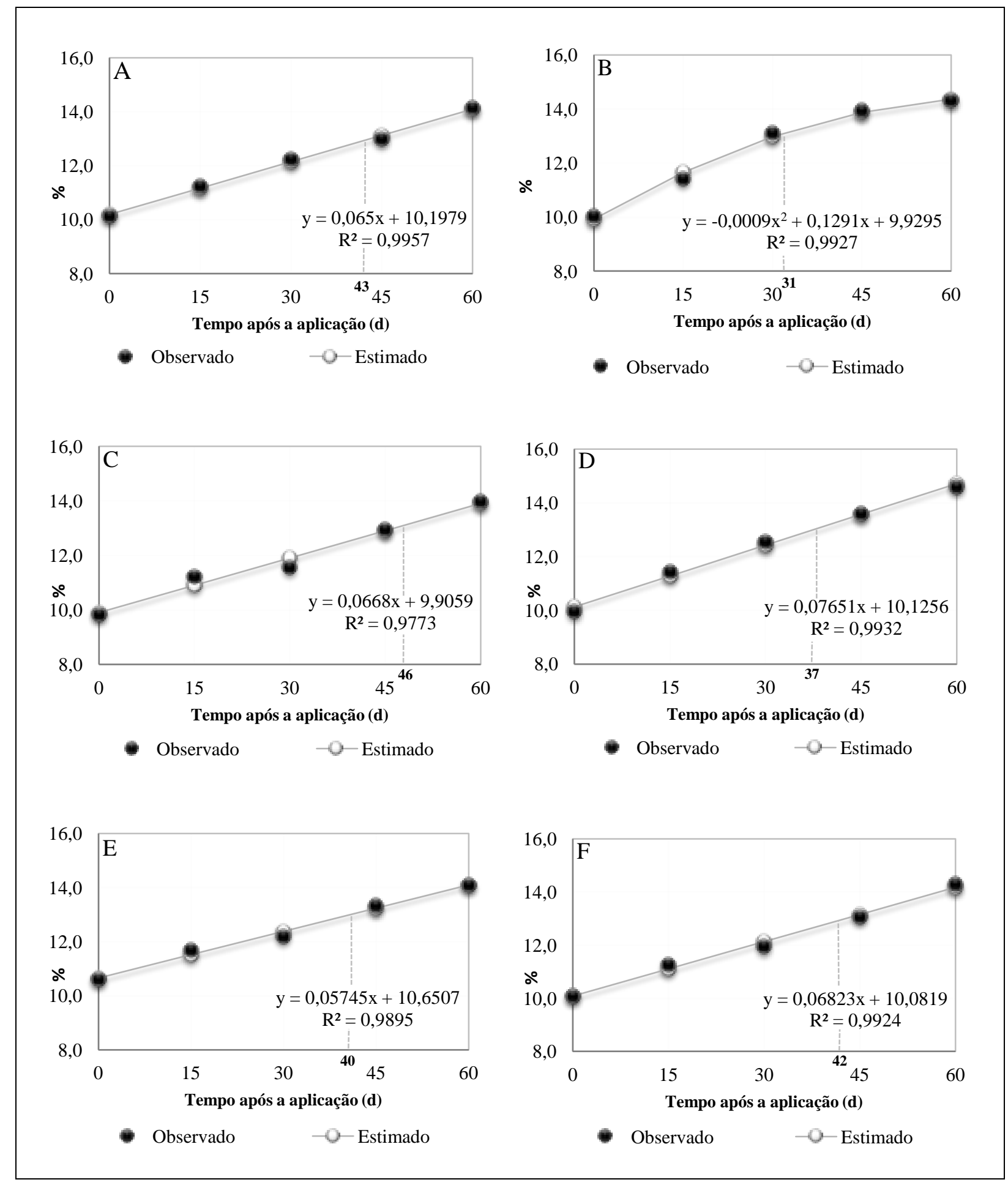

Figura 18. Padrões de variação de Pol da cana em função do tempo após a aplicação dos tratamentos. (A) Boro 50g/ha, (B) Boro $150 \mathrm{~g} / \mathrm{ha}$, (C) Boro $250 \mathrm{~g} / \mathrm{ha}$, (D) Nitrato de Potássio+ Boro $150 \mathrm{~g} / \mathrm{ha}$, (E) Complexo de micronutrientes, (F) Complexo de micronutrientes + Biorregulador $(\mathrm{p}<0,01)$..... Tempo (dias) para o tratamento atingir Pol da Cana $=13,0 \%$. 


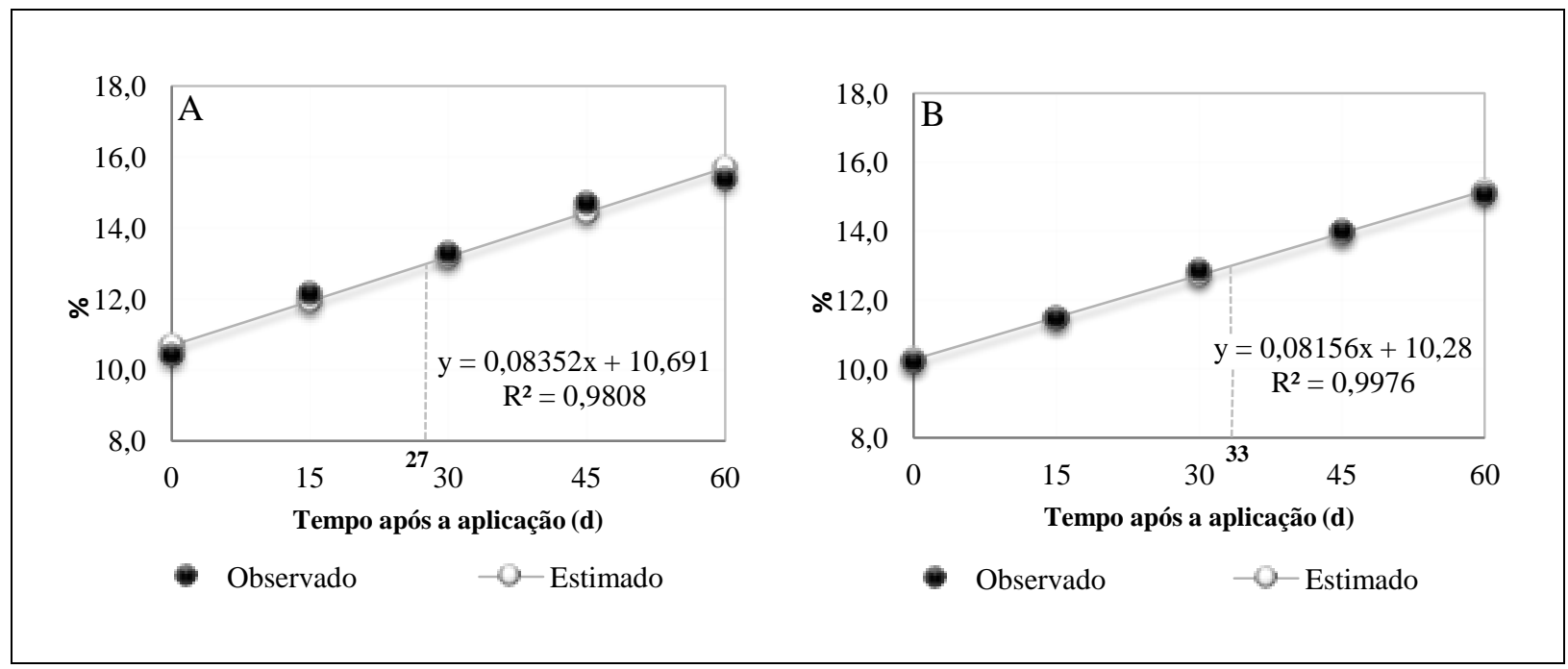

Figura 19. Padrões de variação de Pol da cana em função do tempo após a aplicação dos tratamentos. (A) Sulfometuron metil + Complexo de micronutrientes, (B) Sulfometuron metil + Complexo de micronutrientes + Biorregulador. $(\mathrm{p}<0,01)$. - Tempo (dias) para o tratamento atingir Pol da Cana $=13,0 \%$.

Com a aplicação do tratamento Sulfometuron metil + Complexo de micronutrientes a cana-de-açúcar atingiu $13 \%$ de pol da cana aos 27 DAA, o melhor desempenho entre os tratamentos, antecipando a colheita em 13 dias em relação a maturação natural. Os tratamentos Etil-trinexapac, Sulfometuron metil e Sulfometuron metil/Boro anteciparam a colheita em 10, 9 e 8 dias, respectivamente.

\subsubsection{Pureza}

Para o parâmetro pureza houve efeito significativo para tratamento $(\mathrm{p}<0,05)$ e para época de coleta $(\mathrm{p}<0,01)$. A interação entre tratamento e época de coleta foi não significativa. A análise de variância encontra-se na tabela 12.

Tabela 12. Fontes de variação e significância do valor F para a variável pureza.

\begin{tabular}{cccc}
\hline Efeito $^{1}$ & Gl & F & Pr $>F^{2}$ \\
\hline T & 13 & 2,86 & $0,0439^{*}$ \\
E & 4 & 211,20 & $<0001^{* *}$ \\
T x E & 52 & 2,22 & $0,1941^{\text {ns }}$
\end{tabular}

${ }^{1} . \mathrm{T}=$ efeito de tratamento; $\mathrm{E}=$ efeito de época de coleta; $\mathrm{T} \times \mathrm{E}=$ interação tratamento $\mathrm{x}$ época de coleta.

${ }^{2}$.Teste $\mathrm{F}$ para probabilidade de efeito significativo e discriminatório para os fatores.

$n s=$ não significativo. Os símbolos $* * \mathrm{e}^{*}$ representam $\mathrm{p}<0,01$ e 0,05 respectivamente. 
A porcentagem média de pureza dos tratamentos foi de $84,15 \%$. Os tratamentos que apresentaram melhores resultados foram os maturadores, o $\mathrm{KNO}_{3}$ e o complexo de micronutrientes isolado e nas combinações com o maturador ou maturador + biorregulador. Estes resultados podem ser verificados na tabela 13 .

Tabela 13. Porcentagem de pureza referente a primeira época de aplicação dos tratamentos. Médias seguidas por mesma letra não diferem estatisticamente entre si $(\mathrm{p}<05)$.

\begin{tabular}{ccc}
\hline Tratamento & \multicolumn{2}{c}{ Médias } \\
\hline Controle & 83,209 & $\mathrm{~d}$ \\
Orthosulfamuron & 84,3149 & abcd \\
Etil-Trinexapac & 84,2062 & abcd \\
Sulfometuron metil & 84,9993 & ab \\
KNO 3 & 84,1234 & bcd \\
Boro 50 g/ha & 84,2864 & abcd \\
Boro 150 g/ha & 83,5351 & cd \\
Boro 250 g/ha & 84,6132 & abc \\
KNO 3 + Boro 150 g/ha & 84,0164 & bcd \\
Complexo de Micronutrientes & 83,8849 & bcd \\
Complexo de Micronutrientes + & 84,3248 & abcd \\
Biorregulador & 83,1985 & $\mathrm{~d}$ \\
Sulfometuron metil + Complexo de & 84,1827 & abcd \\
Micronutrientes + Biorregulador & & \\
\hline Sulfometuron metil + Complexo de & 85,4366 & $\mathrm{a}$ \\
\hline
\end{tabular}

Coeficiente de variação: 4,78 \%. Desvio Padrão: 4,03. Média: 84,15.

No decorrer das épocas de análise houve aumento no teor médio de pureza. No início do experimento este teor estava em torno de $78 \%$, saltando para $88 \%$ aos 60 DAA. Segundo Fernandes, Stupiello e Uchoa (2002) o produto químico sulfometuron metil possibilita aumentos da pureza, resultados também verificados neste experimento. 
Siqueira (2014) observou a partir dos 45 DAA a pureza do caldo obtida para o controle foi significativamente superior ao tratamento com B. Os resultados verificados para o B são estatisticamente iguais aos encontrados pelo controle, exceto para a dose de $150 \mathrm{~g} / \mathrm{ha}$, a qual foi superior em $1,4 \%$.

Segundo Ripoli e Ripoli (2004) o valor indicado para pureza é > 85\%, ficando os resultados promovidos pelos tratamentos nesta época de aplicação abaixo do recomendado.

Os padrões de variação da pureza em função do tempo após a aplicação dos tratamentos encontram-se na figura 20. Houve comportamento quadrático da porcentagem de pureza ao longo das épocas de amostragem $(\mathrm{p}<0,01)$. Verifica-se valores crescentes ao longo do tempo após a aplicação, com o ponto de máximo aos 60 DAA, para as épocas estudadas.

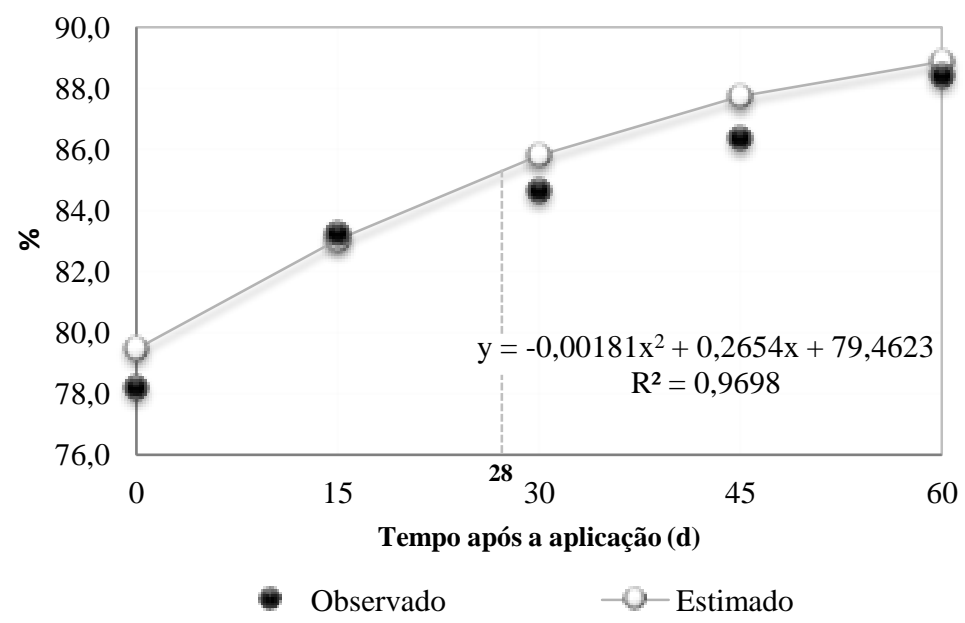

Figura 20. Padrão de variação de pureza em função do tempo após a aplicação dos tratamentos e equação. -...-. Tempo (dias) para atingir pureza $=85 \%$.

A porcentagem de pureza indicada para a colheita foi alcançada aos 28 dias após o início do período experimental.

\subsubsection{Açúcares redutores do caldo}

A análise de variância para a variável açúcares redutores do caldo encontram-se na tabela 14. Houve efeito significativo para os tratamentos $(\mathrm{p}<0,05)$ e para as épocas de coleta $(\mathrm{p}<0,01)$. Não ocorreu interação entre tratamento e época de coleta (tabela 14). 
Tabela 14. Fontes de variação e significância do valor F para a variável açúcares redutores do caldo.

\begin{tabular}{cccc}
\hline Efeito $^{1}$ & Gl & $\mathrm{F}$ & $\mathrm{Pr}>\mathrm{F}^{2}$ \\
\hline $\mathrm{T}$ & 13 & 1,86 & $0,0359^{*}$ \\
$\mathrm{E}$ & 4 & 203,16 & $<0001^{* *}$ \\
T x E & 52 & 1,22 & $0,1632^{\mathrm{ns}}$
\end{tabular}

${ }^{1} . \mathrm{T}=$ efeito de tratamento; $\mathrm{E}=$ efeito de época de coleta; $\mathrm{T} \times \mathrm{E}=$ interação tratamento $\mathrm{x}$ época de coleta.

${ }^{2}$.Teste $\mathrm{F}$ para probabilidade de efeito significativo e discriminatório para os fatores.

ns = não significativo. Os símbolos $* *$ e $*$ representam $\mathrm{p}<0,01$ e 0,05 respectivamente.

O menor teor de açúcares redutores foi proporcionado pelo tratamento composto pela associação Sulfometuron metil e complexo de micronutrientes, não diferindo estatisticamente dos maturadores, do nitrato de potássio, boro na dose $150 \mathrm{~g} / \mathrm{ha}$ e ao complexo de micronutrientes isolado ou em associação com Sulfometuron metil e Sulfometuron metil + biorregulador. A porcentagem média de açúcares redutores foi de $0,75 \%$. Estes resultados encontram-se na tabela 15.

Tabela 15. Porcentagem de açúcares redutores (caldo) referente a primeira época de aplicação dos tratamentos. Médias seguidas por mesma letra não diferem estatisticamente entre si $(\mathrm{p}<05)$.

\begin{tabular}{cl}
\hline Tratamento & Médias \\
\hline Controle & $0,7896 \mathrm{a}$ \\
Orthosulfamuron & $0,7490 \mathrm{abcd}$ \\
Etil-Trinexapac & $0,7527 \mathrm{abcd}$ \\
Sulfometuron metil & $0,7255 \mathrm{~cd}$ \\
Sulfometuron metil + Boro $150 \mathrm{~g} / \mathrm{ha}$ & $0,7553 \mathrm{abc}$ \\
$\mathrm{KNO}_{3}$ & $0,7500 \mathrm{abcd}$ \\
Boro $50 \mathrm{~g} / \mathrm{ha}$ & $0,7757 \mathrm{ab}$ \\
Boro $150 \mathrm{~g} / \mathrm{ha}$ & $0,7388 \mathrm{bcd}$ \\
Boro $250 \mathrm{~g} / \mathrm{ha}$ & $0,7592 \mathrm{abc}$ \\
$\mathrm{KNO}_{3}+$ Boro $150 \mathrm{~g} / \mathrm{ha}$ & $0,7637 \mathrm{abc}$
\end{tabular}




$\begin{array}{lc}\text { Complexo de Micronutrientes } & 0,7487 \text { abcd } \\ \text { Complexo de Micronutrientes + } & 0,7873 \text { a } \\ \quad \text { Biorregulador } & \\ \text { Sulfometuron metil + Complexo de } & 0,7105 \text { d } \\ \quad \text { Micronutrientes } & \\ \text { Sulfometuron metil + Complexo de } & 0,7535 \text { abcd } \\ \text { Micronutrientes + Biorregulador } & \end{array}$

\section{Coeficiente de variação: $18,3 \%$. Desvio Padrão: 0,14 . Média: 0,75 .}

Caputo (2008) observou que de maneira geral, os valores de açúcares redutores do caldo foram decrescentes nas avaliações realizadas, mostrando que o processo de maturação estava ocorrendo, assim como ocorreu e pode ser observado na figura 21.

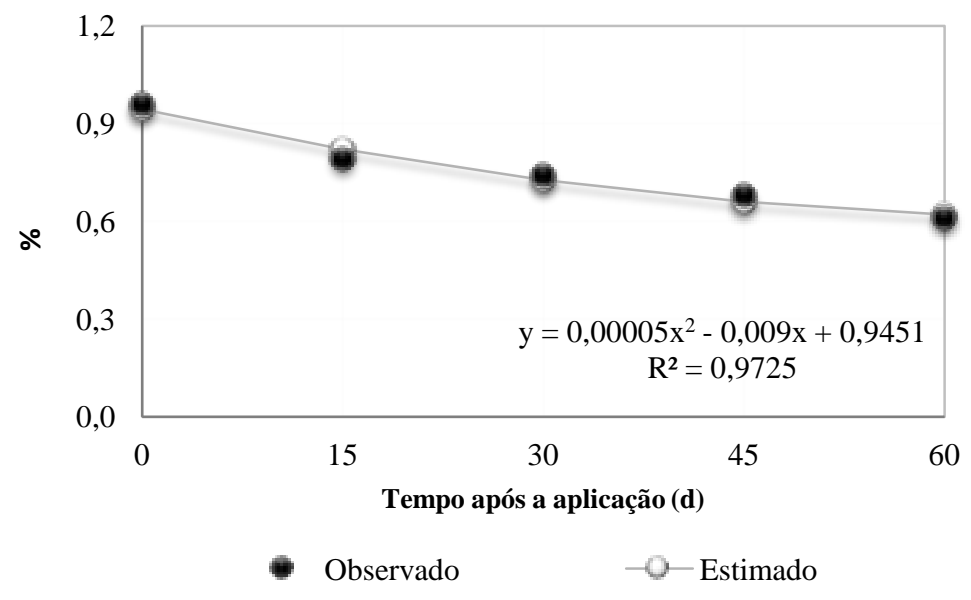

Figura 21. Padrão de variação de açúcares redutores do caldo em função do tempo após a aplicação dos tratamentos e equação.

\subsubsection{Açúcares redutores da cana}

Análise de variância dos resultados de açúcares redutores da cana demonstraram que não houve interação entre tratamento e época de coleta, porém houve efeito significativo para tratamento $(\mathrm{p}<0,05)$ e para época de coleta $(\mathrm{p}<0,01)$ (tabela 16).

Tabela 16. Fontes de variação e significância do valor F para a variável açúcares redutores da cana. 


\begin{tabular}{cccc}
\hline Efeito $^{1}$ & Gl & $\mathrm{F}$ & $\mathrm{Pr}>\mathrm{F}^{2}$ \\
\hline $\mathrm{T}$ & 13 & 1,92 & $0,0291^{*}$ \\
$\mathrm{E}$ & 4 & 211,05 & $<0001^{* *}$ \\
$\mathrm{~T}$ x E & 52 & 1,22 & $0,1672^{\mathrm{ns}}$
\end{tabular}

${ }^{1} \cdot \mathrm{T}=$ efeito de tratamento; $\mathrm{E}=$ efeito de época de coleta; $\mathrm{T} \times \mathrm{E}=$ interação tratamento $\mathrm{x}$ época de coleta.

${ }^{2}$.Teste $\mathrm{F}$ para probabilidade de efeito significativo e discriminatório para os fatores.

$\mathrm{ns}=$ não significativo. Os símbolos $* * \mathrm{e} *$ representam $\mathrm{p}<0,01$ e 0,05 respectivamente.

A porcentagem média de açúcares redutores da cana foi de 0,67 . Os tratamentos que apresentaram menores valores, que demonstram maior maturação, foram os maturadores Etiltrinexapac e Sulfometuron metil, o Boro 150g/ha, o nitrato de potássio e o complexo de nutrientes isolado ou em associação com o maturador (tabela 17).

Tabela 17. Porcentagem de açúcares redutores da cana referente a primeira época de aplicação dos tratamentos.

\begin{tabular}{cc}
\hline Tratamento & Média $^{1}$ \\
\hline Controle & $0,6973 \mathrm{a}$ \\
Orthosulfamuron & $0,6625 \mathrm{abcd}$ \\
Etil-Trinexapac & $0,6671 \mathrm{abc}$ \\
Sulfometuron metil & $0,6405 \mathrm{~cd}$ \\
Sulfometuron metil + Boro 150g/ha & $0,6686 \mathrm{abc}$ \\
$\mathrm{KNO}_{3}$ & $0,6646 \mathrm{abcd}$ \\
Boro 50 g/ha & $0,6876 \mathrm{ab}$ \\
Boro 150 g/ ha & $0,654 \mathrm{bcd}$ \\
Boro 250 g/ ha & $0,6742 \mathrm{abc}$ \\
KNO $_{3}+$ Boro 150 g/ha & $0,6749 \mathrm{abc}$ \\
Complexo de Micronutrientes & $0,6625 \mathrm{abcd}$ \\
Complexo de Micronutrientes + & $0,6969 \mathrm{a}$ \\
Biorregulador & \\
Sulfometuron metil + Complexo de & $0,6274 \mathrm{~d}$ \\
Micronutrientes & \\
Sulfometuron metil + Complexo de & $0,6679 \mathrm{abc}$ \\
Micronutrientes + Biorregulador & \\
\hline
\end{tabular}


Coeficiente de variação: 18,86\%, Desvio Padrão: 0,13, Média:0,67.

${ }^{1}$ Médias seguidas por mesma letra não diferem estatisticamente entre si $(\mathrm{p}<05)$.

Leite et al. (2009), constataram que houve redução nos níveis de açúcares redutores com a aplicação de Etefon, Etil-trinexapac, $\mathrm{KNO}_{3}$ e $\mathrm{KNO}_{3}+$ Boro. A regressão dos teores de açúcares redutores em função das épocas de coleta e sua respectiva representação gráfica da equação encontra-se na figura 22.

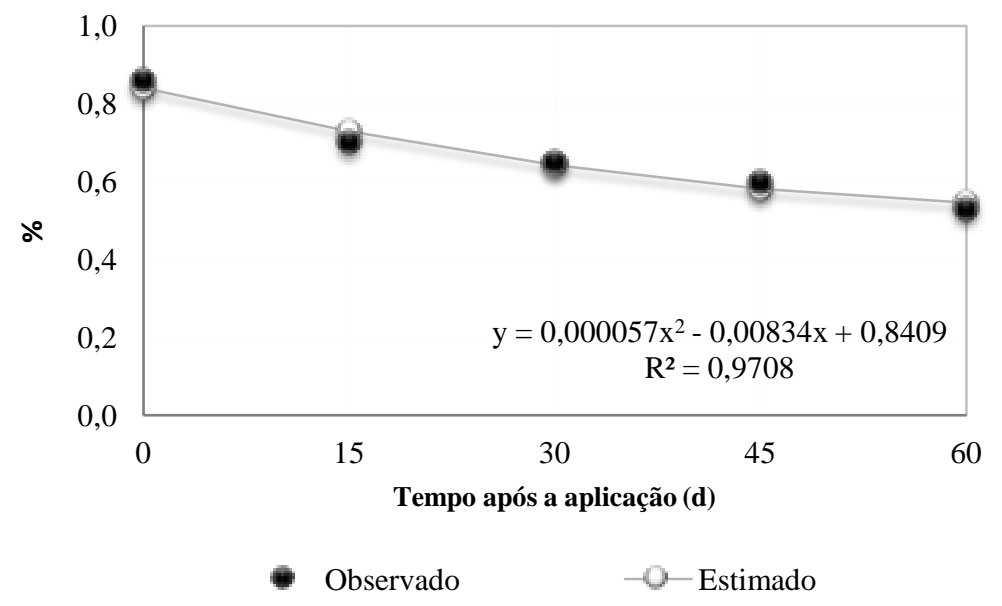

Figura 22. Padrões de variação de açúcares redutores da cana em função do tempo após a aplicação dos tratamentos e equação.

\subsubsection{Açúcar Total Recuperável (ATR)}

Para açúcar total recuperável (tabela 18) verifica-se que houve efeito significativo para tratamento $(\mathrm{p}<0,01)$, época de coleta $(\mathrm{p}<0,01)$ e interação entre tratamento e época de coleta $(\mathrm{p}<0,05)$.

Tabela 18. Fontes de variação e significância do valor $F$ para a variável açúcar total recuperável.

\begin{tabular}{cccc}
\hline Efeito $^{1}$ & Gl & F & Pr $>\mathrm{F}^{2}$ \\
\hline T & 13 & 7,78 & $<0001^{* *}$ \\
E & 4 & 583,81 & $<0001^{* *}$ \\
T x P & 52 & 1,58 & $0,0135^{*}$
\end{tabular}

${ }^{1} \cdot \mathrm{T}=$ efeito de tratamento; $\mathrm{E}=$ efeito de época de coleta; $\mathrm{T} \times \mathrm{E}=$ interação tratamento $\mathrm{x}$ época de coleta.

${ }^{2}$.Teste $\mathrm{F}$ para probabilidade de efeito significativo e discriminatório para os fatores. 
Os símbolos ** e * representam $\mathrm{p}<0,01$ e 0,05 respectivamente.

A partir dos 30 DAA os tratamentos diferiram estatisticamente entre si, sendo que os melhores resultados foram proporcionados pelos três maturadores, pelas associações maturador com boro, ou com complexo de micronutrientes, ou com complexo de micronutrientes + biorregulador, bem como o boro na dose de $150 \mathrm{~g} / \mathrm{ha}$.

Aos 45 DAA os tratamentos etil-trinexapac e sulfometuron metil (isolado ou nas combinações) apresentaram resultados superiores dos demais, resultados que permaneceram até os 60 DAA. Entretanto, aos 60 dias, a maturação natural (controle) não diferiu estatisticamente destes tratamentos. Estes resultados encontram-se na tabela 19.

Tabela 19. Quilogramas de açúcar total recuperável por tonelada de cana referente a primeira época de aplicação dos tratamentos.

\begin{tabular}{|c|c|c|c|c|c|c|c|}
\hline \multirow{2}{*}{ Tratamento } & \multicolumn{7}{|c|}{ Tempo após a aplicação $(\mathrm{d})^{\mathbf{1}}$} \\
\hline & 0 & & 15 & & 30 & 45 & 60 \\
\hline Controle & 98,79 & $\mathrm{a}$ & 115,82 & $\mathrm{a}$ & $120,24 \mathrm{de}$ & 133,13 bcd & 144,4 abc \\
\hline Orthosulfamuron & 106,47 & $\mathrm{a}$ & 116,99 & $\mathrm{a}$ & 126,51 abcd & $131,73 \mathrm{~cd}$ & 142,9 bcd \\
\hline Etil-Trinexapac & 97,04 & a & 115,63 & $\mathrm{a}$ & $131,87 \mathrm{ab}$ & $139,39 \mathrm{ab}$ & $149,7 \mathrm{ab}$ \\
\hline Sulfometuron metil & 103,42 & $\mathrm{a}$ & 116,15 & $\mathrm{a}$ & 133,16 a & $139,18 \mathrm{ab}$ & 151,4 a \\
\hline Sulfometuron metil+Boro $150 \mathrm{~g} / \mathrm{ha}$ & 99,93 & a & 116,42 & a & $131,66 \mathrm{ab}$ & 138,48 abc & 151,2 a \\
\hline $\mathrm{KNO}_{3}$ & 103,74 & a & 118,29 & $\mathrm{a}$ & 125,39 bcd & 133,20 bcd & $142,3 \mathrm{bcd}$ \\
\hline Boro $50 \mathrm{~g} / \mathrm{ha}$ & 104,14 & a & 113,56 & $\mathrm{a}$ & $122,59 \mathrm{cde}$ & $129,63 \mathrm{~d}$ & $139,9 \mathrm{~cd}$ \\
\hline Boro $150 \mathrm{~g} / \mathrm{ha}$ & 103,32 & a & 114,93 & $\mathrm{a}$ & $130,56 \mathrm{ab}$ & $137,84 \mathrm{bc}$ & $141,2 \mathrm{~cd}$ \\
\hline Boro $250 \mathrm{~g} / \mathrm{ha}$ & 101,41 & a & 113,66 & a & $116,58 \mathrm{e}$ & $129,04 \mathrm{~d}$ & $137,1 \mathrm{~d}$ \\
\hline KNO3 + Boro $150 \mathrm{~g} / \mathrm{ha}$ & 102,49 & $\mathrm{a}$ & 115,16 & $\mathrm{a}$ & 125,59 bcd & 135,08 bcd & 143,8 bcd \\
\hline Complexo de Micronutrientes & 108,02 & a & 117,33 & a & 122,27 cde & 132,49 bcd & $139,3 \mathrm{~cd}$ \\
\hline Complexo de Micronutrientes + & & & & & & & \\
\hline Biorregulador & 103,69 & a & 113,80 & a & $120,23 \mathrm{de}$ & $130,10 \mathrm{~d}$ & $141,4 \mathrm{~cd}$ \\
\hline Sulfometuron metil + Complexo & & & & & & & \\
\hline de Micronutrientes & 106,50 & a & 121,62 & $\mathrm{a}$ & $132,30 a b$ & 145,25 a & 151,3 a \\
\hline Sulfometuron metil + Complexo & & & & & & & \\
\hline de Micronutrientes+ & & & & & & & \\
\hline Biorregulador & 104,98 & $\mathrm{a}$ & 115,78 & $\mathrm{a}$ & 128,39 abc & $138,72 \mathrm{ab}$ & $148,6 a b$ \\
\hline
\end{tabular}

Coeficiente de variação: $12,53 \%$. Desvio Padrão: 15,66. Média: 124,97.

${ }^{1}$ Amostragens realizadas aos $0,15,30,45$ e 60 dias após a aplicação dos tratamentos.

${ }^{2} \mathrm{Em}$ cada época de avaliação as letras comparam os tratamentos. Médias seguidas por mesma letra não diferem estatisticamente entre si $(\mathrm{p}<05)$. 
Maschede et al., (2009) avaliando o efeito dos maturadores, ethephon, trinexapacethyl, sulfumeturon-methyl, fluazifop-p-butil e glyphosate, aplicados em 16/04/2007, em cana soca variedade RB86 7515 que os maturadores influenciaram na qualidade tecnológica da cana-de-açúcar, sendo que o glyphosate e o sulfumeturon ,methyl promoveram as maiores produtividades, assim como os índices de Pol e ATR apresentaram incrementos significativos com aplicação de maturadores.

Silva et al., (2010) trabalhando com as variedades PO88-62, RB72454, RB845210, SP83-2847 e SP81-3250 verificaram maior ganho em teor de sacarose após a aplicação dos maturadores foi obtido com o emprego do sulfometuron-metil e o etefon.

Caputo et al., (2008) verificaram que genótipos de maturação precoce IAC89-3124 e IAC91-2195, indicados para colheita entre abril e maio, que os valores médios de ATR se diferenciaram significativamente entre tratamentos aos 42 e 63 DAA.

Galdino (2008) em experimento com a variedade SP81-3250, cana soca de $5^{\circ}$ corte, não verificou efeito dos maturadores e da interação maturadores x épocas, sendo observado apenas efeito significativo das épocas de amostragem.

Segundo Ripoli e Ripoli (2004) para a variável ATR, quanto maior seu teor melhor. Analisando-se estes teores os melhores resultados foram observados aos 60 DAA para todos os tratamentos avaliados.

As regressões dos tratamentos em função das épocas de coleta e suas respectivas representações gráficas das equações encontram-se nas figuras 23, 24 e 25. Houve efeito linear $(\mathrm{p}<0,01)$ das épocas de coleta no teor de açúcar total recuperável para todos os tratamentos, exceto para maturador etil-trinexapac e boro na dose $150 \mathrm{~g} / \mathrm{ha}$ que apresentaram comportamento quadrático $(\mathrm{p}<0,01)$.

O número de dias antecipados pelos tratamentos, aos 30 e 45 dias, utilizando-se como base o ATR do tratamento controle $(30$ dias $=120,24$ e 45 dias $=133,13)$ encontram-se na figura 26. A maior antecipação da industrialização em relação a maturação natural, aos 30 DAA, foi proporcionada pelo tratamento Sulfometuron metil + Complexo de micronutrientes, antecipando a colheita em 15 dias. O B (150 g/ha) apresentou o mesmo comportamento do maturador Sulfometuron metil antecipando a colheita em 11 dias. Aos 45 DAA o tratamento 
Sulfometuron metil na combinação com complexo de micronutrientes antecipou a colheita em 13 dias. Quando utilizado isolado o mesmo antecipou a colheita em 9 dias.

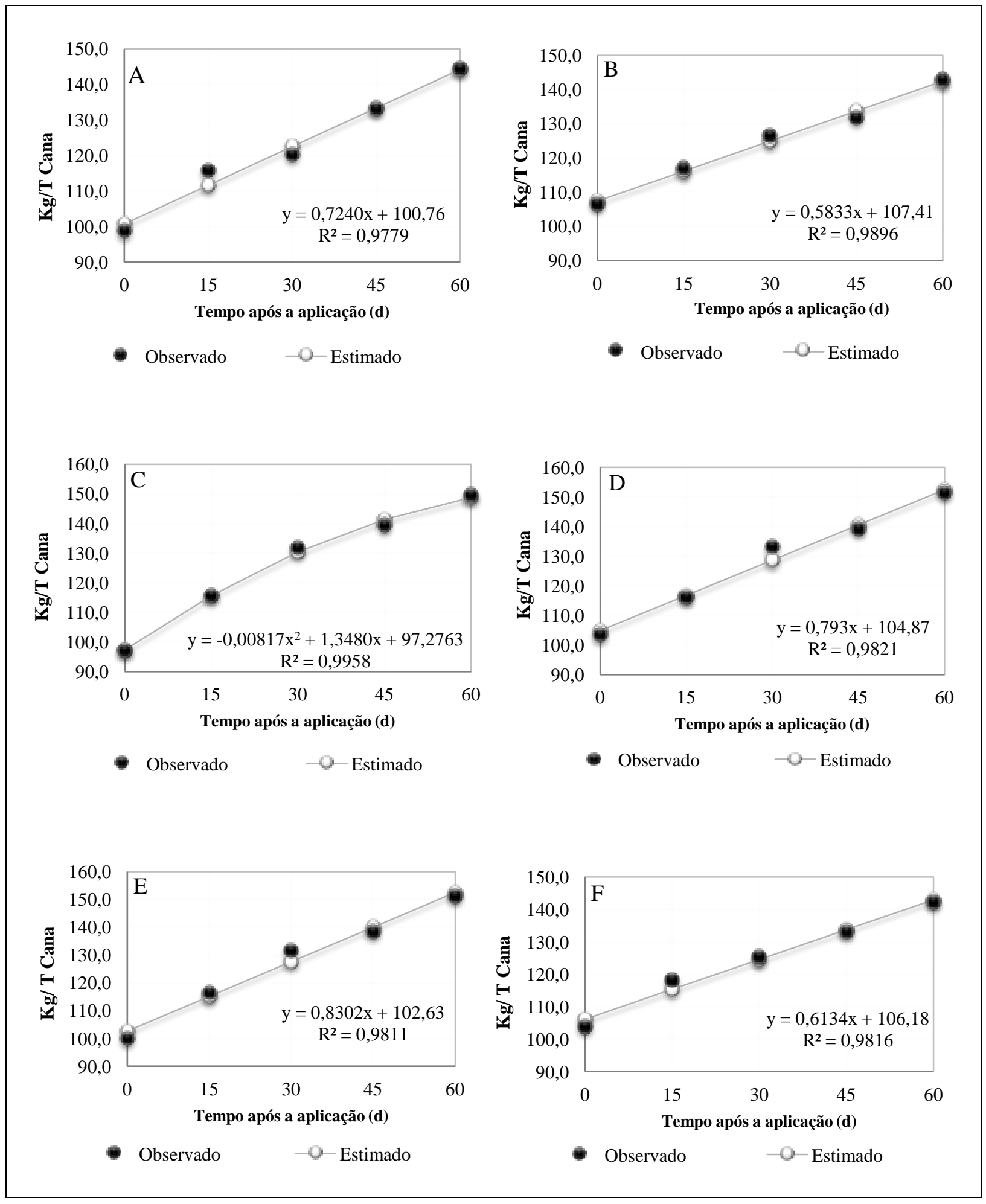

Figura 23 Padrões de variação de ATR da cana em função do tempo após a aplicação dos tratamentos. (A) Controle, (B) Orthosulfamuron, (C) Etil-trinexapac, (D) Sulfometuron metil, (E) Sulfometuron metil + Boro $150 \mathrm{~g} / \mathrm{ha}$ e (F) Nitrato de Potássio $(\mathrm{p}<0,01)$. 


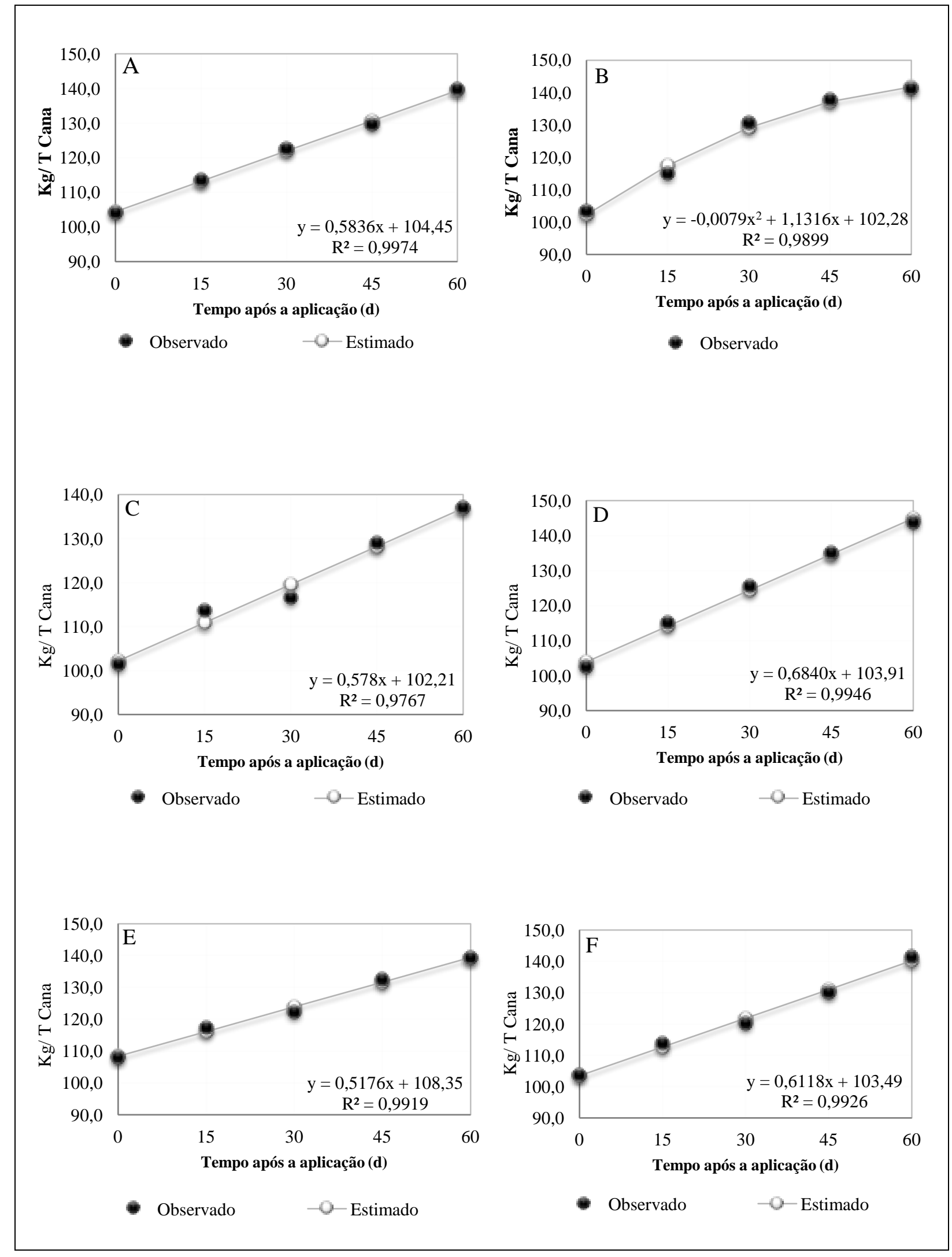

Figura 24. Padrões de variação de ATR da cana em função do tempo após a aplicação dos tratamentos. (A) Boro $50 \mathrm{~g} / \mathrm{ha}$, (B) Boro $150 \mathrm{~g} / \mathrm{ha}$, (C) Boro $250 \mathrm{~g} / \mathrm{ha}$, (D) Nitrato de Potássio + Boro $150 \mathrm{~g} / \mathrm{ha}$, (E) Complexo de micronutrientes, $(\mathrm{F})$ Complexo de micronutrientes + Biorregulador $(\mathrm{p}<0,01)$. 


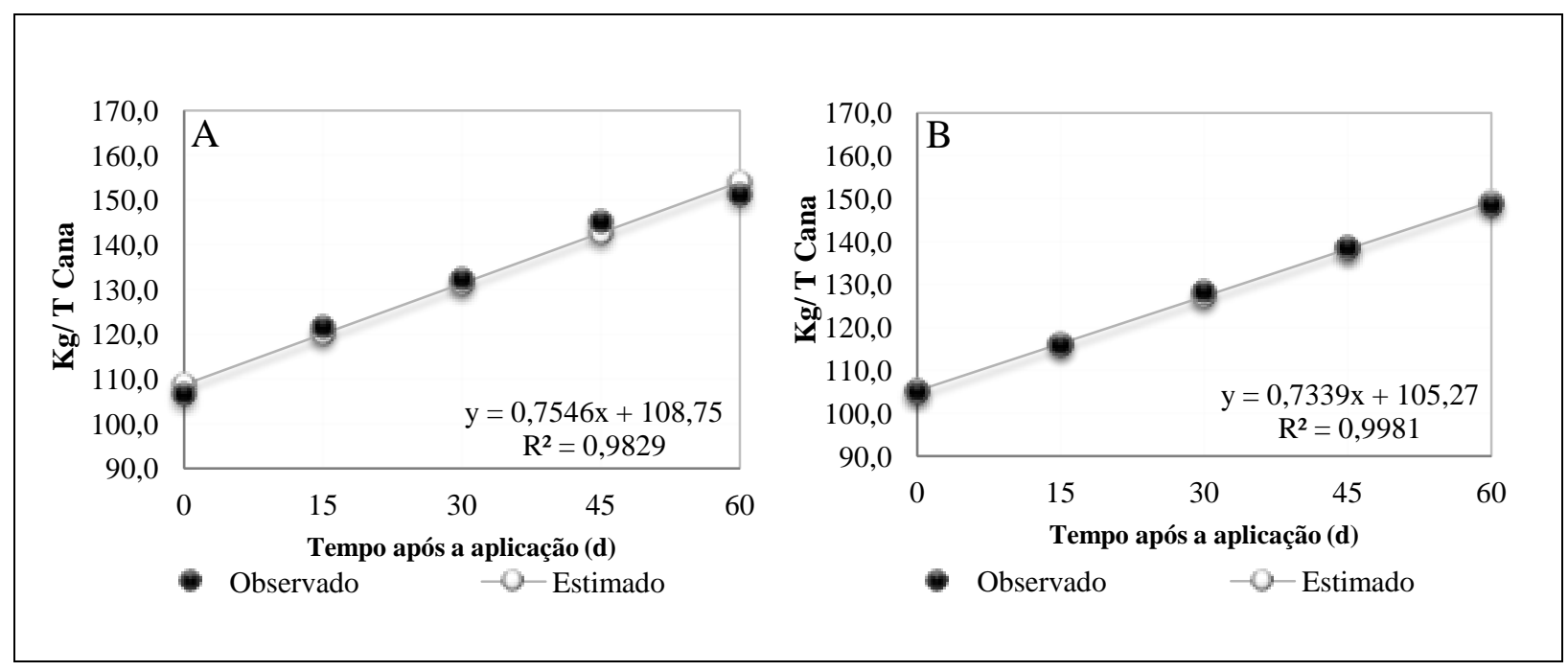

Figura 25. Padrões de variação de ATR da cana em função do tempo após a aplicação dos tratamentos. (A) Sulfometuron metil + Complexo de micronutrientes, (B) Sulfometuron metil + Complexo de micronutrientes + Biorregulador $(\mathrm{p}<0,01)$.

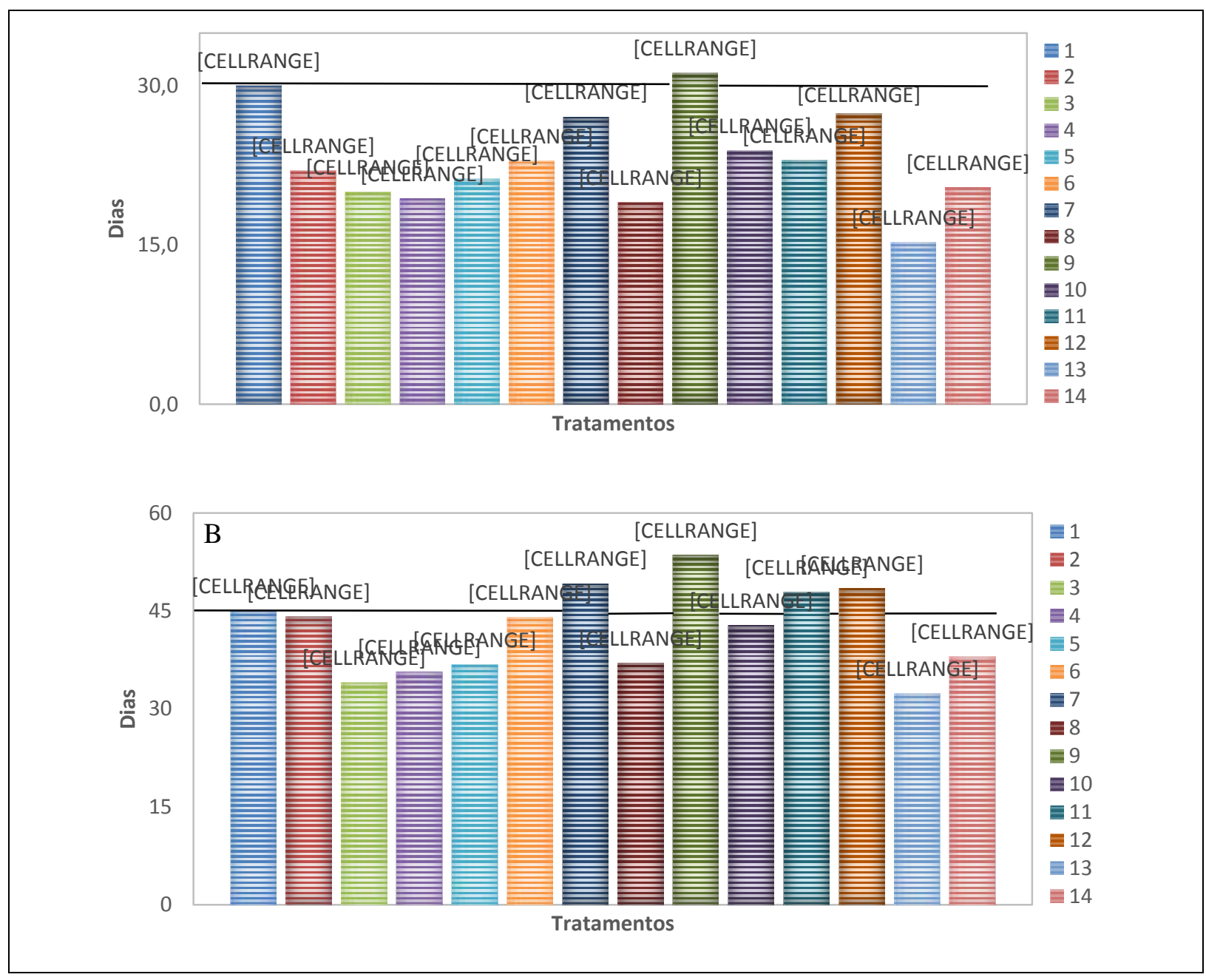

Figura 26. Número de dias antecipados pelos tratamentos em relação ao controle, aos 30 (a) e 45 dias (b). (1) Controle, (2) Orthosulfamuron, (3) Etil-Trinexapac, (4) Sulfometuron metil, (5) Sulfometuron 
metil/ Boro 150 g/ha, (6) Nitrato de Potássio, (7) Boro 50 g/ha, (8) Boro 150 g/ha, (9) Boro 250 g/ha, (10) Nitrato de Potássio + Boro $50 \mathrm{~g} / \mathrm{ha}$, (11) Complexo de micronutrientes, (12) Complexo de Micronutriente + Biorregulador, (13) Sulfometuron metil + Complexo de micronutrientes, (14) Sulfometuron metil + Complexo de micronutrientes + Biorregulador

\subsection{Segunda época de aplicação}

\subsubsection{Sólidos solúveis - Brix \%}

Para o teor de sólidos solúveis - Brix\% na segunda época de aplicação houve efeito significativo $(\mathrm{p}<0,01)$ apenas para época de coleta. Não ocorreram efeitos de tratamento e interação tratamento x época de coleta (tabela 20).

Tabela 20. Fontes de variação e significância do valor F para a variável brix.

\begin{tabular}{cccc}
\hline Efeito $^{1}$ & Gl & $\mathrm{F}$ & $\mathrm{Pr}>\mathrm{F}^{2}$ \\
\hline $\mathrm{T}$ & 13 & 1,47 & $0,1327^{\mathrm{ns}}$ \\
$\mathrm{E}$ & 4 & 384,03 & $<0001^{* *}$ \\
$\mathrm{~T}$ x E & 52 & 0,82 & $0,7962^{\mathrm{ns}}$
\end{tabular}

${ }^{1} \mathrm{~T}=$ efeito de tratamento; $\mathrm{E}=$ efeito de época de coleta; $\mathrm{T} \times \mathrm{E}=$ interação tratamento $\mathrm{x}$ época de coleta.

${ }^{2}$ Teste $\mathrm{F}$ para probabilidade de efeito significativo e discriminatório para os fatores. ns $=$ não significativo. $\mathrm{O}$ símbolo $* *$ representa $\mathrm{p}<0,01$.

A porcentagem de brix foi crescente ao longo do tempo, sendo as porcentagens estatisticamente iguais aos 45 e 60 DAA (tabela 21). Este resultado pode demonstrar que após os 60 dias provavelmente ocorreria uma estabilização nos teores, ou uma possível queda, pelas características de maturação da variedade.

Admitindo-se a porcentagem de brix de $18 \%$ para a colheita da cana, esta poderia ser realizada quinze dias após o início do experimento.

Tabela 21.Porcentagem de brix referente a segunda época de aplicação dos tratamentos.

\begin{tabular}{ccc}
\hline Época & Médias $^{1}$ & \\
& & \\
\hline 0 & 16,1034 & $\mathrm{~d}$ \\
15 & 18,2626 & $\mathrm{c}$
\end{tabular}




$\begin{array}{lll}30 & 18,6976 & \mathrm{~b} \\ 45 & 19,4357 & \mathrm{a} \\ 60 & 19,5859 & \mathrm{a}\end{array}$

Coeficiente de variação: $7,50 \overline{\% \text {. Desvio Padrão: } 1,38 \text {. Média: }}$ 18,38.

${ }^{1}$ Médias seguidas por mesma letra não diferem estatisticamente entre si $(\mathrm{p}<01)$.

O padrão de variação do Brix da cana em função do tempo após a aplicação dos tratamentos encontra-se na figura 27. Houve efeito quadrático $(\mathrm{p}<0,01)$ das épocas de coleta sobre a porcentagem de Brix.

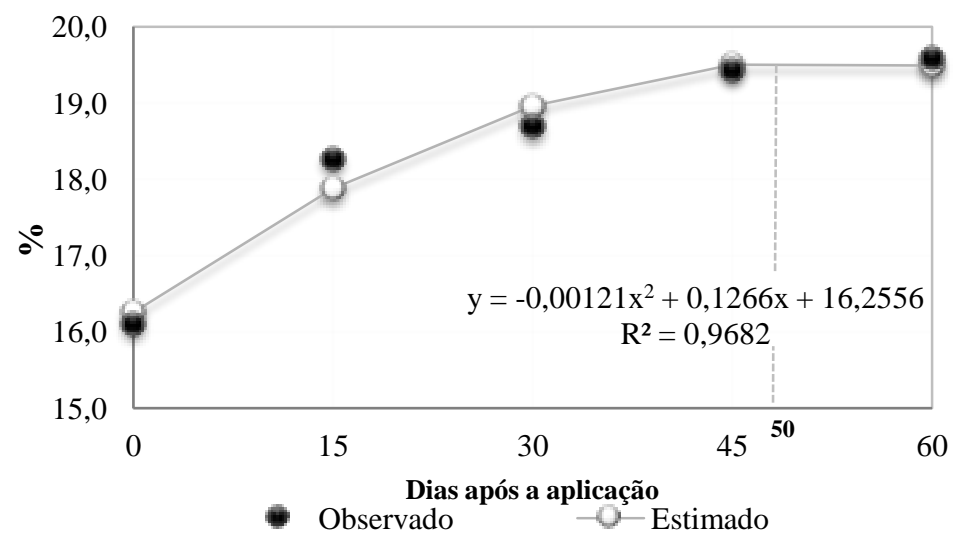

Figura 27. Padrão de variação do brix em função do tempo após a aplicação dos tratamentos e equação e $\mathbf{r}^{2}(\mathrm{p}<0,01)$. ...-. Tempo (dias) para atingir o nível máximo Brix\%.

A maior porcentagem de sólidos solúveis foi verificada aos 50 dias após a aplicação dos tratamentos.

Observa-se para o Brix, assim como será demonstrado para as demais variáveis, comportamentos distintos analisando-se as épocas de aplicação. $\mathrm{Na}$ aplicação ocorrida em março houve efeito dos tratamentos sob todas as variáveis analisadas. Entretanto, na aplicação ocorrida em abril, este efeito não foi observado. Esta diferença ocorrida na segunda época estudada pode ser explicada por fatores abióticos, principalmente pela ocorrência de precipitações e fortes ventos que promoveram o acamamento da área experimental.

Na figura 3 verifica-se também que no mês posterior a primeira época de aplicação dos tratamentos a precipitação foi de aproximadamente $92,6 \mathrm{~mm}$ contrastando com os $289 \mathrm{~mm}$ posteriores a segunda época de aplicação. A ocorrência desta alta taxa de chuva pode ter 
causado a retomada do metabolismo de crescimento da cana-de-açúcar resultando em uma baixa performance dos produtos utilizados.

\subsubsection{Fibra}

Os teores de fibra não foram influenciados pelos tratamentos, bem como não houve interação entre tratamento e época de coleta. Houve efeito significativo apenas para época de coleta, com $\mathrm{p}<0,01$ (tabela 22).

Tabela 22. Fontes de variação e significância do valor F para a variável fibra.

\begin{tabular}{cccc}
\hline Efeito $^{1}$ & Gl & F & $\operatorname{Pr}>\mathrm{F}^{2}$ \\
\hline T & 13 & 1,19 & $0,2877^{\text {ns }}$ \\
E & 4 & 33,1 & $<0001^{* *}$ \\
T x E & 52 & 0,86 & $0,7287^{\text {ns }}$
\end{tabular}

${ }^{1} \cdot \mathrm{T}=$ efeito de tratamento; $\mathrm{E}=$ efeito de época de coleta; $\mathrm{T} \times \mathrm{E}=$ interação tratamento $\mathrm{x}$ época de coleta.

${ }^{2}$.Teste $\mathrm{F}$ para probabilidade de efeito significativo e discriminatório para os fatores.

${ }^{2}$. ns $=$ não significativo. $\mathrm{O}$ símbolo $* *$ representa $\mathrm{p}<0,01$.

Os teores de fibra foram crescentes, atingiram o ponto máximo aos 30 DAA e decresceram após este período (tabela 23). Aos 30 e 45 dias após a aplicação estes teores foram estatisticamente iguais, decrescendo após este período.

Tabela 23. Porcentagem de fibra referente a segunda época de aplicação dos tratamentos.

\begin{tabular}{ccc}
\hline Época & Médias $^{1}$ \\
\hline 0 & 9,3549 & $\mathrm{c}$ \\
15 & 9,7443 & $\mathrm{~b}$ \\
30 & 9,9553 & $\mathrm{a}$ \\
45 & 9,9437 & $\mathrm{a}$ \\
60 & 9,7685 & $\mathrm{~b}$
\end{tabular}

Coeficiente de variação: $3,92 \%$. Desvio Padrão: 0,38 . Média: 9,74 .

${ }^{1}$ Médias seguidas por mesma letra não diferem estatisticamente entre si $(p<01)$. 
O padrão de variação de fibra em função do tempo após a aplicação dos tratamentos encontra-se na figura 28.

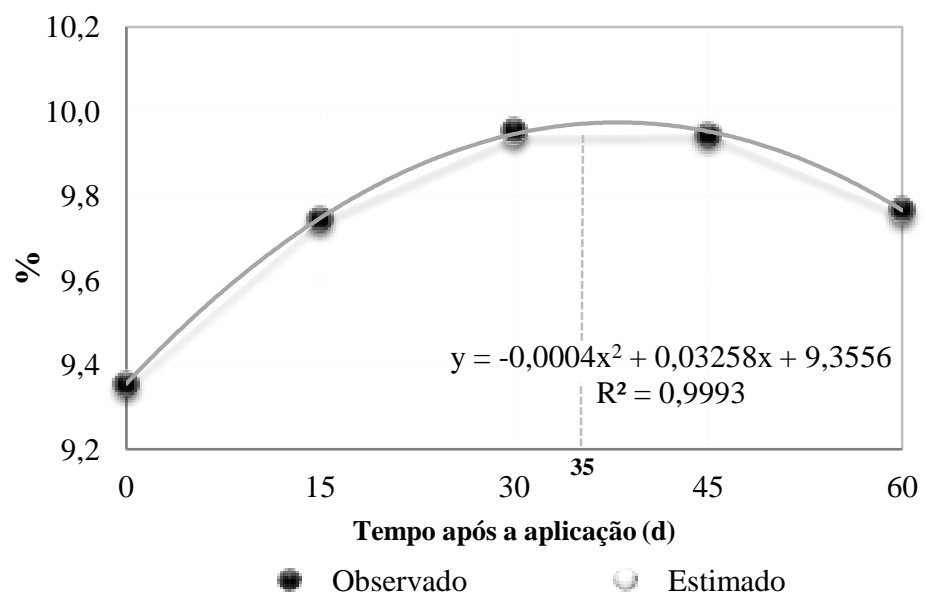

Figura 28. Padrão de variação de fibra em função do tempo após a aplicação dos tratamentos, equação e $\mathrm{r}^{2}$. $(\mathrm{p}<0,01)$. . Tempo (dias) para atingir o nível máximo de fibra.

Em experimento realizado por Viana et al. (2008) com o avanço da maturação, ocorreram aumentos para fibra\% com intensidades diferentes para cada maturador. O ponto máximo de fibra foi verificado aos 30 dias após o início do experimento.

Almeida et al. (2005), trabalhando com cana soca de segundo corte, variedade SP813250, concluíram que a aplicação dos maturadores não proporcionou aumento significativo no teor de fibras em relação a testemunha nas épocas analisadas, resultados que corroboram, com os alcançados, nos quais foram observados apenas efeitos de época de coleta.

Os teores de fibra foram diferentes entre época de aplicação sendo que na primeira época foram crescentes até os 60 DAA apresentaram resposta linear. Na segunda época, o pico de \% fibra ocorreu aos 30 dias, com decréscimo nas coletas posteriores.

\subsubsection{Pol do caldo}

Para a variável pol do caldo houve efeito significativo apenas para época de coleta $(\mathrm{p}<0,01)$, como pode ser observado na tabela 24 .

Tabela 24. Fontes de variação e significância do valor F para a variável pol do caldo.

\begin{tabular}{llll}
\hline Efeito & Gl & $\mathrm{F}$ & $\mathrm{Pr}>\mathrm{F}$ \\
\hline
\end{tabular}




$\begin{array}{cccc}\mathrm{T} & 13 & 0,58 & 0,8716^{\mathrm{ns}} \\ \mathrm{E} & 4 & 171,05 & <0001^{* *} \\ \mathrm{Tx} \mathrm{E} & 52 & 1,18 & 0,2058^{\text {ns }}\end{array}$

${ }^{1} \mathrm{~T}=$ efeito de tratamento; $\mathrm{E}=$ efeito de época de coleta; $\mathrm{T} \times \mathrm{E}=$ interação tratamento $\mathrm{x}$ época de coleta.

${ }^{2}$ Teste $\mathrm{F}$ para probabilidade de efeito significativo e discriminatório para os fatores.

ns = não significativo. $\mathrm{O}$ símbolo $* *$ representa $\mathrm{p}<0,01$.

O comportamento da variável pol do caldo, bem como o brix, foi crescente no decorrer das épocas de amostragem. A maior porcentagem de pol do caldo foi verificada aos 60 DAA, não diferindo estatisticamente dos 45 DAA, ou seja, houve uma estabilização na quantidade de pol a partir dos 45 dias. Ao longo do experimento, o aumento de pol do caldo foi de $4,25 \%$ (tabela 25 e figura 29 ).

Tabela 25. Porcentagem de pol do caldo referente a segunda época de aplicação dos tratamentos. Médias seguidas por mesma letra não diferem estatisticamente entre si $(p<01)$.

\begin{tabular}{ccc}
\hline Época & Médias $^{1}$ & \\
& & \\
\hline 0 & 13,353 & $\mathrm{~d}$ \\
15 & 15,5777 & $\mathrm{c}$ \\
30 & 16,4435 & $\mathrm{~b}$ \\
45 & 17,1624 & $\mathrm{a}$ \\
60 & 17,6042 & $\mathrm{a}$
\end{tabular}

${ }^{1}$ Médias seguidas por mesma letra não diferem estatisticamente entre si $(p<01)$.

Coeficiente de variação: 11,28\%. Desvio Padrão: 1,80. Média: 15,99.

O aumento gradual da Pol do caldo no decorrer das amostragens está relacionado a maturação natural da cana. Considerando-se a cana-de-açúcar com condição de colheita quando atinge 14,4\% de Pol, aos 15 dias após o início do experimento poderia ser realizado o corte e envio a indústria.

O comportamento da pol do caldo seguiu ajuste quadrático, com $\mathrm{p}<0,01$, como demonstrado na figura 29. 


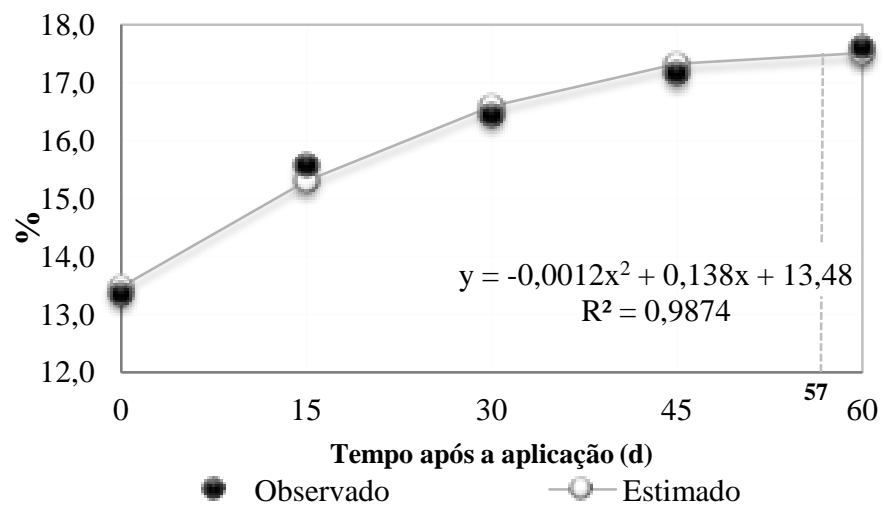

Figura 29. Padrão de variação de pol do caldo em função do tempo após a aplicação dos tratamentos, equação e $\mathrm{r}^{2}(\mathrm{p}<0,01)$. ..... Tempo (dias) para atingir o nível máximo de pol do caldo.

O nível máximo de pol do caldo foi verificado aos 57 dias após o início do período experimental.

Leite et. al (2009) utilizando Glifosato e Sulfometuron metil em início de safra, e trabalhando com a variedade utilizada neste experimento, sob condições climáticas favoráveis ao desenvolvimento vegetativo constataram que os maturadores permitiram antecipar a colheita em 27 e 23 dias respectivamente, em relação à testemunha, resultados distintos dos verificados para esta época de aplicação. De acordo com James (1999), o clima tem grande influência sobre a qualidade da cana, e pode ou não favorecer o acúmulo de sacarose, o que provavelmente pode ter ocorrido.

\subsubsection{Pol da cana}

O efeito de época de coleta sobre a variável pol da cana foi significativo ( $\mathrm{p}<0,01)$. Não houve efeito de tratamento e interação tratamento x época de coleta (tabela 34). Como pode ser visto na tabela 26.

Tabela 26. Fontes de variação e significância do valor F para a variável pol da cana.

\begin{tabular}{cccl}
\hline Efeito $^{1}$ & Gl & F & Pr $>F^{2}$ \\
\hline T & 13 & 0,64 & $0,8219^{\text {ns }}$ \\
E & 4 & 170,46 & $<0001^{* *}$ \\
T x E & 52 & 1,23 & $0,159^{\text {ns }}$ \\
\hline
\end{tabular}


${ }^{1} \mathrm{~T}$ = efeito de tratamento; $\mathrm{E}=$ efeito de época de coleta; $\mathrm{T} \times \mathrm{E}=$ interação tratamento $\mathrm{x}$ época de coleta.

${ }^{2}$ Teste $\mathrm{F}$ para probabilidade de efeito significativo e discriminatório para os fatores. ns $=$ não significativo. $\mathrm{O}$ símbolo $* *$ representa $\mathrm{p}<0,01$.

A porcentagem de pol da cana foi crescente no decorrer das épocas, atingindo maior nível aos 60 DAA. Houve incremento de 3,65 \% no teor de pol da cana durante o período experimental. Estes resultados podem ser verificados na tabela 27.

Tabela 27. Porcentagem de pol da cana referente a segunda época de aplicação dos tratamentos.

\begin{tabular}{ccc}
\hline Período & \multicolumn{2}{c}{ Médias } \\
& & \\
\hline 0 & 11,8309 & $\mathrm{e}$ \\
15 & 13,7114 & $\mathrm{~d}$ \\
30 & 14,4189 & $\mathrm{c}$ \\
45 & 15,0553 & $\mathrm{~b}$ \\
60 & 15,4875 & $\mathrm{a}$
\end{tabular}

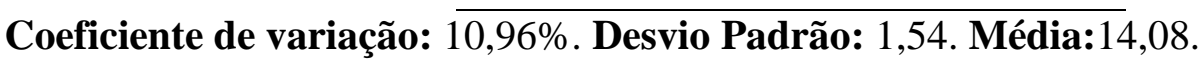

${ }^{1}$ Médias seguidas por mesma letra não diferem estatisticamente entre si $(p<01)$.

Além da influência das condições climáticas, ao analisar-se a curva de maturação da variedade estudada nota-se os maiores incrementos em PC\% entre os meses de maio a julho. A aplicação da segunda época no final de abril pode não ter proporcionado resultados significativos pelo fato de que neste período o incremento de PC\% pela maturação natural ser elevado.

Em condições de umidade, há um aumento na atividade de microorganismos, refletindo em aumento da mineralização da matéria orgânica e proporcionando aumento na disponibilidade de boro, o que pode ter contribuído para que não ocorressem efeitos significativos do tratamento.

Segundo Carlin, Silva e Rossetto (2008) trabalhando com variedades tutoradas e não tutoradas observou houve diferença de Pol entre variedades após o tombamento indicando comportamentos diferentes das variedades quanto a esse atributo de maturação no período.

Em relação as épocas de coleta e a porcentagem de pol da cana houve efeito 
quadrático (figura 30) atingindo ponto máximo aos 60 após o início do experimento, dentre as épocas analisadas.

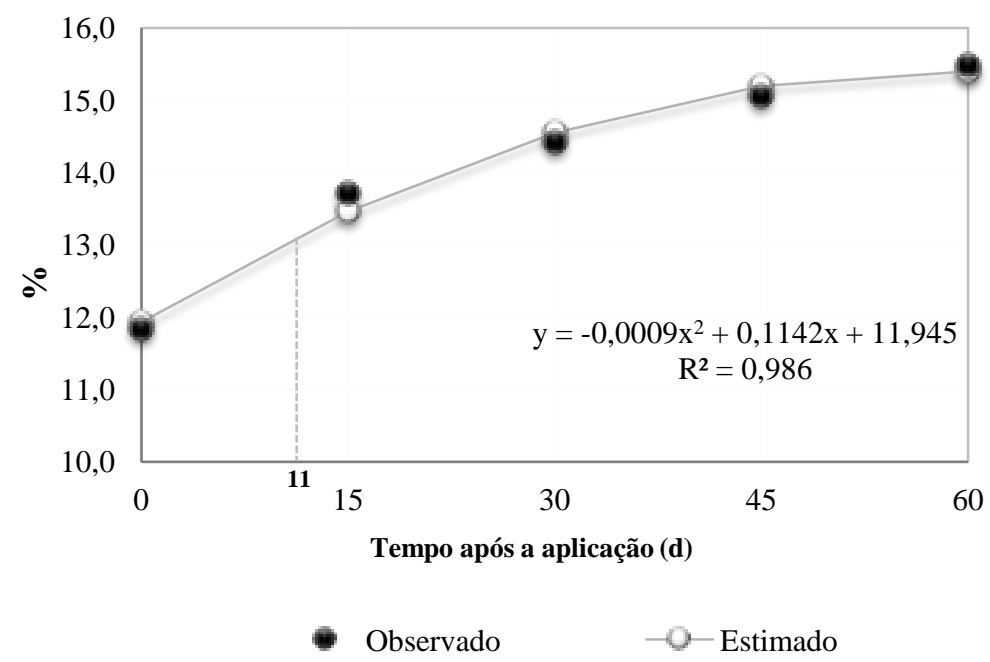

Figura 30. Padrão de variação do pol da cana em função do tempo após a aplicação dos tratamentos, equação e $\mathrm{r}^{2}$. $(\mathrm{p}<0,01)$. . Tempo (dias) para atingir o nível de pol da cana $=$ $13 \%$.

Para a variável pol da cana, aos 11 dias após o período experimental, os teores já estavam dentro dos mínimos indicados para a industrialização da cana-de-açúcar.

\subsubsection{Pureza}

Analisando-se a pureza, houve efeito significativo para época de coleta $(\mathrm{p}<0,01)$. Não houve efeito significativo para tratamentos e interação tratamento x época de coleta (tabela 28).

Tabela 28. Fontes de variação e significância do valor F para a variável pureza.

\begin{tabular}{cccc}
\hline Efeito $^{1}$ & Gl & F & Pr $>F^{2}$ \\
\hline T & 13 & 0,83 & $0,6279^{\text {ns }}$ \\
E & 4 & 23,45 & $<0001^{* *}$ \\
T x E & 52 & 1,38 & $0,0592^{\text {ns }}$
\end{tabular}

${ }^{1} . \mathrm{T}=$ efeito de tratamento; $\mathrm{E}=$ efeito de época de coleta; $\mathrm{T} \times \mathrm{E}=$ interação tratamento $\mathrm{x}$ época de coleta.

${ }^{2}$.Teste $\mathrm{F}$ para probabilidade de efeito significativo e discriminatório para os fatores. ns $=$ não significativo. $\mathrm{O}$ símbolo $* *$ representa $\mathrm{p}<0,01$. 
Os níveis de pureza aumentaram 6,99\% no decorrer das épocas de amostragem. Os maiores níveis foram verificados aos 60 DAA. Porém, a partir dos 30 DAA, as épocas não diferiram estatisticamente entre si. Sabendo-se que a pureza da cana é maior na cana madura quando comparada com a cana verde, verificou-se o amadurecimento da mesma durante o período experimental (tabela 29).

Tabela 29. Porcentagem de pureza referente a segunda época de aplicação dos tratamentos. Médias seguidas por mesma letra não diferem estatisticamente entre si $(\mathrm{p}<01)$.

\begin{tabular}{ccr}
\hline Época & Médias & \\
\cline { 1 - 2 } 0 & 82,8992 & $\mathrm{c}$ \\
15 & 85,3001 & $\mathrm{~b}$ \\
30 & 87,9515 & $\mathrm{a}$ \\
45 & 88,4125 & $\mathrm{a}$ \\
60 & 89,8938 & $\mathrm{a}$
\end{tabular}

Coeficiente de variação: 5,79\%. Desvio Padrão: 5,03. Média:86,88.

${ }^{1}$ Médias seguidas por mesma letra não diferem estatisticamente entre si $(p<01)$.

César e Silva (1993) classificaram as variedades em relação a pureza em ricas e pobres. Uma variedade rica contém pureza do caldo superior a $85 \%$, média com pureza superior a $82 \%$ e pobre com pureza inferior a esse valor. Segundo esta classificação, a variedade utilizada é considerada como rica pois atingiu 89,9\% de pureza no final do período experimental.

Houve efeito linear crescente em relação a época de coleta $(\mathrm{p}<0,01)$ para a variável pureza, como pode-se verificar na figura 31. 


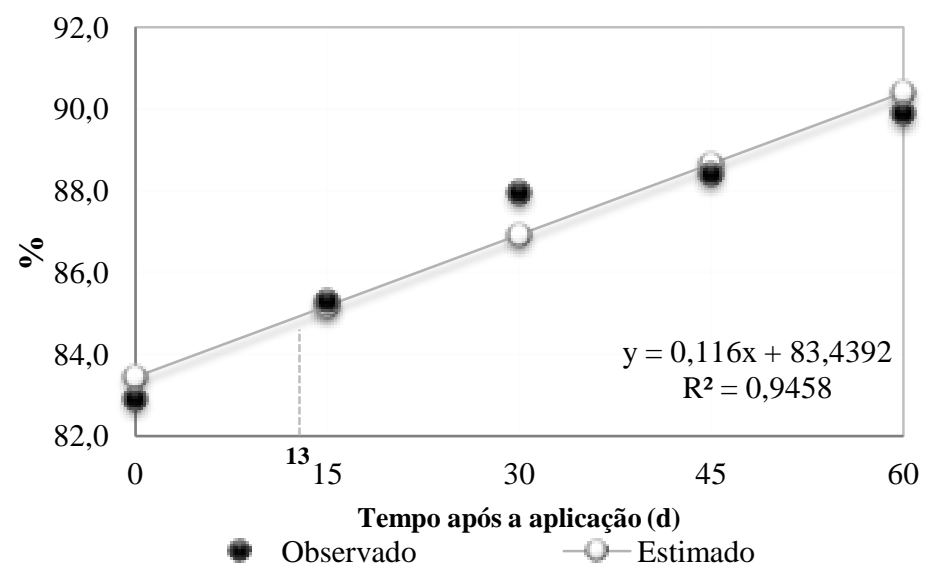

Figura 31. Padrão de variação de pureza em função do tempo após a aplicação dos tratamentos, equação e $r^{2}(p<0,01)$. ..... Tempo (dias) para atingir o nível de pureza $=85 \%$.

Nesta época experimental, aos 13 dias após o início do experimento, a cana-de-açúcar atingiu o patamar mínimo indicado para a industrialização de $85 \%$.

\subsubsection{Açúcares redutores do caldo}

Para açúcares redutores do caldo houve efeito significativo apenas para época de época de coleta $(\mathrm{p}<0,01)$, como demonstrado na tabela 30 .

Tabela 30. Fontes de variação e significância do valor F para a variável açúcares redutores do caldo

\begin{tabular}{cccc}
\hline Efeito $^{1}$ & Gl & F & Pr $>\mathrm{F}^{2}$ \\
\hline T & 13 & 0,83 & $0,6242^{\text {ns }}$ \\
E & 4 & 23,49 & $<0001^{* *}$ \\
T x E & 52 & 1,39 & $0,0587^{\text {ns }}$
\end{tabular}

${ }^{1} \mathrm{~T}=$ efeito de tratamento; $\mathrm{E}=$ efeito de época de coleta; $\mathrm{T} \times \mathrm{E}=$ interação tratamento $\mathrm{x}$ época de coleta.

${ }^{2}$ Teste $\mathrm{F}$ para probabilidade de efeito significativo e discriminatório para os fatores.

ns $=$ não significativo. $\mathrm{O}$ símbolo $* *$ representa $\mathrm{p}<0,01$.

Analisando-se as épocas de coleta, verifica-se que houve decréscimo de 0,24\% nos teores de açúcares redutores do caldo durante o período experimental. A maior redução ocorreu entre os 15 e 30 DAA $(0,09 \%)$. Houve estabilização dos teores após os 30 dias (tabela 31). Sendo os teores máximos de $1 \%$, os resultados alcançados ficaram dentro dos limites durante todas as épocas de coleta (tabela 31). 
Tabela 31. Porcentagem de açúcares redutores referentes a segunda época de aplicação dos tratamentos.

\begin{tabular}{ccc}
\hline Período & Médias $^{1}$ & \\
& & \\
\hline 0 & 0,7976 & $\mathrm{a}$ \\
15 & 0,7152 & $\mathrm{~b}$ \\
30 & 0,6243 & $\mathrm{c}$ \\
45 & 0,6079 & $\mathrm{c}$ \\
60 & 0,5576 & $\mathrm{c}$
\end{tabular}

Coeficiente de variação: $26,13 \%$. Desvio Padrão: 0,17. Média:0,66.

${ }^{1}$ Médias seguidas por mesma letra não diferem estatisticamente entre si $(p<01)$.

Os açúcares redutores apresentaram comportamento linear descendente em relação as épocas estudadas, como se verifica na figura 32, o que indica que o processo de maturação estava ocorrendo.

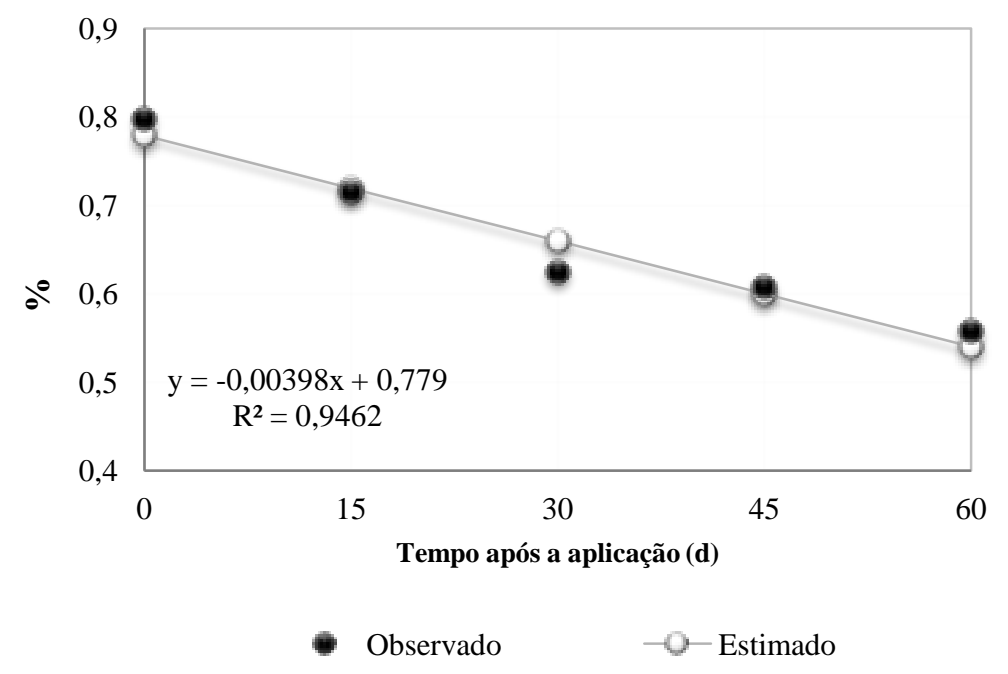

Figura 32. Padrão de variação de açúcares redutores do caldo em função do tempo após a aplicação dos tratamentos, equação e $\mathrm{r}^{2}(\mathrm{p}<0,01)$.

\subsubsection{Açúcares redutores da cana}

Para os açúcares redutores da cana ocorreu efeito significativo apenas para época de coleta $(\mathrm{p}<0,01)($ tabela 32). 
Tabela 32. Fontes de variação e significância do valor F para a variável açúcares redutores da cana.

\begin{tabular}{cccc}
\hline Efeito $^{1}$ & Gl & $\mathrm{F}$ & $\mathrm{Pr}>\mathrm{F}^{2}$ \\
\hline $\mathrm{T}$ & 13 & 0,81 & $0,6508^{\mathrm{ns}}$ \\
$\mathrm{E}$ & 4 & 25 & $<0001^{* *}$ \\
Tx E & 52 & 1,38 & $0,0629^{\mathrm{ns}}$
\end{tabular}

${ }^{1} \mathrm{~T}=$ efeito de tratamento; $\mathrm{E}=$ efeito de época de coleta; $\mathrm{T} \times \mathrm{E}=$ interação tratamento $\mathrm{x}$ época de coleta.

${ }^{2}$ Teste $\mathrm{F}$ para probabilidade de efeito significativo e discriminatório para os fatores. ns $=$ não significativo. $\mathrm{O}$ símbolo $* *$ representa $\mathrm{p}<0,01$.

As porcentagens de açúcares redutores após 30 DAA mantiveram estatisticamente iguais, com uma ligeira queda. A média do período foi de 0,58 (tabela 33).

Tabela 33. Porcentagem de açúcares redutores (cana) referente a segunda época de aplicação dos tratamentos. Médias seguidas por mesma letra não diferem estatisticamente entre si $(\mathrm{p}<01)$.

\begin{tabular}{cll}
\hline Período & \multicolumn{2}{c}{ Médias } \\
\\
\hline 0 & 0,7068 & $\mathrm{a}$ \\
15 & 0,6296 & $\mathrm{~b}$ \\
30 & 0,5479 & $\mathrm{c}$ \\
45 & 0,5331 & $\mathrm{c}$ \\
60 & 0,4907 & $\mathrm{c}$
\end{tabular}

Coeficiente de variação: $26, \overline{16 \%}$. Desvio Padrão: 0,15. Média:0,58.

Os açúcares redutores da cana apresentaram comportamento linear descendente em relação as épocas estudadas, como se verifica na figura 33. 


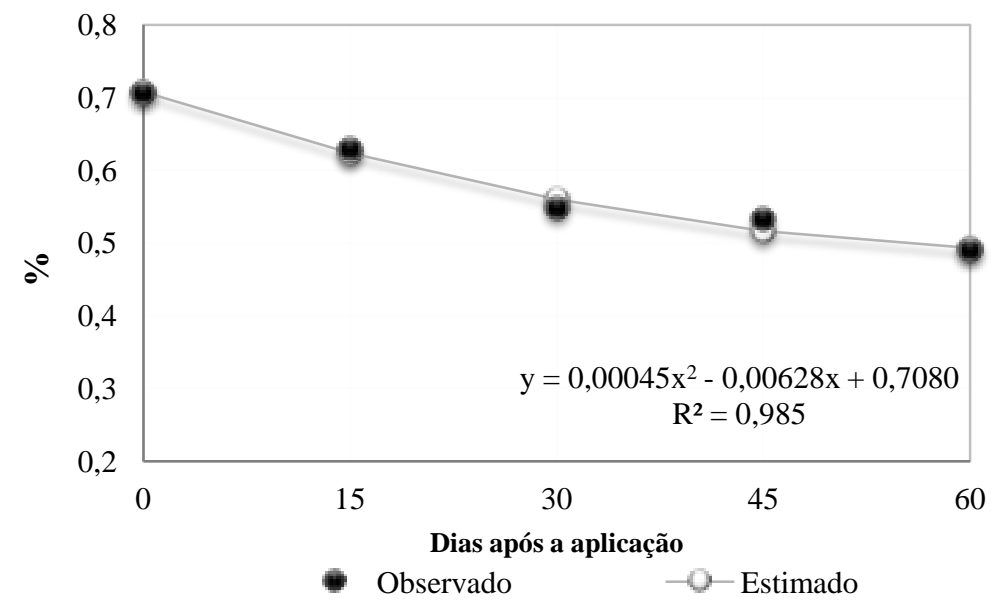

Figura 33. Padrão de variação de açúcares redutores do caldo em função do tempo após a aplicação dos tratamentos, equação e $\mathrm{r}^{2}$. ( $\left.\mathrm{p}<0,01\right)$.

\subsubsection{Açúcar Total Recuperável (ATR)}

Assim como as demais variáveis, para açúcar total recuperável, não ocorreram efeitos de tratamentos e interação tratamento x época de coleta. Verificou-se apenas efeito de época, $\mathrm{p}<0,01$ (Tabela 34).

Tabela 34. Fontes de variação e significância do valor $F$ para a variável açúcar total recuperável.

\begin{tabular}{cccc}
\hline Efeito $^{1}$ & Gl & F & Pr $>F^{2}$ \\
\hline T & 13 & 0,64 & $0,8205^{\text {ns }}$ \\
E & 4 & 200,65 & $<0001^{* *}$ \\
T x E & 52 & 1,19 & $0,1973^{\text {ns }}$
\end{tabular}

${ }^{1} \mathrm{~T}=$ efeito de tratamento; $\mathrm{E}=$ efeito de época de coleta; $\mathrm{T} \times \mathrm{E}=$ interação tratamento $\mathrm{x}$ época de coleta.

${ }^{2}$ Teste $\mathrm{F}$ para probabilidade de efeito significativo e discriminatório para os fatores. ns $=$ não significativo. $\mathrm{O}$ símbolo $* *$ representa $\mathrm{p}<0,01$

A maior produção de ATR foi verificada aos 59 dias após o início do experimento. O aumento durante o período experimental foi de $32,88 \mathrm{Kg}$ de ATR por tonelada de cana, e a média de produção igual a 139,38 (figura 34). 
Tabela 35. Quilogramas de açúcar total recuperável por tonelada de cana referente a segunda época de aplicação dos tratamentos.

\begin{tabular}{ccc}
\hline Período & Médias & \\
\hline 0 & 119,1 & $\mathrm{e}$ \\
15 & 136,32 & $\mathrm{~d}$ \\
30 & 142,33 & $\mathrm{c}$ \\
45 & 148,23 & $\mathrm{~b}$ \\
60 & 151,98 & $\mathrm{a}$
\end{tabular}

Coeficiente de variação: 9,74\%. Desvio Padrão: 13,57. Média: 139,38 .

${ }^{1}$ Médias seguidas por mesma letra não diferem estatisticamente entre si $(\mathrm{p}<01)$.

Maschede, Carbonari e Velini (2009) trabalhando com a variedade RB86-7515 constataram que o sulfumeturon methyl e o glyphosate promoveram os maiores índices de Pol e ATR, resultados que diferem dos encontrados para esta época de aplicação.

Em relação as épocas de coleta e a porcentagem de ATR da cana houve efeito quadrático (figura 34). Os níveis de ATR foram crescentes ao longo das épocas de coleta.

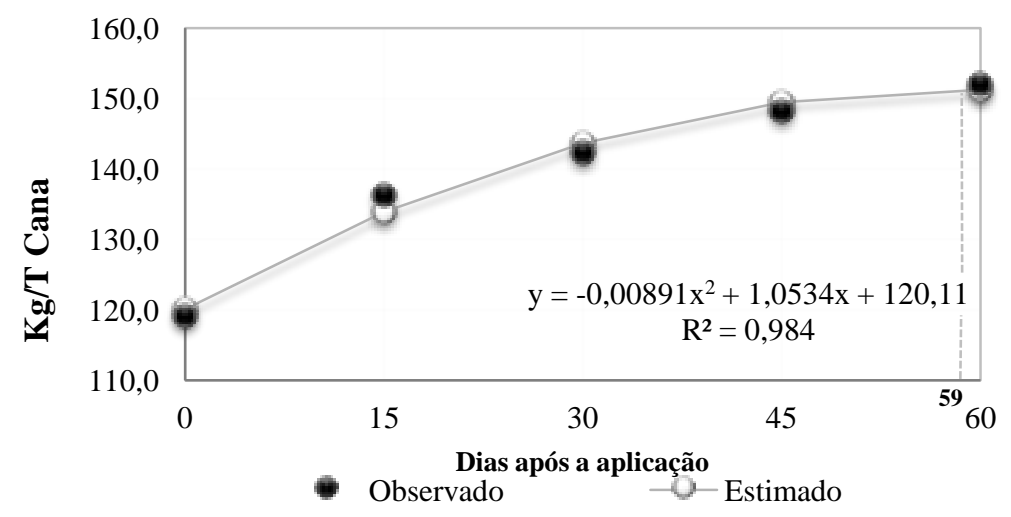

Figura 34. Padrão de variação de açúcar total recuperável em função do tempo após a aplicação dos tratamentos, equação e $\mathrm{r}^{2}(\mathrm{p}<0,01)$. ....-Tempo (dias) para atingir o máximo nível de ATR por tonelada de cana. 
7. CONCLUSÃO 


\section{CONCLUSÃO}

De acordo com os resultados obtidos pode-se concluir que:

1. A utilização do maturador promoveu melhorias na qualidade tecnológica da cana-deaçúcar.

2. Na $1^{\text {a }}$ época, a utilização dos maturadores isoladamente ou associado com os nutrientes, levou as melhores respostas para ATR aos 30, 45 e 60 dias, enquanto que para o Boro $150 \mathrm{~g} / \mathrm{ha}$ somente aos 30 dias.

3. As épocas de aplicação dos produtos em pré-colheita implicaram em comportamentos distintos da cana de açúcar, sendo favorável para a $1^{\mathrm{a}}$ época, e sem resposta para a $2^{\mathrm{a}}$. 
REFERÊNCIAS BIBLIOGRÁFICAS 


\section{REFERÊNCIAS}

ABREU, C.A.; LOPES, A.S.; SANTOS, G.C.G.; Micronutrientes. In: Fertilidade do Solo, Novais, et al. - Viçosa, MG; Sociedade Brasileira de Ciência do Solo, 2007. 1017p.

AGRIANUAL. Anuário da Agricultura Brasileira. Informa Economics. FNP. South America. 480 p. 2013.

ALFONSI, R.R.; PEDRO JÚNIOR, M.J.; BRUNINI, O.; BARBIERI, V. Condições climáticas para a cana-de-açúcar. In: Paranhos, S. B. (ed.). Cana-de-açúcar: Cultivo e utilização. Campinas: Fundação Cargill, v.1, p.42-55. 1987.

ALLEONI, L.R.F; CAMARGO, O.A.; CASAGRANDE J.C. Isotermas de Langmuir e de Freundlich na descrição da adsorção de boro em solos altamente intemperizados. Sci. agric. vol. 55 n. 3 Piracicaba 1998

ALMEIDA, J.C.V.; LEITE, C.R.F.; SOUZA, J.R.P. Efeitos de maturadores nas características tecnológicas da cana-de-açúcar com e sem estresse hídrico. Semina: Ciências Agrárias, Londrina, v. 26, n. 4, p. 441-448, out./dez. 2005

ALMEIDA, J.C.V.; SANOMYA, R.; LEITE, C.F.; CASSINELLI, N.F. Eficiência agronômica de sulfometuron-methyl como maturador na cultura da cana-de-açúcar (Saccharum spp). Stab Açúcar, Álcool e Subprodutos. Piracicaba: Sociedade dos Técnicos Açucareiros e Alcooleiros do Brasil, v.21, n.3. 2003.

ANDRADE, L. A. de B.; ANDRADE, P. P. Implantação e condução de canaviais. Informe agropecuário, Belo Horizonte, v. 28, n. 239, p. 44-54, jul. /ago.2007.

AUDE, M.I.S. Estádios de desenvolvimento da cana-de-açúcar e suas relações com a produtividade. Ciência Rural, Santa Maria, v.23, n.2, p.241-248, 1993.

AZANIA, A.A.P.M. Influência de subprodutos da indústria alcooleira nos atributos químicos do solo e em plantas de cana-de-açúcar, guanxuma e capim-braquiária. 2003. f. 1. Dissertação (Mestre em Produção Vegetal) - Faculdade de Ciências Agrárias e Veterinárias, Universidade Estadual Paulista, Jaboticabal, 2003.

ALONSO, O.; Estratégias para melhorar a qualidade da cana-de-açúcar para a indústria. Cap 22. Pag 361-367. Atualização em produção de cana-de-açúcar. Piracicaba CP 2, 2006. 
BARBOSA, M.H.P.; SILVEIRA, L.C.I. Melhoramento genético e recomendação de cultivares. Cana-de-açúcar. Bioenergia, açúcar e álcool. Tecnologias e perspectivas. Viçosa, MG. Cap 11- pag 311-331, 2010.

BARBOSA, M.H.P.; SILVEIRA, L.C.I. Cana-de-açúcar: variedades, estabelecimento e manejo.In: Simpósio sobre manejo estratégico de pastagem, 2006.Viçosa. Anais... Viçosa: UFV, 2006. P 245-276.

BRIEGER, F.O. Início da safra. Como determinar a maturação. Boletim Informativo Copereste, Ribeirão Preto, v.4, número único, p.1-3, 1968.

BROWN, P.H.; HU, H. Phloem mobility of boron is species dependent: evidence for phloem mobility in sorbitol-rich species. Ann. Bot., v.77, p.497- 505, 1996.

CAMARA, G.M.S. Ecofisiologia da cultura da cana-de-açúcar. In: Simpósio sobre adubação nitrogenada no Brasil. Produção de cana-de-açúcar. Piracicaba, ESALQ, 1993. P 31-64.

CAMARGO, P.N. Fisiologia de la caña de azucar. Trad. de B. Ortiz-villanueva. México: Instituto para el Mejoramiento de la Producción de Azúcar, 1976. 63 p.

CAMARGO, P.N.; SILVA, O. Manual de adubação foliar. São Paulo: Herba, 1990.

CAPUTO, M.M.; BEAUCLAIR. E.G.F.; SILVA, M.A.; PIEDADE, S.M.S. Resposta de genótipos de cana-de-açúcar à aplicação de indutores de maturação. Bragantia, Campinas, v.67, n.1, p.15-23, 2008.

CARLIN, S.D.; SILVA, M.A.; ROSSETTO, R. Parâmetros biométricos e produtividade da cana-de-açúcar após tombamento dos colmos.

Bragantia vol.67 no.4 Campinas Oct./Dec. 2008

CAKMAK, I.; RÖMHELD, V. Boron deficiency-induced impairments of celular functions in plants. Plant and Soil, Netherlands, v.193, p.121-123, 1997.

CASTRO, P.R.C. Fisiologia da cana-de-açúcar. In: ENCONTRO DE CANA-DE- AÇÚCAR, Anais... São Paulo, 1992. p. 5-8.

CASTRO, P.R.C., PACHECO, A.C., MEDINA, C.L. Efeitos de Stimulate e de micro-citros no desenvolvimento vegetativo e na produtividade da laranjeira pêra (Citrus sinensis L. osbeck). Scientia Agrícola, Piracicaba, v. 55, n. 2, p. 338-341. 1998. 
CASTRO, P.R.C.; KLUGE, R.A.; PERES, E.P. Manual de fisiologia vegetal: teoria e prática. Piracicaba: Editora Agronômica Ceres, 2005. 650p.

CESAR M.A.A.; SILVA F.C.A. Cana-de-açúcar como matéria prima para a indústria sucroalcooleira. Piracicaba. CALQ, 1993. $108 \mathrm{p}$

CID, L.P. Cultivo in vitro de plantas. Brasília, DF. EMBRAPA. 2010. cap. 1. 25-30. 1ed.

CONAB, Companhia Nacional de Abastecimento. Perfil do Setor do Açúcar e do Etanol no Brasil: safra 2010/2011. Brasília: CONAB 2013. 64p.

CONAB, Companhia Nacional de Abastecimento. Acompanhamento da safra brasileira de cana-de-açúcar. - v.1 - Brasília: Conab, 2014.

CONAB, Companhia Nacional de Abastecimento. Acompanhamento da safra brasileira de cana-de-açúcar. - v.1 - Brasília: Conab, 2015.

CONSECANA. Conselho dos Produtores de Cana-de-Açúcar, Açúcar e Álcool do Estado de São Paulo. Manual de instruções. 5. ed. Piracicaba, 2006. 112 p.

COPERSUCAR. Fundamentos dos processos de fabricação de açúcar e álcool. Caderno Copersucar - Série Industrial, nº 20, p. 1-12, 1999.

CORRÊA, M.A. Sinopse histórica do açúcar em São Paulo. Anuário Açucareiro, Rio de Janeiro, p.153-163,1935.

CRUSCIOL, C.A.C.; LEITE, G.H.P.; SIQUEIRA, G.F. de. Uso de maturadores com ou sem mistura. In: CRUSCIOL, C.A.C. et al. (Ed). Tópicos em ecofisiologia da cana-de-açúcar. Botucatu: FEPAF, 2010. P: 93-102.

DELGADO, A.A.; CESAR, M. A. A. Elementos da tecnologia e engenharia de açúcar de cana. Departamento de Tecnologia Rural - ESALQ, Piracicaba, SP, v. 1, 1977, 363 p.

DOOREMBOS, J.; CASSAM, A.H. Efectos del agua sobre el rendimento de los cultivos. Roma: FAO. (FAO, Ryego y Drenaje 33) 1979. 212 p.

DIOLA, V.; SANTOS, F. Cana-de-açúcar. Bioenergia, açúcar e álcool. Tecnologias e perspectivas. Viçosa, MG. Cap 2- pag 25-50, 2010.

FAUCONIER, R.; BASSEREAU, D. La caña de azúcar. Barcelona: Blume, 1975, 433p. 
FERNANDES, A.C.; Cálculos na agroindústria canavieira. Piracicaba: STAB, 2000. 193p.

FERNANDES, A.C.; Cálculos na agroindústria canavieira. Piracicaba: STAB, 2003, 240 p.

FERNANDES, A.C.; STUPIELLO, J.P.; UCHOA, P.E. de A. Utilização do Curavial para melhoria da qualidade da cana-de-açúcar. STAB, v.20, p.43-46, 2002.

FERNANDES, A.J. Manual da Cana-de-Açúcar. Piracicaba, LIVROCERES, 1984. 196p.

FIGUEIREDO, O. Cana-de-açúcar. Campinas: Instituto Agronômico, cap 1, pag 31-44. 2008. 882 p.

FIGUEIREDO, P.; LANDELL, M.G.A.; CAMPANA, M.P. Cana-de-açúcar. 6 ed. Campinas: IAC, 1998. 393 p. (Boletim Técnico 200).

FRANZÉ, R.V. Qualidade tecnológica e teores de nutrientes da cana-de-açúcar sob efeito de maturadores. Jaboticabal, 2010. Dissertação (mestrado) - Universidade Estadual Paulista, Faculdade de Ciências Agrárias e Veterinárias, 2010.

GALDINO, L.C.; Qualidade da cana-de-açúcar (Saccharum spp) submetida à aplicação de maturadores químicos em final de safra. Dissertação de mestrado. Universidade Estadual Paulista Faculdade de Ciências Agrárias e Veterinárias Campus de Jaboticabal.2008.

GASCHO, G.J.; SHIH, S.F. Sugarcane. In: TEARE, I.D. \& PEET, M.M., ed. Crop-water relations. New York, JohnWiley, 547p, 1983.

GAUCH, H.G. Ann Rev. Plant Physiol 8:31, 1957.

GHELLER, A.C.A. Fatores que afetam o desempenho de maturadores e reguladores de crescimento em cana-de-açúcar. In: Semana da Cana de Açúcar de Piracicaba, 4. Piracicaba 1999. Anais. Piracicaba Saccharum, 1999. p. 16-19.

GHELLER, A.C.A. Resultados da aplicação de maturadores vegetais em cana-de-açúcar, variedades RB72454 e RB835486 na região de Araras, SP. In: 4 Jornada Científica da UFSCar, 2001, São Carlos. Resumos... 2001. 
GOMES, F.P.; LIMA, U.A. A cana-de-açúcar no Mundo. In: Cultura e Adubação da Canade-açúcar. Capítulo 1, Instituto Brasileiro de Potassa Experimentações e Pesquisas, São Paulo. 1964.

GUPTA, V.; RAGHUVANSHI, S.; GUPTA, A.; SAINI, N.; GAUR, A.; KHAN, M.N.; GUPTA, R.S.; SINGH, J.; DUTTA-MAJUMDER, S.K.; SUMAN, A.; KHURANA, J.P.; KAPUR, R.; TYAGI, A.K. The water-deficit stress- and red-rot-related genes in sugarcane. Functional Integrative Genomics, v.10, n.2, p.207-214, 2010.

HARO, M. et al. Aplicación de madurantes en canteros con riesgo por cultivos colindantes. Sugar Journal, v.64, n.5, p.12-21, 2001.

HARTT, C.E.; Potassium deficiency in sugarcane. Botanical Gazette. Chicago, 88:229-61, 1929.

Studies on the invertase of sugarcane. Hawaiian Planters' Record, Honolulu, 37:13-4, 1933.

HAUCK, F.W.; DICKISON, J. Conveniencia y experimentacion con potasio en el cultivo de cana de azucar. ATC: Rev. Tec. Inform. La Habana. V 13. 1954. 626 p.

HEWITT, E.J. Role of the mineral elements in plant nutrition. Ann. Rev. Pl. Physiology, 11:25-52. 1951.

INOUE, M.H.; CAPPELESSO, E.J.S.; MENDES, K.F.; RONEI, B.; CONCIANI, P.A. Eficiência do bispyribac-sodium como maturador na cultura da cana-de-açúcar. Revista Ciência Agronômica, v. 46, n. 1, p. 80-88, jan-mar, 2015.

JAMES, G. The chemical ripening of sugarcane. International Sugar Journal, v.101, n.1211, p.560-562, 1999

KÖPPEN, W.; GEIGER, R. Klimate der Erde. Gotha: Verlag Justus Perthes. 1928. Wallmap $150 \mathrm{~cm} \times 200 \mathrm{~cm}$.

LARCHER, W. Ecofisiologia vegetal. São Carlos: Rima, 2006. p.295-338.

LAVANHOLI, M.G.D.P. Qualidade da cana-de-açúcar como matéria prima para produção de açúcar e álcool. In: DINARDO-MIRANDA, L.L.; VASCONCELOS, A.C. M.; 
LANDELL, M.G.A. (Ed.). Cana-de-açúcar. Campinas: Instituto Agronômico e Fundação: IAC, 2008. Cap.32, p. 697-722.

LEITE, G.H.P. Maturação induzida, alterações fisiológicas, produtividade e qualidade tecnológica da cana-de-açúcar (Saccharum officinarum L.). 2005, 141p. Dissertação (Mestrado em Produção Vegetal) - Faculdade de Ciências Agronômicas - UNESP, Botucatu.

LEITE, G.H.P.; CRUSCIOL, C.A.C. Reguladores vegetais no desenvolvimento e produtividade da cana-de-açúcar. Pesquisa Agropecuária Brasileira, v. 43, n. 8, p. 995$1001,2008$.

LEITE, G.H.P.; CRUSCIOL, C.A.C.; SILVA, M.A.; LIMA, G.P.P. Atividade das enzimas invertases e acúmulo de sacarose em cana-de-açúcar sob efeito do nitrato de potássio, etefon e etil-trinexapac. Ciênc. agrotec, Lavras, v.35, n.4, p.649-656, 2011.

LEITE, G.H.P.; CRUSCIOL, C.A.C.; SILVA, M.A.; VENTURINI FILHO, W.G.; SURIANO, A. Qualidade tecnológica, produtividade e margem de contribuição agrícola da cana-de-açúcar em função da aplicação de reguladores vegetais no início de safra. Ciência Rural, v.39, n3, p 726-732, 2009.

LEITE， G.H.P; CRUSCIOL， C.A.C.; SIQUEIRA， G.F.; SILVA， M.A.S.; Qualidade tecnológica em diferentes porções do colmo e produtividade da cana-de-açúcar sob efeito de maturadores. Bragantia, Campinas, v. 69, n. 4, p861-870, 2010.

LISSON，S.N.; INMAN-BAMBER，N.G.; ROBERTSON，M.J.; KEATING，B.A. The historical and future contribution of crop physiology and modeling research to sugarcane production systems. Field Crops Research, v.92, p.321-335, 2005.

LUCCHESI, A.A. Cana-de-açúcar. In: Manual de Fisiologia Vegetal: Fisiologia dos Cultivos. Piracicaba. Editora Agronômica Ceres, 2008. 864 pags.

LUCCHESI, A.A. Processos fisiológicos da cultura da cana-de-açúcar (Saccharum spp). Boletim técnico ESALQ/ CENA. Número 7, p 1-50. 1995.

MALAVOLTA, E. Cultura e adubação da cana-de-açúcar. São Paulo: Instituto Brasileiro da Potassa, p.237-278, 1964. 
MALAVOLTA, E. Manual de nutrição mineral de plantas. São Paulo: Editora: CERES. 2006. 638p.

MALAVOLTA, E.; CROCOMO, O.J. O potássio e a planta. In: SIMPÓSIO SOBRE POTÁSSIO NA AGRICULTURA BRASILEIRA, Londrina, 1982. Anais. Piracicaba: Fundação IAPAR, 1982. p.95-162.

MALAVOLTA, E.; HAAG, H.P.; MELO, F.A.F. de; BRASIL SOBRINHO, M.O.C. Nutrição mineral e adubação de plantas cultivadas. São Paulo: Pioneira, 1974. 752p.

MAPA, Ministério da Agricultura, Pecuária e Abastecimento, Plano Nacional de Agroenergia Secretaria de Produção e Agroenergia. 2. ed. rev. - Brasília, DF : Embrapa Informação Tecnológica, 2006-2011 / 2015. 110 p.

MARAFON, A.C. Análise quantitativa de crescimento em cana-de-açúcar: uma introdução ao procedimento prático. Embrapa Tabuleiros Costeiros, 29 p. 2012.

MARGARIDO, F.B.; SANTOS F. Planejamento da lavoura. Cana-de-açúcar -Do plantio a colheita. Cap I, pag 9-26. Viçosa, MG, 2013.

MARTINS, M.B.G.; CASTRO, P.R.C. Efeitos de giberilina e ethephon na anatomia de plantas de cana-de-açúcar. Pesquisa Agropecuária Brasileira, Brasília, v.34, n.10, p.1855 - 1863, 1999.

MASCHEDE, D.K.; CARBONARI, C.A.; VELINI, E.D.; Ação de diferentes maturadores na produtividade e qualidade tecnológica da cana-de-açúcar. Revista Brasileira de Herbicidas, v.8, n.2, p.62-67, mai./ago. 2009.

MIRANDA, J.R. História da cana-de-açúcar = History of sugarcane. Campinas, SP. Komedi, 2008.

MOZAMBANI, A.E.; PINTO, A.de S.; SEGATO, S.V.; MATTIUZ, C.F.M.; História e morfologia da cana-de-açúcar. Atualização em produção de cana-de-açúcar. Cap I, pag 11-18. Piracicaba CP 2, 2006.

MUTTON, M.A. Modo de ação do sal de isopropilamina de N-(fosfonometil) glicina (glifosate) e efeito maturador na cana-de-açúcar. In: SEMINÁRIO ROUNDUP EFEITO MATURADOR, 1., 1993, Guarujá. Anais...Guarujá, 1993. p. 9-17. 
NEVES, M.F.; TROMBIN, V.G.; A dimensão do setor Sucroenergético: mapeamento e quantificação da safra 2013/14 / [coordenação e organização]. - Ribeirão Preto: Markestrat, Fundace, FEA-RP/USP 2014.

NEVES, M.F.; OLIVEIRA, M.A.; Ações de comunicação em organizações do Agronegócio. Londrina. XLV Congresso da SOBER "Conhecimentos para Agricultura do Futuro" Sociedade Brasileira de Economia, Administração e Sociologia Rural. 2007.

MORGAN, T.; JACKSON, O.; McDONALD, L.; HOLTUM, J. Chemical ripeners increase early season sugar content in a range of sugarcane varieties. Australian Journal of Agricultural Research Collengwood, v.58, n.3, p 233-241. 2007.

NICHOLAS, D.J.D. Ann Rev Plant Physiol 12:63, 1961.

OLIVEIRA, D.A. Efeito do sulfometuron-metil em cultura de cana-de-açúcar, cultivada em Podzólico vermelho-amarelo, como maturador vegetal. In: CONGRESSO BRASILEIRO DE HERBICIDAS E PLANTAS DANINHAS 19. 1993, Londrina. Anais... p. 221-223.

OLIVEIRA FILHO, P.B. Aplicação de maturadores químicos e diferentes épocas de colheita em cana-de-açúcar. Dissertação (mestrado em Agronomia). Universidade Estadual do Oeste do Paraná (Campus Marechal, Cândido Rondon), 2011.

OTTO, R.; VITTI, G.C. e LUZ, P.H.C. Manejo da adubação potássica na cultura da cana-deaçúcar. Revista Brasileira de Ciência do Solo, 34:1137-1145, 2010.

PECEGE. Custos de produção de cana-de-açúcar, açúcar e etanol no Brasil: Fechamento da safra 2010/2011. Piracicaba: Universidade de São Paulo, Escola Superior de Agricultura “Luiz de Queiroz", Programa de Educação Continuada em Economia e Gestão de Empresas/ Departamento de Economia, Administração e Sociologia. 2011. 141p.

RAIJ, B.V.; ANDRADE, J.C.; CANTARELLA, H.; QUAGGIO, J.A.; Análise química para avaliação da fertilidade de solos tropicais. Campinas, Instituto Agronômico, 2001. 285 p.

RAMALHO, M.A.P.; SANTOS, J.B.; PINTO, C.A.B.P. Genética na agropecuária. 2 ed, Lavras: UFLA, 2001. 472p. 
RAVEN, P.H.; EVERT, R.F.; EICHHORN, S.E. Biologia Vegetal. Rio de Janeiro; Guanabara Koogan, 2007. 832 p.

RIPOLI, T.C.C.; RIPOLI, M.L.C. Biomassa de cana-de-açúcar: colheita, energia e ambiente. Piracicaba, Edição dos autores, 2004. 302 p.

RIPOLI, T.C.C; RIPOLI, M.L.C.; CASAGRANDI, D.V.; IDE, B.Y. Plantio de cana-deaçúcar: estado da arte. $2^{\circ}$ ed. rev. E ampl. Piracicaba, 2007.

RODRIGUES, J.D. Fisiologia da cana-de-açúcar. Universidade Estadual Paulista, Instituto de Biociências, Campus de Botucatu, 1995.

ROSA, R.F. Manejo de cultivares de cana-de-açúcar com a utilização de maturadores químicos. In: Tecnologias da agroindústria canavieira. MARQUES et. al. Jaboticabal: FCAV. Capítulo VII. Pag 87-98. 2008.

ROSSETTO, R. Maturação. Disponível em http://www.agencia.cnptia.embrapa.br/ gestor/ cana-de-acucar/arvore/CONTAG01_90_22122006154841.html. Acesso em 13/03/2015.

ROSSETTO, R.; KORNDÖRFER, G.H.; DIAS, F.L.F. Nutrição e adubação da cana de açúcar. Tecnologias da agroindústria canavieira. In: MARQUES et. al. Jaboticabal: FCAV. Capítulo X. Pag 125-140. 2008.

SAS, Statistical Analysis Software, SAS Institute Inc., Cary, NC, USA. Copyright @ 2012.

SAMPAIO, S.C. A composição do caldo de cana de açúcar. Contribuição para o estudo dos efeitos de adubações. Boletim técnico da divisão de experimentação e pesquisas. Instituto Agronômico. v.5, $\mathrm{n}^{\circ} .5 .1945$

SANTOS, F.; QUEIROZ, J.H.; COLODETTE, J.L.; RABELO, S.C. Qualidade da cana-deaçúcar para processamento industrial. Cana-de-açúcar -Do plantio a colheita. Cap X, pag 225-2257. Viçosa, MG, 2013.

SEGATO, S.V.; ALONSO, O.; LAROSA, G. Terminologias no setor sucroalcooleiro. Atualização em produção de cana-de-açúcar. Cap: 26, pag 397-405. Piracicaba: CP 2, 2006. 415 p. (a). 
SEGATO, S.V.; MATTIUZ, C.F.M.; MOZAMBANI, A.E.; Aspectos fenológicos da cana-deaçúcar. Atualização em produção de cana-de-açúcar. Cap: 2, pag 19-36. Piracicaba: CP 2, 2006. 415 p. (b)

SEGATO, S.V.; PEREIRA L.L. Colheita da cana-de-açúcar: corte manual. Atualização em produção de cana-de-açúcar Cap: 19, pag 317-332. Piracicaba: CP 2, 2006. 415 p.

SIEMER, S.R. Developmental field studies of gibberellic acid treatment of hawaiian sugarcane. Reports of the Havaiian Sugar Technology. Hawaii, 1969. P 1-5.

SIQUEIRA, G.F. Aplicação de boro e maturadores na pré-colheita da cana-de-açúcar em início e final de safra. Tese (doutorado). Universidade Estadual Paulista Julio de Mesquita Filho. 2014.

SILVA, M.A.; CATO, S.C.; COSTA, A.G.F. Produtividade e qualidade tecnológica da soqueira de cana-de-açúcar submetida à aplicação de biorregulador e fertilizantes líquidos. Ciência Rural, Santa Maria, v.40, n.4, p.774-780, abr, 2010.

SILVA, M.A.; GAVA, G.J.C.; CAPUTO, M.M.; SORRILLA, P.F.; BASSETTO. S.C. Produtividade de colmos e de sacarose em cana-de-açúcar em função da interação entre cultivares e maturadores. Scientia Agraria, Curitiba, v.11, n.4, p.323-329, July/Aug. 2010

SILVA, F.R.; FERREYRA F.F.H. Avaliação de extratores de boro em solos do estado do Ceará. R. Bras. Ci. Solo, 22:471-478, 1998.

SOBRAL, A.F.; WEBER H.; Nutrição e adubação da cana-de-açúcar no Brasil. Coordenação José Orlando Filho. Piracicaba, Coleção Planalsucar 2. 1983. 369 p.

TAIZ, L.; ZEIGER, E. Fisiologia vegetal. 5. ed. Porto Alegre: Artmed, 2013. 918p.

TEIXEIRA FILHO, M.C.M; BUZETTI S.; GARCIA C.M.P.; BENETT, C.G.S.; RODRIGUES, M.A.C.; MAESTRELO, P.R.; CELESTRINO, T.S ; GAZOLA R.N. Qualidade tecnológica e produtividade agroindustrial de cana-deaçúcar submetida a adubação com zinco. Semina: Ciências Agrárias, Londrina, v. 34, n. 4, p. 1603-1614, jul./ago. 2013 
TOPPA, E.V.B.; JADOSKI, C.J.; JULIANETTI, A.; HULSHOF, T.; ONO E.O.O; RODRIGUES, J.R.; Aspectos da fisiologia de produção da cana-de-açúcar (Saccharum Officinarum L.) Pesquisa Aplicada \& Agrotecnologia v3 n3 set.- dez. 2010.

VASCONCELOS, J.N.; Fermentação etanólica. Cana-de-açúcar. Bioenergia, açúcar e álcool. Tecnologias e perspectivas. Viçosa, MG. Cap XV-pag 401-437, 2006.

VIANA, R.S. Aplicação de maturadores químicos no final de safra, associado à eliminação de soqueira em área de reforma do canavial. Dissertação (mestrado) - Universidade Estadual Paulista, Faculdade de Ciências Agrárias e Veterinárias, Jaboticabal, 2007.

VIANA R.S.; MUTTON M.A.; BARBOSA V.; DURIGAN A.M.P.R. Maturadores químicos na cana-de-açúcar (Saccharum spp) aplicados em final de safra. Revista de Biologia e Ciências da Terra. Volume 7 - Número 2 - 2ºmestre 2007.

VIANA, R.S.; SILVA, P.H.; MUTTON, M.A.; MUTTON, M.J.R.; GUIMARÃES, E.R.; BENTO, M. Efeito da aplicação de maturadores químicos na cultura da cana-de-açúcar (Saccharum spp.) variedade SP81-3250. Acta Scientiarum Agronomy, v. 30, n. 1, p. 65$71,2008$.

WEHLING, A. Formação do Brasil Colonial. Rio de Janeiro: Editora da Universidade Federal Fluminense, 1994. 432 p.6 